Portland State University

PDXScholar

1994

\title{
An Experimental Study of Scotopic Sensitivity Irlen Syndrome in Learning Disabled Students
}

Kathleen Hickam Farber

Portland State University

Follow this and additional works at: https://pdxscholar.library.pdx.edu/open_access_etds

Part of the Disability and Equity in Education Commons

Let us know how access to this document benefits you.

\section{Recommended Citation}

Farber, Kathleen Hickam, "An Experimental Study of Scotopic Sensitivity Irlen Syndrome in Learning Disabled Students" (1994). Dissertations and Theses. Paper 1329.

https://doi.org/10.15760/etd.1328

This Dissertation is brought to you for free and open access. It has been accepted for inclusion in Dissertations and Theses by an authorized administrator of PDXScholar. Please contact us if we can make this document more accessible: pdxscholar@pdx.edu. 


\title{
AN EXPERIMENTAL STUDY OF \\ SCOTOPIC SENSITIVITY/IRLEN SYNDROME \\ IN LEARNING DISABLED STUDENTS
}

by

KATHLEEN HICKAM FARBER

A dissertation submitted in partial fulfillment of the requirements for the degree of

\author{
DOCTOR OF EDUCATION \\ in \\ EDUCATIONAL LEADERSHIP: \\ ADMINISTRATION AND SUPERVISION
}

\author{
Portland State University \\ 01994
}




\section{DISSERTATION APPROVAL}

The abstract and disgertation of Kathleen Hickam Farber for the Doctor of Education in Educational Leadership: Administration and Supervision were presented May 18, 1994, and accepted by the dissertation committee and the doctoral program.

COMMITTEE APPROVALS:
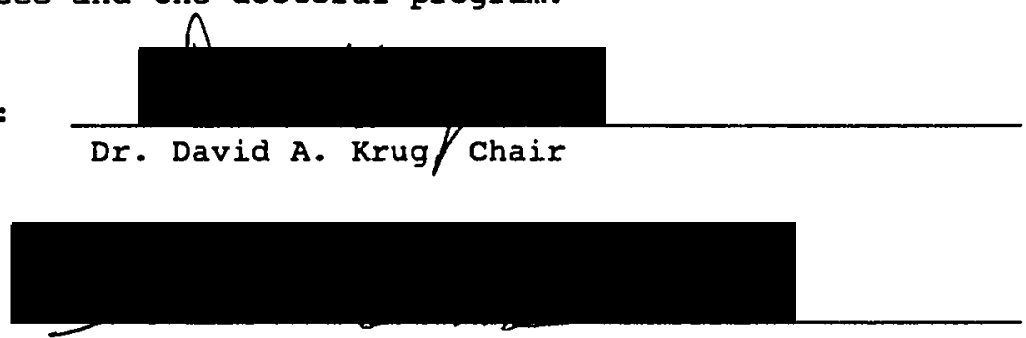

Dr. Steven A. Brannan

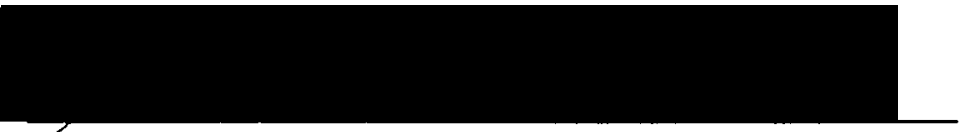

Dr. Sorca M. O'Connor

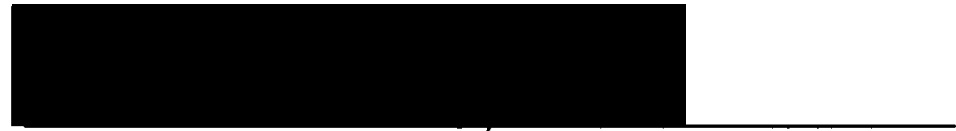

Dr. Jane H. Arends

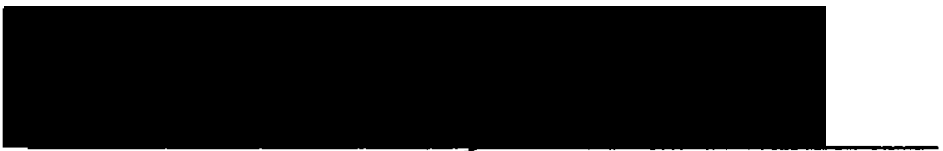

Dr. Cathleen I. Smith

Representative of the office of Graduate studies

DOCTORAI, PROGRAM APPROVAL:

David A. Krug, Acting Dean

School of Education

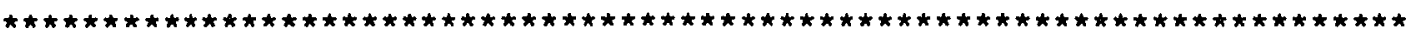
ACCEPTED FOR PORTLAND STATE UNIVERSITY BY THE LIBRARY

by on 


\begin{abstract}
An abstract of the dissertation of Kathleen Hickam Farber for the Doctor of Education in Educational Leadership: Administration and Supervision presented May 18, 1994.
\end{abstract}

Title: An Experimental Study of Scotopic Sensitivity/Irlen Syndrome in Learning Disabled Students

This study examined the effect on reading performance of a controversial treatment for a dysfunction of visual perception known as Scotopic sensitivity/Irlen syndrome. The treatment, referred to as spectral modification, involved the use of colored transparent overlays for reading by four elementary school children in their actual school environments.

The diagnostic, prescriptive and remediation procedures used in this study were originally developed by Helen Irlen, a California psychologist and researcher. Irlen conceptualized scotopic Sensitivity syndrome as a difficulty in visual processing of the printed page when perceived through full spectrum light. spectral modification techniques were considered controversial in that they were employed prior to scientific validation of the syndrome. Previous research used pre-test/post-test experimental designs to test the effect of spectral modification on reading performance. The 
research problem addressed here was that the technique had not been systematically examined over time in the school setting, and from the practitioner's point of view.

Sample selection involved pre-screening and screening phases. The pre-screening procedures of teacher recommendation and file review resulted in a pool of 26 children who were screened with the Irlen Differential Perceptual Interview Survey. Four subjects were selected who were in separate school settings, who demonstrated Irlen syndrome to a significant extent, and whose profiles did not present variables which would compromise their participation. These four underwent comprehensive vision evaluations as a preliminary assessment procedure.

A four-strand single-subject experimental design was used to generate data on subjects' rate and accuracy of oral reading, and comprehension of silent reading. Performance changes during experimental reading trials varied between the four, although three subjects exhibited positive performance change on one indicator. A supporting procedure was that subjects were pre and post-tested on the three performance indicators. Post-test results corroborated the changes demonstrated by three subjects.

Interview formats were employed to obtain qualitative data from teachers, parents, and the subjects themselves. Recommendations for practitioners intending to implement spectral modification techniques were generated from this data. 


\section{ACKNOWLEDGEMENTS}

Special education teachers, classroom teachers, building administrators, and media specialists in the schools from which subjects were selected provided valuable support and assistance. The researcher is grateful for their contributions, although the provision of subject confidentiality prevents the identification of persons directly associated with school sites.

Acknowledgement of contributions is extended to the following representatives of Portland Public Schools.

Dr. Jane Arends, Department of Research and Evaluation

Diana Thompson, Department of Research and Evaluation

Vicky Wiley, Department of Research and Evaluation

Ron Reilly, Director of Instruction for Area II

Elleen Deck, Coordinator of Special Education for Area II Julie Haggerty, Coordinator of Reading Recovery

Special acknowledgement must also be extended to the four subjects and their parents: for assuming the risk of trying an innovative treatment, and for conscientious adherence to the research procedures. 


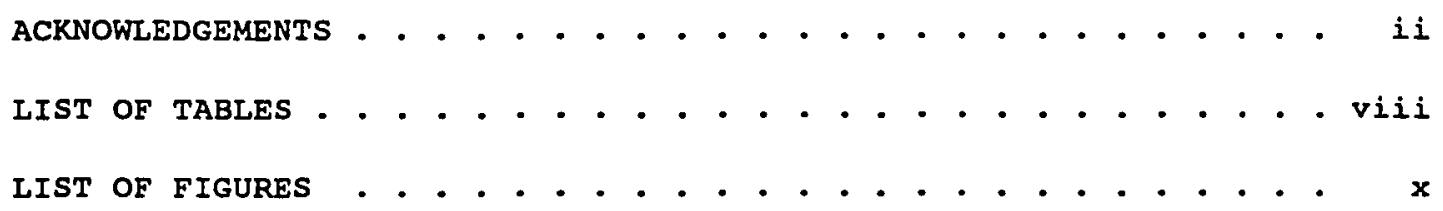


Studies Originating in Education and Psychology

Studies Originating in optometry and Ophthalmology

Toward Interdisciplinary Cooperation

Interdisciplinary studies

Applications to the Current Study . . . . . . 45

Design . . . . . . . . . . . . . . . .

Rationale for Single Group Design

Maturational Factors

Dependent Variable Indicators

Multiple Baseline Sequencing

Procedural Guidelines

Additional Control Factors

Sample Selection Procedures . . . . . . .

60

Criteria for selecting schools

Procedure for selecting schools and

Teachers

Subject Characteristics

Pre-Screening Procedures . . . . . . . . 66

Parent Involvement . . . . . . . . . . . . 67

Screening Procedures .. . . . . . . . . 68

Final subject selection .. . . . . . . 70

Vision Examination . . . . . . . . . . . . 71

Pre-Testing Procedures . . . . . . . . . 72

Interval Measurement Procedures. . . . . . 73

Selection of Reading Material

Subject orientation

Trial Environment

Trial Process and sequencing

Text Format

Interview and Observational procedures . . . . .

Weekly subject Interview

parent and Teacher Interviews

on-Going Teacher Observation 
Miscellaneous Support Procedures . . . . . . 84

Provision of Materials

Subject Reading Log

Time Parameters

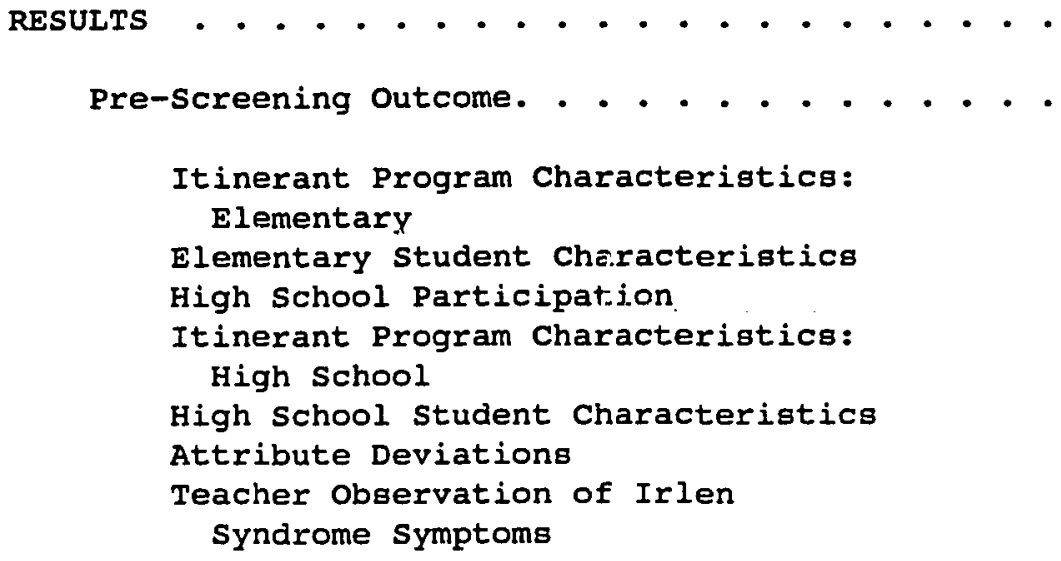


Graphic Data Analysis

Baseline Phase

Intervention Phase

Post-Intervention Trials

Conclusions

Reading Trial Results--Jered

Graphic Data Analysis

Baseline Phase

Intervention Phase

Conclusions

Reading Trial Results--Sarnantha. . . . . . .

Graphic Data Analysis

Baseline Phase

Intervention Phase

Conclusions

Reading Trial Results--Melissa . . . . . . .

Graphic Data Analysis

Baseline Phase

Intervention Phase

Post-Intervention Trials

Conclusions

Procedural Adjustments . . . . . . . . . . .

Taping of Oral Reading

Reading Material

Post-Test Results . . . . . . . . . . . .

Portland Achievement Levels Test

Word Recognition

Oral Reading

Interview and Observational Data . . . . . .

Use of Colored Paper

Observed Performance Changes: Jeremy

Observed Performance Changes: Jered

Observed Performance Changes: Samantha

Observed Performance Changes: Melissa

Personal History Factors . . . . . . . . .

Influences Within School Environment

External Influences 
Generalizations Based on Interview and observation . . . . . . . . . . . . . 154

V DISCUSSION . • . . . . . . . . . . . . . 156

Specific Contributions of the Dissertation . . . 158

Changes in Reading Performance

Relationship of Performance

Changes to Use of Overlays

Interaction of Optometric and Spectral Intervention

Recommendations for Practitionerg

Experimenter Effect . . . . . . . . . . . .

Jeremy

Jered

Samantha

Melissa

Conclusions

Recommendations for Future Research. . . . .

Conclusions . . . . . . . . . . . . . 180

REFERENCES • • • . . . . . . . . . . . . . . . . . . . .

APPENDICES

A PRE-SCREENING MATERIALS . . . . . . . . . . . 188

B PERMISSION AND CONSENT DOCUMENTS . . . . . . . . . . 192

C SCREENING REPORT FORM. . . . . . . . . . . . . . . 198

D OBSERVATION AND INTERVIEW FORMS. . . . . . . . . . 202

E ADDITIONAL INFORMATION FROM OBSERVATIONS

AND INTERVIEWS . . . . . . . . . . . . . . . . 210

F COMPARATIVE OVERVIEW OF READING

INSTRUCTION. . . . . . . . . . . . . . . . 229 
IIST OF TABLES

TABLE

PAGE

1. Scotopic Sensitivity/Irlen Syndrome . . . . . . . . . . 7

2. Professional Orientation of Applied Studies on Use of Spectral Modification Techniques . . . . . . . . 25

3. Applications of Source Material to the Methodology of this study... . . . . . . . . . . . . . 46

4. Indicators of Reading Performance . . . . . . . . . . 52

5. Performance Data Management . . . . . . . . . . . 56

6. Intersubject Attributes . . . . . . . . . . . . . 64

7. Intrasubject Attributes . . . . . . . . . . . . 65

8. Timeline . . . . . . . . . . . . . . . . 85

9. Attribute Deviations Demonstrated by Prospective Subjects ... . . . . . . . . . . . . 89

10. Symptoms Noted by Teachers . . . . . . . . . . . . 93

11. Demonstrated Severity of Irlen syndrome in Prospective subjects. . . . . . . . . . . . . . . 94

12. Screening Profiles of Selected Subjects . . . . . . . 98

13. Attributes Demonstrated by Selected Subjects . . . . 105

14. Pre-Test Results and Selected Reading Trial Material . . . . . . . . . . . . . . 116

15. Numerical Trial Data--Jeremy . . . . . . . . . . 117

16. Numerical Trial Data--Jereà . . . . . . . . . . 122

17. Numerical Trial Data--Samantha . . . . . . . . . 127

18. Numerical Trial Data-Melissa . . . . . . . . . . 131

19. PALT Reading Results . . . . . . . . . . . . . 139 
20. Word Recognition Post-Test Assessment . . . . . . . . 140

21. Oral Reading Post-Test Assessment . . . . . . . . . . 141

22. Cross-Subject Summary of Demonstrated Changes in Reading Performance... . . . . . . . . . 160 
1. Graphic Representation of Jeremy's Oral Reading Rate Across Three Experimental Phases . . . . . . . . 118

2. Graphic Representation of Jeremy's Oral Reading Accuracy Across Three Experimental Phases . . . . . 118

3. Graphic Representation of Jeremy's Silent Reading Comprehension Across Three Experimental Phases . • . 119

4. Graphic Representation of Jered's Oral Reading Rate Across Two Experimental Phases . . . . . . . . 123

5. Graphic Representation of Jered's Oral Reading Accuracy Across Two Experimental Phases . . . . . 123

6. Graphic Representation of Jered's Silent Reading Comprehension Across Two Experimentai Phases . . . . 124

7. Graphic Representation of Samantha's Oral Reading Rate Across Two Experimental Phases . . . . . . . . . 128

8. Graphic Representation of Samantha's Oral Reading Accuracy Across Two Experimental Phases . . . . . . 128

9. Graphic Representation of Samantha's Silent Reading Comprehension Across Two Experimental Phases . . . . 129

10. Graphic Representation of Melissa's Oral Reading Rate Across Three Experimental Phases . . . . . . . . 132

11. Graphic Representation of Melissa's Oral Reading Accuracy Across Three Experimental Phases . . . . . 132

12. Graphic Representation of Melissa's Silent Reading Comprehension Across Three Experimental Phases . . . 
CHAPTER I

INTRODUCTION

Purpose of the study

The intent of this study was to employ, observe and document the effects of an innovative method for the treatment of one type of perceptual dysfunction that impedes reading. A review of previous research revealed limited information on the effects of this method as experienced by students and teachers in the actual school setting. This is a practitioner's pilot study of techniques which had been largely unknown and untried in Portland Public Schools, where the research was conducted.

The key factor in this treatment method is the modification of full spectrum light with colored transparent overlays. This intervention has been found to alleviate the perceptual distortions experienced by some readers who are unable to efficiently perceive the printed page when it is perceived through full spectrum light.

A few special education teachers in Portland have experimented informally with colored transparent overlays, and found that some of their students favored the spectral modification and reduction of light intensity provided by the overlays. (This statement is based on personal contacts made by this researcher, who is a special education 
teacher and one of the informal experimenters.) This study extended the informal inquiry to an experimentally designed, systematic application of spectral modification techniques with a small group of subjects who were in separate school settings.

Several previously published studies have explored the effects of colored overlays on reading achievement. Thoge which were experimentally designed have generally employed a test-retest design. Although this study included pre- and post-test data, the inquiry was primarily intended to address the extent and direction of change in reading performance over a period of time. The overlays were analyzed as a change factor, operating in conjunction with other influences in the actual school setting.

The study was conducted within the time frame of the academic year (approximately nine months), and involved three phases:

1. Students for whom spectral modification was appropriate were identified.

2. Students selected as subjects had optometric evaluations of their visual systems.

3. Subjects used colored transparent overlays for nine weeks, as data on their reading performance and personal adjustment to the intervention was compiled.

Researchers in education who had previously studied spectral modification did not include optometric evaluation as a procedural element. One significant departure of this study is that optometric treatment was combined with the use of overlays by some subjects. This produced information relevant to understanding the perceptual 
dysfunction itself, and the potential of spectral modification as treatment.

Scotopic Sensitivity/Irlen syndrome

Scotopic Sensitivity syndrome is the name given to the perceptual dysfunction addressed by spectral modification techniques. The syndrome was originally documented and analyzed by Helen Irlen, a California researcher and educational psychologist. Irlen defined it as "a perceptual dysfunction which is related to difficulties with light source, luminance, intensity, wave length, and color contrast" (Irlen \& Lass, 1989, p. 414). The most current professional nomenclature for this condition is scotopic Sensitivity/Irlen syndrome. It is referred to mostly as Irlen syndrome throughout this work.

It is important to distinguish Irlen syndrome as impacting perception rather than vision. The locus is between the eye and the brain, not in the mechanisms of visual acuity. The condition cannot be diagnosed by an optometrist or ophthalmologist using conventional techniques (Irlen, 1990). It may occur for an individual who wears glasses or for one with $20 / 20$ vision, and may also occur in conjunction with other learning disabilities.

\section{History}

An account of Irlen's (1990) first observation of this syndrome is helpful in understanding its nature and definition. The following summary of events surrounding her discovery and conceptualization of 
the syndrome was documented in her book Reading by the colors:

Overcoming Dyslexia and other Reading Disabilities Through the Irlen

Method.

In 1982, Irlen was director of a federally funded research

project at California State University-Long Beach. Subjects involved

in the Long Beach study were learning disabled adults; the intended

outcome was research data on factors of learning problems that had not

responded to remedial instruction, had not been alleviated by

maturity, and had in some cases gone undetected by the school system.

During the first year of the Long Beach project, Irlen (1990)

interviewed over 1,500 adults for information on the life experience emanating from their reading problems. The interview process evolved

into a search for responses that would indicate more than a commonality

of experience and symptoms. The purpose evolved to a search for

factors that appear to cause persistent reading disabilities.

Irlen (1990) began to ask both proficient and disabled readers to

report on the actual appearance of the printed page. Some disabled

readers responded with observations such as,

The letters and words are running together,... The white

spaces form rivers which run down the page,. . . When I

start to read, the words become a black line and I don't see

them anymore. (p. 20)

Most had not previously disclosed these distortions because they

assumed that others saw print in the same way.

Irlen (1990) identified 35 students who reported similar

distortions, and referred them to a variety of ophthalmologists,

optometrists, developmental specialists, neurologists, reading 
specialists, and psychologists for treatment. Their adherence to ensuing professional recommendations was documented over a nine-month period. Some treatments were helpful, but none made any significant difference in relieving the distortions. Irlen's conclusion was that these 35 gtudents exhibited a condition that had gone unrecognized and unaddressed by the professional community.

It was an accidental discovery that led to her eventual conceptualization of scotopic sensitivity Syndrome (Irlen, 1990). One of the research subjects placed a red transparent overlay, which had been given to another student for visual training exercises, over a page of text. For the firgt time, she saw a page on which the letters did not sway back and forth. Irlen obtained a variety of colored transparent gels from the theater arts department, and began weeks of experimentation with her students. Thirty-one of the 35 were able to gelect a preferred color and density of overlay, which reduced the perceptual distortions and improved their ease and efficiency in reading.

During a personal interview on November 7,1991 , Irlen was asked to explain the use of the word "scotopic." She explained that the colored transparencies modify frequencies in the scotopic band of the light spectrum. In an earlier paper, she proposed that the response of affected individuals to the colored transparancies indicates that their retinal receptors are hypersensitive to full spectral light (Irlen, 1983). 
Symptoms

Irlen and Lass (1989) presented the symptoms of Scotopic Sensitivity/Irlen syndrome as grouped under five factors. An affected individual may experience symptoms in any one factor, in several factors, or in all. Table 1 presents the five factors with a sample of related symptoms and resulting deficits in reading for each.

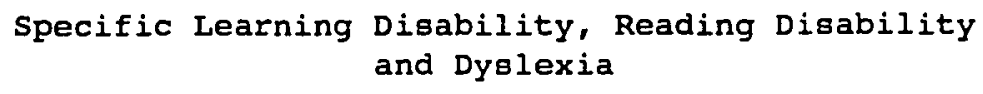

The subjects selected for this study were identified as specifically learning disabled. The major criterion for identifying a child as learning disabled (LD) in portland is that there be a significant discrepancy between general learning potential and the level of achievement in one or more specific areas. Public Law (PL) 94-142, the Education for All Handicapped Children Act of 1975, offered this definition:

Specific learning disability means a disorder in one or more of the basic psychological processes involved in understanding or in using language, spoken or written, which may manifest itself as an imperfect ability to listen, think, speak, read, write, spell, or to do mathematical calculations. (89 stat. 794)

A reading disability is one manifestation of a specific learning disability, which can involve several manifestations within one child. The PI 94-142 definition presented learning disabilities as an umbrella which includes dyslexia, plus other conditions such as perceptual handicaps, minimal brain dysfunction, and developmental aphasia (Irlen, 1990). 
Table 1

Scotopic sensitivity/Irlen syndrome

\begin{tabular}{|c|c|c|}
\hline $\begin{array}{l}\text { Factor or } \\
\text { Category }\end{array}$ & symptom & $\begin{array}{l}\text { Observable Skill } \\
\text { Deficit in Reading }\end{array}$ \\
\hline $\begin{array}{l}\text { Light } \\
\text { Sengitivity }\end{array}$ & $\begin{array}{l}\text { - Complains of glare } \\
\text { - Shades eyes or book } \\
\text { - Fatigue, sleepiness } \\
\text { - Eyestrain signs: squinting, } \\
\text { blinking, opening wide }\end{array}$ & $\begin{array}{l}\text { - Short attention span } \\
\text { - Hesitant horizontal } \\
\text { and/or vertical } \\
\text { tracking } \\
\text { - slow reading rate }\end{array}$ \\
\hline $\begin{array}{l}\text { Inadequate } \\
\text { Background } \\
\text { Accommodation }\end{array}$ & $\begin{array}{l}\text { - White rivers form } \\
\text { - Blurry symbols } \\
\text { - Sees white flashes } \\
\text { - Loses place }\end{array}$ & $\begin{array}{l}\text { - Word recognition skills } \\
\text { delayed, inconsistent } \\
\text { - word guessing } \\
\text { - slow rate }\end{array}$ \\
\hline $\begin{array}{l}\text { Poor Print } \\
\text { Resolution }\end{array}$ & $\begin{array}{l}\text { - Symbols change } \\
\text { - Letters and words vibrate } \\
\text { - Aversion to small print } \\
\text { - Tracking devices } \\
\text { - Headache, nausea } \\
\text { - Eyestrain }\end{array}$ & $\begin{array}{l}\text { Poor spelling (visual } \\
\text { memory impeded) } \\
\text { - Unable to proofread } \\
\text { - Unable to skim or speed } \\
\text { read }\end{array}$ \\
\hline $\begin{array}{l}\text { Restricted } \\
\text { Span of } \\
\text { Recognition }\end{array}$ & $\begin{array}{l}\text { - Sounds out word by word, } \\
\text { or letter by letter } \\
\text { - Looses place } \\
\text { - Does not get meaning } \\
\text { - from context } \\
\text { - Tracking devices, moves } \\
\text { close to work }\end{array}$ & $\begin{array}{l}\text { Poor comprehension } \\
\text { - Unable to copy } \\
\text { - Unable to skim or speed } \\
\text { - read } \\
\text { - Poor spelling }\end{array}$ \\
\hline $\begin{array}{l}\text { Lack of } \\
\text { Sustained } \\
\text { Attention }\end{array}$ & $\begin{array}{l}\text { - Takes frequent breaks } \\
\text { - Displays symptoms from } \\
\text { othex categories }\end{array}$ & $\begin{array}{l}\text { - Has difficulty } \\
\text { completing assignments }\end{array}$ \\
\hline
\end{tabular}

For purposes of this study, reading disability and dyslexia are

defined in common as:

A disorder in children who, despite conventional classroom experience, fail to attain the language skills of reading, writing and spelling commensurate with their intellectual abilities. (Critchley, 1970, p. 11) 
Scotopic sensitivity syndrome can be an underlying factor in manifestations of dyslexia. Dyslexia can, however, involve factors unrelated to Irlen syndrome.

This researcher's primary reason for gelecting subjects identified as learning disabled was the availability of information on their learning profiles and educational history. This information allowed for control of contaminating influences, and was not sufficiently available on students not in special education. A secondary rationale was that a pattern of delayed reading skills is established and documented for Portland students who are learning disabled in the area of reading. However, the diagnosis and treatment of Irlen Syndrome has not been explored as a treatment option for these students.

Research Problem

This study was intended to address the following problem: treatment of Irlen Syndrome with available means of spectral modification has not been systematically tried with students identified as learning disabled in the Portland Public Schools. If children in this population experience perceptual difficulties that are not addressed, they cannot receive full benefit from the reading instruction that is provided. Therefore the gap between their grade level and achievement level in reading widens over time. To support this statement, the researcher drew upon 14 years of experience teaching special education at elementary and secondary grade levels. She observed that learning disabled fourth graders were typically 
reading at the second grade level. Her learning disabled students in the high school grades typically read at the fifth grade level, although they were similar in intelligence and learning profile to the fourth grade group. The gap appeared to widen from two years (grade 4) to five years (grade 10). A significant number of the learning disabled adolescents taught by this researcher have shared two characteristics with the adults who participated in Irlen's 1983 research: their reading disabilities were not significantly improved by specialized instruction, nor were they alleviated by maturity. This widening gap between skill level and grade level leads to a more serious issue: students who experience it are significantly at risk of failure in the school system. A related issue is that those who experience tension and frustration due to conditions such as Irlen Syndrome often exhibit behavior which negatively impacts the classroom environment for all children.

\section{Research Questions}

In response to the problem stated and discussed above, this study provided thorough diagnosis and systematic treatment of four learning disabled students who manifested Irlen syndrome. The two major research questions were:

1. What will be the extent and direction of change in the reading performance of subjects who use colored transparent overlays consistently for a nine-week period? 
2. What recommendations for the implementation and continued use of spectral modification techniques in the public school setting can be derived from this study?

As a single subject experiment having four strands, the work generated in-depth data on each student. This information was both quantitative and qualitative in nature, and was used to address the research questions. 


\section{CHAPTER II}

REVIEW OF THE LITERATURE

The Irlen Institute

This chapter opens with a discussion of the Irlen Institute, of which Helen Irlen is founder and Executive Director. One of the Institute's missions is to support and disseminate research on the effects of spectral modification. In so doing, it provided a portion of the literature here reviewed (18 of 65 sources).

The Irlen Institute has also developed and franchised the only existing diagnostic tool for the identification of scotopic Sensitivity syndrome. This tool, the Irlen Differential Perceptual Interview Survey (IDPIS), was employed in 10 of the 16 applied studies analyzed for this review. It was used to identify subjects for this study, the researcher having been trained directly by Helen Irlen at the Irlen Institute in Long Beach, California.

It is recognized that the objectivity of this study could be challenged on grounds that a vested agency has provided the researcher with information and training. This challenge is addressed by the following description of the Irlen Institute's policies and services.

The Institute endeavors to collaborate with the established professional fields of education and optometry. The diagnostic training is offered, at a modest fee, to professionals in education 
and psychology who must submit professional resumes to be accepted. Those who are given the training become, like this researcher, "first level screeners" who can administer the Irlen Differential Perceptual Interview Survey, prescribe transparent colored overlays, and recommend environmental modifications to the client. Completion of the first-level screening gives a client the option of proceeding to the second level.

The second level of diagnostic procedures must be performed by a full-service clinic that is affiliated with the Irlen Institute. This intensive process involves trial of 54 color tints, alone and in combination, in order to prescribe an eyeglass filter that will best mediate the effects of Irlen syndrome for the client. An optometric examination is required prior to this procedure. The filter treatment could be provided to subjects of this study by a traveling clinic, at a cost of $\$ 300$ to $\$ 500$ for each subject. The nearest clinician to which subjects could travel is in Eastern Oregon. These factors of cost and geography made treatment with Irlen Filters impractical for this study.

One of the Institute's services is the provision of inservice screener training to public school personnel. In the summer of 1991 , this researcher was provided with a listing of 31 public school agencies which have enlisted the Irlen Institute to provide on-site training. Five additional school districts have established full-service clinics, which can provide both levels of diagnosis and treatment. 
The Irlen Institute's efforts to work with established

professional fields is a principle argument for its objectivity. This researcher's assessment of the Institute's approach to training was that it was service oriented rather than marketing oriented. At the time this researcher was trained, the single reference to marketing was the recommendation of a fee for private screening, with advice not to exceed it.

\section{Scope of the Review}

The remainder of this chapter focuses on four issues that are relevant to Irlen syndrome and its treatment. The first is the need for scientific evidence that would validate the concept of scotopic Sensitivity syndrome. The following sources were reviewed and synthesized in an effort to address this issue: Bassi and Lehmkuhle (1990); Blakeslee (1991); Breitmeyer and Ganz (1976); Fricker (1989); Garzia and Nicholson (1990); Livingstone, Rosen, Drislane, and Galaburda (1991); Lovegrove, Martin, and Slaghuis (1984); Reeves (1988); Riding and Pugh (1977); Sackitt (1976); Suchoff (1981); Williams and Lecluyse (1990). Insights of other writers were interjected where relevant to this subtopic.

The second issue is that the diagnostic tool used to detect Irlen syndrome should be established as valid and reliable. This is addressed by an assessment of the Irlen Differential Perceptual Interview survey.

The prevalence of scotopic sensitivity syndrome in specific populations, both observed and projected, is the third significant 
issue. Studies which involved the diagnosis of Irlen syndrome in a gample of reading disabled subjects have noted a range of 468 (Irlen, 1991) to 738 (Miller, 1984). It is important to note that the Byndrome exists on a continuum from mild to severe.

Following the discussion of these three issues, the literature review analyzes a body of applied research on the use of spectral modification techniques to address reading difficulties. The results and methodological details of 17 studies, completed 1986 through 1991, were examined. Most of these studies fell into two broad categories: those conducted by researchers in education and those of researchers in optometry and ophthalmology. The focus, methodology, and outcome characteristic of each group is compared.

Theoretical Basis for Irlen syndrome

To be scientifically credible, a treatment for dyslexia--or a reading disability that is identified through psychometric evaluation--should do two things: (a) demonstrate a sensorimotor deficit experienced by a subset of dyslexics, and (b) offer a hypothesis for the way in which the treatment can address the deficit (Reeves, 1988). Irlen (1990) has conceptualized and named a deficit (Scotopic sensitivity syndrome), and has identified a subset. This gection will present work that has been done toward scientific demonstration of the deficit, which has not yet been fully validated. Suchoff's (1981) conclusion, following a literature review, was that previous research had convincingly demonstrated the absence of a simplistic causal relationship between visual characteristics and 
reading. This was possibly due to the lack of a wholistic orientation to the visual system. Visual components have a complex interrelationship within an individual; the key is not the condition itself, but the way in which an individual compensates for it. This wholistic orientation is reflected in current practices of vision therapy. Some researchers claim that vision therapy can effectively address the symptoms of Irlen Syndrome (Blaskey et al., 1990).

The concept of iconic memory led to an early theory of a neurological basis for reading difficulties. Iconic memory was conceptualized as the retention of a visual image, or icon, in the retinal photoreceptors. This image of the word must be retained for transmission to the meaning analysis stage. Decoding would be impaired should the image fade too quickly or last too long (Sackitt, 1976).

In 1977, Riding and Pugh hypothesized a relationship between iconic persistence on the retina and reading performance. They recommended research involving a variation on print/background contrasts. Hoien (cited in Fricker, 1989) hypothesized that some students with reading difficulties have longer iconic persistence, and that this has a decisive effect on their decoding ability. It was found that an increase in illumination caused longer iconic persistence, so that readers with this problem would prefer dim light. These conclusions precurse methods of spectral modification, which serve to vary black-white contrast and reduce brightness on the page. 
A later concept of visual perception which is relevant to reading difficulties is that of the transient and sustained pathways. This was addressed by Lovegrove, Martin and Slaghuis (1984). These researchers presented the transient system as being activated by eye movement, and signaling stimulus change. They found that 758 of the reading disabled subjects exhibited an abnormality of transient visual information.

The transient and sustained systems were conceptualized as operating at the retinal level, and as mutually inhibiting. The transient system detects global movement and spatial location. It transmits information quickly, and only operates at the beginning and end of an eye fixation. The sustained system specializes in otructural detail; it transmits information slowly for the duration of the fixation (Solman, Dain, \& Keech, 1991). The onset of transient activity terminates sustained activity, and separates information taken in during a series of fixations. If this separation is impeded in reading by a transient dysfunction, words and letters would overlap and create confusion (Breitmeyer \& Ganz, 1976).

A number of recent studies have been conducted within the conceptual framework of the dual processing system. Results have indicated that approximately 708 of students with specific reading disabilities may have deficits in the transient subsystem (Williams, 1990). While the deficits in the sustained system are readily detectable as impaired vision, those associated with transient processing are more subtle. They could impair complex visual behaviors such as reading, while leaving the individual with normal 
vision according to most clinical assessments. Perceptual consequences of a transient processing deficit would include selective attention deficits, longer visual search time, slower visual processing of both simple stimuli and words, and impaired figure-ground perception (Williams, 1990). These are also symptoms associated with Irlen syndrome.

The dual processing system has been reconceptualized based on recent physiological investigations of the primate visual system. The current theory is that of the magnocellular (transient) and parvocellular (sustained) systems (Williams \& Lecluyse, 1990). The etiology of some reading disorders can be understood as an abnormal flow of information through the "M-cell" and "P-cell" pathways (Bassi \& Lehmkuhle, 1990). Techniques which have been credited with normalizing this flow--and consequently improving the visual processing of reading disabled subjects--include image blurring and coloring text (Williams, 1990), and the use of colored filters to reduce figure-ground contrast (Solman et al., 1991).

The findings of a recent study sponsored by the Department of iveurubiology, Harvard Medical School (Livingstone, Rosen, Drislane \& Galaburda, 1991) have been cited as giving theoretical support to the use of spectral modification techniques in the treatment of reading disabilities (Blakeslee, 1991). One of the Harvard findings was that under high contrast conditions, when both magno and parvo systems should be active, dyslexic subjects' response to a rapidly changing visual stimulus was the same as that of a non-dyslexic control group. Under low contrast 
conditions, when only the fast magno system should respond, the dyslexic subjects showed a greatly diminished response. This suggested an underdeveloped magnocellular system, which was indicated in a comparative autopsy of five dyslexic and five normal brains. Examination of the visual relay stations in both groups revealed that the parvocellular systems were similar. In the dyslexic brains, the magnocellular systems were more disorganized, and the cell bodies appeared smaller (Livingstone et al., 1991).

It has been projected that information from the fast magno system must precede that from the slower parvo system in exactly the right timing, for reading to be efficient. If the magno system is operating sluggishly, words could appear to blur, fuse, or jump off the page (Breitmeyer cited in Blakeslee, 1991).

The perceptual deficit identified as scotopic Sensitivity/Irlen Syndrome can be supported by a body of scientific research that has been evolving for 15 years. Colored overlays and lenses appear to address this deficit by normalizing the interaction between visual subsystems, thus relieving the perceptual distortions that some inefficient readers experience.

To this researcher's knowledge, one aspect of Irlen's technique remains unexplained in theory. This involves color choice, which is individualized and crucial to success. An incorrectly chosen color can be detrimental to an individual's reading capacity (Podell, 1990 ). 
Efficacy of the Diagnostic Procedure

This researcher was unable to locate a technical evaluation of the IDPIS screening tool. An assessment of face validity was therefore made by examining the instrument itself. As the title (Irlen Differential Perceptual Interview Survey) indicates, it is essentially an interview and direct trial process.

The first step in this process is a series of questions on the type of reading difficulties, and evidence of strain or fatigue, experienced by the subject when reading for information. This serves a purpose similar to the doctor-patient interviews that would precede a medical diagnosis: to identify symptoms associated with the condition in question. Individuals who have Irlen Syndrome in conjunction with learning disabilities are expected to show a moderate to high incidence of "always" or sometimes" responses on this section (Irlen, 1991).

Section II of the IDPIS consists of vision tasks designed to actually elicit the symptoms of Irlen Syndrome. These involve operations of counting, tracking, and focusing, but not actual reading. Whether or not a subject can actually complete the tasks is not considered relevant. The significant element is the subject's response to specific questions that probe his or her perception of the print and the background.

The tasks in Section II are designed to elicit a wide range of symptoms, and subjects are not expected to have equal difficulty with the activities. It is possible for a subject to have problems with 
only one of the tasks (Irlen, 1991). The Irlen screening manual makes the following statement about the appropriateness of the tasks for young subjects:

The types of perceptual skills being tested in this section appear to be fully developed at a young age. There appears to be little change or development of these perceptual functions as the child grows older. These perceptual problems do not improve with maturation. Even children as young as seven years old should be able to complete most of these activities without experiencing sss (Scotopic sensitivity syndrome) symptoms. (p. 8)

Section III of the IDPIS is designed to determine the individual's overlay preference. Transparent overlays in seven tints are tried, singly and in combination, over a page of text printed in the Dutch language. The Dutch feature frees the subject from the task of reading, allowing him or her to concentrate on the clarity, sharpness, and contrast of the printed page as seen with spectral modification.

After using the Dutch page to select a color and density, the subject is asked to read passages aloud and silently in the following order: with overlay, without overlay, with overlay. The subject's report on changes experienced during the reading trial is the principal indicator of the overlay's effectiveness in relieving symptoms. The amount of improvement or change induced by the preferred overlay is influenced by the severity of Irlen syndrome, and by the presence or absence of other factors which can cause reading problems (Irlen, 1991).

The IDPIS procedure provides direct inquiry into the following assessment questions: 
1. Does the subject manifest symptoms of scotopic sensitivity Syndrome when perceptual and reading tasks are presented?

2. Can the subject's symptoms be mediated by spectral modification techniques?

These questions are closely tied to the purpose of this study, which was to observe and measure changes in reading performance that occurred over time and in conjunction with the use of colored overlays. It is on this basig that the IDPIS is offered as a valid tool for this study. Conventional vision examination, educational and prychological evaluations, and other school-related tests have not been designed to reveal symptoms of Irlen Syndrome (Irlen, 1991). To consider the reliability of the IDPIS procedure, it is necessary to account for several factors that can cause an individual's diagnosis to vary over time (Irlen, 1991). These include the demands of the educational environment, the verbal skills of the individual, and acquired physical and emotional compensatory strategies. The recommendation is that children be screened at different times during their school careers. The screening manual offers the following justification for repeated screening:

For example, children as young as seven or eight might be successfully diagnosed if the type of distortions they are experiencing are readily identifiable and easy to describe. However, for some readers, sss reading problems--such as accuracy and fluency--might not manifest themselves until third grade when the print size decreases and the amount of print on the page increases. Problems in reading comprehension, ease and efficiency in reading, or the length of time it takes to read may be due to the sss perceptual distortions. The appearance of and ability to detect these problems might not occur until middle school or later on in 


\begin{abstract}
a child's school career. It is at this time that the demand for sustained reading and concentration increases and some children can no longer survive by using their listening and verbal skills. (p. 6)
\end{abstract}

Support for the Irlen diagnostic procedures can also be derived from the review of applied research in the field, as presented in this chapter. Those studies which indicated positive results for treatment by spectral modification included a detailed assessment component. Due to the complexity of both the reading process and the learner's profile, diagnosis is intrinsic to effective treatment (H. I. Irlen, personal communication, November 7, 1991).

Prevalence of Irlen Syndrome

The Irlen (1991) Screening Manual makes the following statement: "Forty-six percent $(46 \%)$ of those with reading problems have been found to have Scotopic Sensitivity syndrome as one layer contributing to their reading difficultieg" (p. 2). Other studies which have documented a 46-50\% prevalence of Irlen syndrome in low ability readers comprising their samples include the following: Irlen (1983), Robinson and Miles (1987), Adler and Atwood (1987).

Miller (1984) found a higher prevalence in an unpublished study that investigated the applicability of the IDPIS for identifying the subset of a given population who suffer from Irlen Syndrome. She made a random selection of adult subjects who could be classified as low-ability and high-ability readers, based on reading scores on record at Leeward Community college, Hawaii. Subjects were given three additional measures of reading achievement, plus the IDPIS 
Findings were (a) that the IDPIS distinguished between low-ability and high-ability groups at a statistically significant level, and (b) 738 of the low-ability group were diagnosed as scotopically sensitive. Lovegrove's estimate, based on his research, was that $75 \%$ of the reading disabled may have deficits in early (i.e., transient or magnocellular) visual processing operations (Lovegrove, Martin \& Slaghuis, 1984).

The Irlen (1991) Screening Manual states that findings support a 128 prevalence of mild to moderate Irlen syndrome among good readers in the general population. Miller's (1984) finding was that 14.88 of her high-ability subjects had some degree of Irlen Syndrome.

\section{Applied Research on Treatment of Irlen syndrome}

\section{Origin of Applied Studies}

Seventeen studies were located through a search effort that had three phases: (a) computer search of the ERIC data base by the Professional Library of Portland Public Schools, (b) direct inquiry to the Irlen Institute, and (c) a Medline computer search assisted by the School of Optometry, Pacific University.

At the time of this review, the body of literature addressing spectral modification techniques was small. A significant portion of the research data originated in Australia, where use of the Irlen techniques is more prevalent. The screening of Australian school children for Irlen syndrome is actually mandated in some regions (Rickelman \& Henk, 1990). The Australian Institute of Health has 
summarized research proceedings, both published and unpublished, in its Health Care Technology Series No. 2: Tinted Lenses in Treatment of the Reading Disabled (Lea \& Hailey, 1990). The authors of this monologue open their section on "gtudies of efficacy" with this comment :

Studies validating the efficacy of the Irlen approach have been slow to emerge. Available data are contained in several unpublished reports by holders of the Irlen franchises and a small number of articles in the literature. (p. 12)

The studies here reviewed fell into three broad categories, as indicated by Table 2. This grouping was based on the professional orientation of the researchers. Table 2 includes the institutional affiliation, or sponsorship, of each study.

\section{Olive Meares}

Meares (1980) was a special educator who published her attempts to address perceptual problems in reading during the 1970 s. The following statement from Meares was based on her work at a New zealand reading clinic:

Experience working with children in a reading clinic tells me that blurring, moving, jumping, flickering print distortions are indeed a visual reality for many children. Their comments suggest that this is not the result of a vision defect, but rather that it is due to a perceptual instability stemming from and induced by the conventional figure/ground organization of books, i.e., black print on a white page. (p. 14)

Meares' (1980) technique was to have children who complained of brightness or print distortions place tinted perspex sheets over reading material. She noted that some children used the perspex 
Table 2

Professional orientation of Applied Studies on Use of Spectral Modification Techniques

\begin{tabular}{|c|c|c|c|c|c|}
\hline \multicolumn{2}{|c|}{ Education, Psychology } & \multicolumn{2}{|c|}{ Optometry, Ophthalmology } & \multicolumn{2}{|c|}{ Interdisciplinary } \\
\hline Researcherg & Affiliation & Researchers & Affiliation & Researchers & Affiliation \\
\hline $\begin{array}{l}\text { Adler \& Atwood } \\
1987\end{array}$ & $\begin{array}{l}\text { California } \\
\text { Dept. of } \\
\text { Education }\end{array}$ & $\begin{array}{l}2 \text { winter } \\
1986\end{array}$ & $\begin{array}{l}\text { Affiliation } \\
\text { unknown; work } \\
\text { performed in } \\
\text { Hong Kong }\end{array}$ & $\begin{array}{l}\text { Fricker } \\
1989\end{array}$ & $\begin{array}{l}\text { Dept. of } \\
\text { Education \& } \\
\text { Medical Dept. } \\
\text { Tasmania Govt. }\end{array}$ \\
\hline $\begin{array}{l}\text { Robinson \& Miles } \\
1987\end{array}$ & $\begin{array}{l}\text { University of } \\
\text { Newcastle, } \\
\text { Australia }\end{array}$ & $\begin{array}{l}\text { Gregg } \\
1988\end{array}$ & $\begin{array}{l}\text { Private } \\
\text { optometry } \\
\text { practice in } \\
\text { Rugby, } \\
\text { Warwickshire, } \\
\text { Great Britain }\end{array}$ & $\begin{array}{l}\text { Gole, Dibden, } \\
\text { Pearson, } \\
\text { Pidgeon } \\
1989\end{array}$ & $\begin{array}{l}\text { SPELD tinted } \\
\text { lenses study } \\
\text { group, Australia }\end{array}$ \\
\hline $\begin{array}{l}1 \text { Whiting \& } \\
\text { Robinson } \\
1988\end{array}$ & $\begin{array}{l}\text { Sydney } \\
\text { Institute of } \\
\text { Education, } \\
\text { Australia }\end{array}$ & $\begin{array}{l}\text { Blaskey, } \\
\text { Scheiman, } \\
\text { Parisi, } \\
\text { Ciner, } \\
\text { Gallaway \& } \\
\text { Selznick } \\
1990 \\
\end{array}$ & $\begin{array}{l}\text { Pennsylvania } \\
\text { College of } \\
\text { Optometry, } \\
\text { Philadelphia, } \\
\text { PA }\end{array}$ & $\begin{array}{l}\text { Hannell, Gole, } \\
\text { Dibden, } \\
\text { Rooney, } 1989\end{array}$ & $\begin{array}{l}\text { SPELD tinted } \\
\text { lenses study } \\
\text { group }\end{array}$ \\
\hline $\begin{array}{l}\text { Chan \& Robinson } \\
1989\end{array}$ & $\begin{array}{l}\text { University of } \\
\text { Newcastle, } \\
\text { Australia }\end{array}$ & $\begin{array}{l}\text { Fitzgerald } \\
1989\end{array}$ & $\begin{array}{l}\text { University of } \\
\text { Sydney Dept. } \\
\text { of Clinical } \\
\text { Ophthalmology, } \\
\text { Australia }\end{array}$ & $\begin{array}{l}\text { Solman, Dain \& } \\
\text { Keech } \\
1991\end{array}$ & $\begin{array}{l}\text { Human Visual } \\
\text { Performance } \\
\text { Research Unit \& } \\
\text { School of } \\
\text { Education, } \\
\text { University of } \\
\text { New South Wales, } \\
\text { Australia }\end{array}$ \\
\hline
\end{tabular}


Table 2

Profegsional Orientation of Applied Studies on Use of Spectral Modification Techniques

(continued)

\begin{tabular}{|c|c|c|c|c|c|}
\hline \multicolumn{2}{|c|}{ Education, Psychology } & \multicolumn{2}{|c|}{ Optometry, Ophthalmology } & \multicolumn{2}{|c|}{ Interdisciplinary } \\
\hline Researchers & Affiliation & Researchers & Affiliation & Researchers & Affiliation \\
\hline $\begin{array}{l}\text { O'Connor, Sofo, } \\
\text { Kendall \& Olsen } \\
1990\end{array}$ & $\begin{array}{l}\text { University of } \\
\text { Canberra, } \\
\text { Australia }\end{array}$ & $\begin{array}{l}\text { Scheiman, } \\
\text { Blaskey, } \\
\text { Ciner, } \\
\text { Gallaway, } \\
\text { Parisi, } \\
\text { Pollack \& } \\
\text { Selznick } \\
1990\end{array}$ & $\begin{array}{l}\text { Pennsylvania } \\
\text { College of } \\
\text { Optometry }\end{array}$ & \multirow{3}{*}{\multicolumn{2}{|c|}{ No additional works }} \\
\hline $\begin{array}{l}\text { Robinson \& Conway } \\
1990\end{array}$ & $\begin{array}{l}\text { University of } \\
\text { Newcastle, } \\
\text { Australia }\end{array}$ & $\begin{array}{l}\text { Scheiman, } \\
\text { Blaskey, } \\
\text { Gallaway, } \\
\text { Ciner \& Parisi } \\
1990\end{array}$ & $\begin{array}{l}\text { Pennsylvania } \\
\text { College of } \\
\text { Optometry }\end{array}$ & & \\
\hline $\begin{array}{l}\text { Williams } \\
1990\end{array}$ & $\begin{array}{l}\text { Dept. of } \\
\text { Psychology } \\
\text { University of } \\
\text { New Orleans, } \\
\text { Louisiana }\end{array}$ & & & & \\
\hline
\end{tabular}

1 The Whiting (1980) reference is a commentary on this study, and does not represent a separate study.

2 Unpublished paper reviewed by Rosner and Rosner (1987). 
indefinitely. Others would phase it out as their skill improved, often discarding it completely as they moved into smaller print.

Studies originating in Education and Psychology

All studies in this category except Williams (1990) used Irlen assessment procedures to identify Irlen syndrome in their samples. The first level screening procedure (IDPIS) was used in the two studies which investigated the effectiveness of overlays only (O'Connor, Sofo, Kendall, \& Olson, 1990; Robinson, \& Miles, 1987). Neither overlays nor tinted lenses were used in the Williams study. The remaining four investigated tinted lenses, and involved both levels of the Irlen assessment procedures.

The Irlen Institute's recommendation is that all prospective clients have a professional vision examination, and subsequent correction of visual problems prior to screening for Irlen syndrome (Irlen \& Lass, 1989). It is therefore possible that subjects in the education/psychology studies had their vision optometrically assessed as a prerequisite. However, none of the researchers cited independent vision evaluations as part of their procedures. This point is in contrast to studies in the optometry/ophthalmology category. Williams (1990) did mention the visual status of her subjects, in that records had been checked for normal acuity and color vision.

Larger samples were used for the studies in this category than for the medically oriented research. Sample sizes in the experimental studies ranged from 40 (Robinson \& Miles, 1987) to 92 (0'Connor et 
al., 1990). Whiting and Robinson (1988) used survey methodology and had 250 respondents.

Three studies in this category did not employ a control or comparison group (Robinson \& Conway, 1990; Robinøon \& Miles, 1987; Whiting \& Robinson, 1988). Adler and Atwood (1987) used a control group of students with Irlen syndrome who did not receive treatment. A comparison group of normal readers was in place for chan and Robinson (1989), 0'Connor et al. (1990) and Williams (1990). The results of all seven studies in this category supported the effectiveness of spectral modification techniques. Adler and Atwood (1987) provided their experimental group with Irlen lenses, group counseling, and a career preparation class. These subjects demonstrated reduced symptoms of Irlen syndrome, improved performance on specific reading tasks, and $40 \%$ employment at the end of the five-month treatment period. These gaing were not approximated by the control group, although their control data has been criticized as incomplete (Reeves, 1988). It would be difficult to distinguish effects of lenses from those of other interventions on an outcome such as employment status.

Results published by Whiting and Robinson (1988) were that 908 of all respondents attributed positive gains to the Irlen lenses. Responses ranged from assessment of the lenses as very helpful (50\%) to moderately or slightly helpful.

Robinson and Miles (1987) measured performance changes on four tasks which involved word matching and the identification of common words, letters, and numbers. Each of the 40 subjects was tested on all tasks with three overlays: maximal tint, random tint, and clear. 
Results demonstrated improved performance on letter and number identification with the maximal tint, no improvement with the random tint, and a regression with the clear overlay. The change in word recognition with overlays was not significant.

Chan and Robinson (1989) divided their 80 subjects into four groups. Two groups were classified by the experimenters as reading disabled because their reading achievement was two or more years below expectations for their chronologisal age. One group of disabled readers had worn Irlen lenses for six months or longer. The other group had not been fitted with lenses. One group of non-disabled readers matched the Irlen lens group in reading age; a second group of non-disabled subjects matched the Irlen lens group in chronological age.

All subjects received a detailed demonstration of their task: identification of a number of inconsistent sentences within a set of test passages. Results were that the performance of the tinted lenses group resembled that of both the CA-matched and RA-matched groups, and was significantly better than that of the disabled readers who did not wear Irlen lenses (Lea \& Hailey, 1990). O'Connor, Sofo, Kendall, and Olsen (1990) had their 92 subjects (all children) screened with the Ishihara Test for color Blindness and the IDPIS The 67 found to demonstrate Irlen Syndrome were randomly assigned to one of four groups:

Group "A", post-tested with the colored overlay matching their best performance on the IDPIS Group "B", post-tested with clear overlays. Group "C", post-tested with randomly assigned colored overlays. 
Group "D", not given a pre-test, post-tested with clear overlays. The 25 children who did not demonstrate Irlen syndrome were randomly asgigned to one of two groups: Group " $\mathrm{E}$ ", post-tested with clear overlays. Group "F", post-tested with randomly assigned colored overlays. All subjects except Group " $D$ " were pre-tested with the Neale Analysis of Reading Ability and the Wiederholt Formal Reading Inventory. All were post-tested, one week later, with the same instruments. The reading tests were administered by independent examiners who were blind to group placement. The groupings were designed to test for placebo effects, which results did not support. Post-test results showed a significant improvement in comprehension, reading rate, and accuracy for group " $A$ ". Results for the other groups varied between improvement, no change and regression. The improvement of group " $A$ " was one of two significant changes reported by o'Connor et al. (1990). The other was a regression in rate, accuracy and comprehension for group "B", scotopics who were post-tested with clear overlays. The average negative change for group " $B$ " was smaller than the average positive change for group " $\mathrm{A}$ ", but notable. The group "B" finding was consistent with the Robinson and Miles (1987) observation of regressive performance when subjects used clear overlays. O'Connor et al. (1990) noted that post hoc reports from subjects in group " $B$ " indicated that the clear transparencies made glare from the white paper much worse and intensified eyestrain. 
As mentioned previously, $0^{\prime}$ Connor et al. (1990) had subjects screened for color blindness. The issue of defective color vision was addressed during an Irlen Institute Advanced Screener's Seminar that this researcher attended in January 1993. In general, the ability to perceive true colors has not been found relevant to scotopic Sensitivity/Irlen Syndrome. A color blind individual can still benefit from the spectral filtration effects of a correctly prescribed tint.

Robinson and Conway (1990) administered the IDPIS to 91 people who had self-referred to the Hunter Institute of Higher Education for assistance with specific reading problems. From this group they identified 44 subjects who had Scotopic Sensitivity Syndrome. The average reading age discrepancy for the group was two years nine months below chronological age. The study was designed to compare reading progress during one year of instruction while wearing tinted lenses, to subjects' prior rates of progress. Hence, subjects were seen as serving both a control and an experimental function. The average rate of progress projected (under treatment) was twelve months' growth in reading age for the year.

Results of the Robinson and Conway (1990) study were that subjects increased eleven months in reading rate, 21 months in reading accuracy, and 36 months in reading comprehension. In discussing their study, these researchers admitted that including a control group would have reduced the need to hypothesize as to what constitutes a significant advancement in reading ability. 
The study by Williams (1990) stood apart from others included in this category. This is due more to procedures employed than to results generated. Williams used the computer monitor to vary the background color and resolution of print, rather than tinted overlays or lenses.

Williams' (1990) 38 reading disabled subjects were matched to normal readers by age and I.Q. Each subject was assessed for reading level and given passages, at an appropriate level of difficulty, under three conditions:

1. Words shown individually on the monitor, so that no eye movement was required.

2. Woras shown so that limited eye movement was required, but was assisted by presentation.

3. Passages shown line by line, requiring normal eye movement. Results of comprehension testing indicated that the disabled readers performed poorly in the third condition. Their comprehension was not significantly different from that of normal readers when eye movement was assisted or not required. The comprehension of her disabled sample improved, and approximated that of the normal readers, when lines of print were shown blurred or on a blue ground. Williams (1990) designed this study to test the hypothesis that transient-on-sustained inhibition causes perceptual distortions in reading for some individuals. She concluded that these results both supported the hypothesis, and indicated that the use of tinted overlays to reduce print/ground contrast is an effective measure. Williams' report of the study concluded with this comment: 
We caution that, since there are individual differences in the effects of different colors across individuals, the reading performance of each individual should be measured with various colored and with gray overlays before an assignment is made. (p. 13)

\section{Studies originating in Optometry} and Ophthalmology

Subjects in four of the six studies in this category underwent Irlen assessment procedures. Winter's (cited in Rosner \& Rosner, 1987) sample had been previously fitted with Irlen lenses. Administration of the I.D.P.I.S. by an independent Irlen screener was a procedural element in Blaskey, Scheiman, Parisi, Ciner, Gallaway and Selznick (1990); also in the two studies by Scheiman, Blaskey, Ciner, et al., (1990); Scheiman, Blaskey, Gallaway et al., (1990). One group of subjects in Blaskey et al. was given the second level of Irlen assessment and fitted with lenses.

These six studies used smaller samples, ranging from three in the case study by Scheiman, Blaskey, Ciner, Gallaway, and Parisi (1990), to 39 in the visual characteristics study by scheiman, Blaskey, Gallaway, Ciner and Parisi (1990). Only one of these studies employed a control group: Blaskey et al. (1990). They had a control group of eight, plus two treatment groups of 11 subjects each.

In contrast to the previous category, over half of these studies (four out of $\mathbf{s i x}$ ) involved complete vision evaluations of their samples. This was provided by an independent evaluator in the Blaskey et al. (1990) research. It was performed by the experimenters for the Gregg (1988) Study, and for the two endeavors by scheiman et al. (1990) 
Results in this category varied in reference to the concept of spectral modification. There were results that supported the concept, especially within the work of Gregg (1988) and Blaskey et al. (1990) However, the following three reservations were projected by this small body of work:

1. Individuals who demonstrate Irlen Syndrome are likely to have vision anomalies that are not often detected by optometric examination.

2. The vision care appropriate for individuals with these anomalies should be provided by optometrists and ophthalmologists.

3. Given appropriate vision care, patients are unlikely to need colored overlays or tinted lenses.

These regervations were considered in examining the focus and outcome of studies in this category. The earliest work by Winter (cited in Rosner \& Rosner, 1987) was documented in an unpublished paper that this researcher was unable to locate. Information on Winter's work was taken from a published review (cited in Rosner \& Rosner, 1987).

Winter's subjects were 22 children who already wore Irlen lenses. Their task was to recognize the letter " $b$ " within a context of randomly organized letters, and under each of four conditions: (a) wearing their own Irlen lenses, (b) wearing untinted plano lenses, (c) wearing stock grey tinted lenses, and (d) wearing no lenses. Results were that subjects performed equally well under each condition. Rosner and Rosner (1987) cautioned against generalizing these results, 
based on the experimental task. It was a visual search exercise that may not be predictive of reading performance. This question of predictive appropriateness could also be applied to Robinson and Miles (1987), in which subjects engaged in letter and number identification. Regults of the work by Gregg (1988) were positive in demonstrating the benefits of colored overlays for eight of his 17 subjects. All 17 were identified as dyslexic, and were pre-tested with the Neale Analysis of Reading Achievement (NARA) by an independent examiner. Gregg distinguished between two types of reading difficulties that were demonstrated by his sample. Eight children demonstrated "visualization difficulties" in reading. These would begin reading fluently, but would soon tire and slow down. Given trials with colored filters they made comments such as: "the letters have stopped moving, . . the lines are straight now, . . the letters are not double any more,... the words are bigger and stand out clearer" (p. 17). These were the eight who demonstrated gains on the NARA post-test, for which they used a colored overlay. The other nine subjects were described as having "decoding difficulties" (Gregg, 1988, p. 17), demonstrated as letter transpositions and reversals. These subjects did not demonstrate notable gains on the post-test. Gregg cited the correlation between strength of filter preference and post-test gains as a significant finding. Eighty percent of the children who expressed a strong or moderate preference for their preferred color, as compared to reading black on white, showed definite gains. None of the subjects who expressed a weak preference derived benefit. 


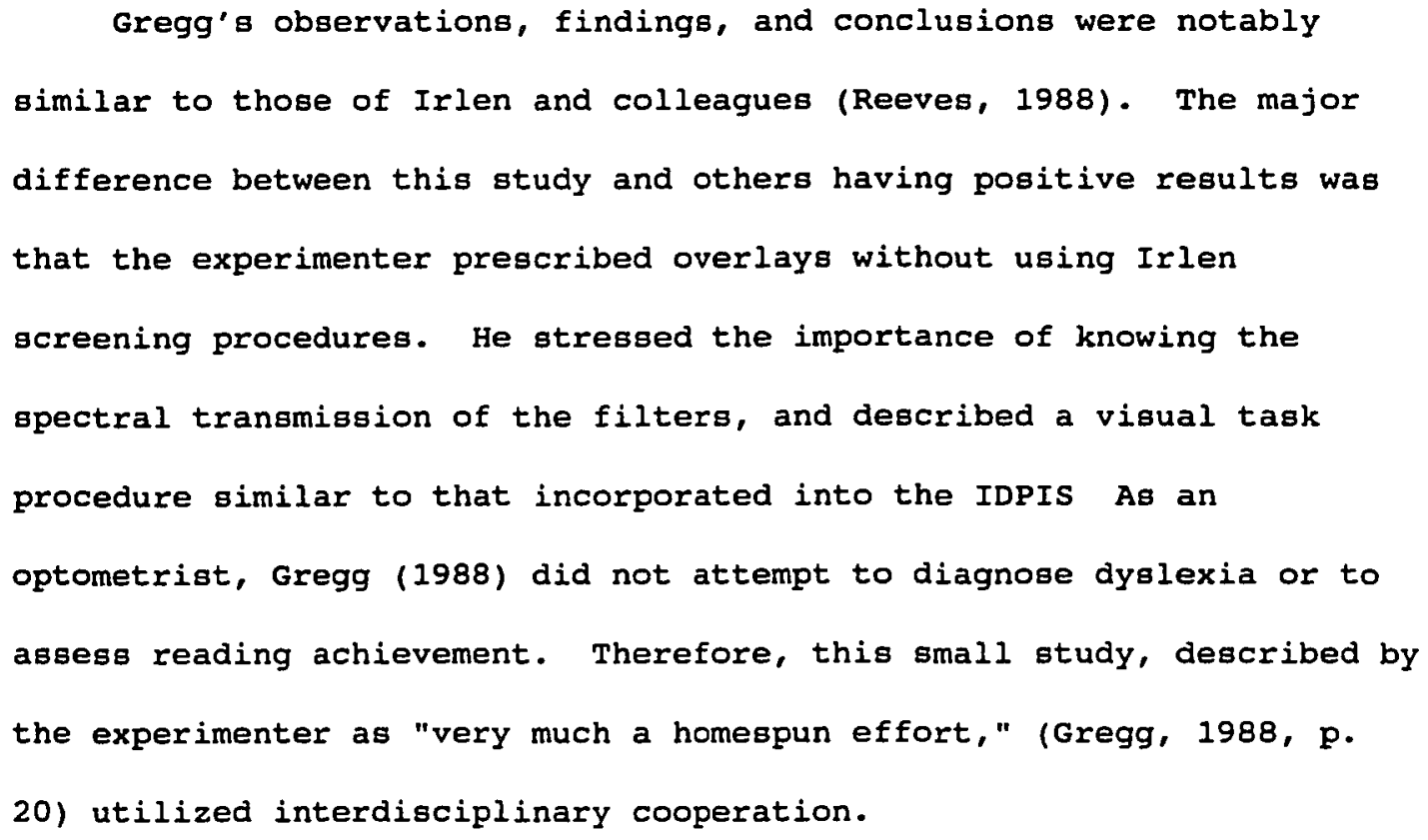


Post-test results indicated positive gains in letter naming and word recognition for the Irlen filter group. Although lenses made these subjects more comfortable, a post vision evaluation revealed that they continued to have vision anomalies. Results for the vision therapy group indicated improvement in oral reading, plus correction of the vision problems their therapy was intended to address. Both groups were given a post-IDPIS, for which the Irlen lens group wore lenses. Results indicated a significant decrease in Irlen synarome for both groups. For the control group of eight subjects, there was no significant change on any measure.

Blaskey et al. (1990) concluded their discussion with this observation:

One final interesting finding was that two subjects who had been treated with vision therapy and achieved moderate relief of symptoms reported additional improvement in comfort after receiving Irlen filters. In both of these subjects there was an additional increase in oral reading rate and improvement in comprehension with the Irlen filters. Thus, although both Irlen filters and vision therapy appear to have the effect of making individuals more comfortable when reading, the underlying physiological basis may be different. (p. 609)

Fitzgerald (1989) published a summary of her master's thesis completed at the University of Sydney. The purpose of this research was to investigate the hypothesis that dyslexic patients' ability to discriminate fine detail was improved by wearing tinted lenses.

Contrast sensitivity was selected as the index of ability to accurately perceive fine detail. The study was designed to compare contrast sensitivity, and the effect of tinted lenses thereon, of 325 dyslexic and 25 normal children. 
Fitzgerald's (1989) results demonstrated that the dyslexic sample had normal contrast sensitivity, and that the lenses had no significant effect on the ability to see the range of spatial frequencies among normals or dyslexics. Unlike Gregg (1989) or Blaskey et al. (1990), Fitzgerald did not identify a subgroup of dyslexics who demonstrated symptoms associated with Irlen syndrome. The summary did not discuss the methods by which tinted lenses were prescribed.

Two studies (Scheiman, Blaskey, Ciner et al., 1990; Scheiman, Blaskey, Gallaway et al., 1990) did not involve colored overlays or tinted lenses. The intent of both was to investigate Irlen's premise that scotopic sensitivity/Irlen syndrome is distinct from vision problems that are treated optometrically. The researchers provided comprehensive vision evaluations to 39 individuals who had independently sought information on the Irlen methods. Each was optometrically evaluated by the researchers, and given the I.D.P.I.S. by a certified Irlen screener. It was found that 37 demonstrated Irlen syndrome. of these 37,35 were diagnosed with vision anomalies as follows:

20 had binocular vision disorders;

9 had ocular motility dysfunction;

10 had miscellaneous uncorrected anomalies. Scheiman, Blaskey, Ciner, et al. (1990) concluded that Irlen's conceptualization of scotopic sensitivity syndrome as distinct from other vision disorders was invalid. They also acknowledged that accommodative, refractive, and ocular motility characteristics are not 
routinely tested by optometrists. Although these 35 individuals had undergone periodic routine eye care, scheiman et al. concluded that their vision problems had not been properly managed. The case study effort by Scheiman, Blaskey, Ciner, et al., (1990) involved the treatment of three of the 35 patients in their diagnostic gtudy. One was given corrective lenses, one was given a combination of corrective lenses and vision therapy, and the third was given vision therapy only. Post treatment evaluation indicated significant reduction of symptoms that would have made these patients candidates for Irlen filters.

\section{Toward Interdisciplinary Cooperation}

Other authors who wrote from a medical perspective--in addition to the researchers cited above--have connected the symptoms of Scotopic Sensitivity syndrome with visual dysfunctions that can be optometrically identified and treated (Garzia \& Nicholson, 1990; Hoyt, 1990). Some recognized the need for an increased level of optometric and educational cooperation, to resolve the controversy that surrounds the emerging correlation between visual function and reading performance (Garzia \& Nicholson, 1990).

It is this researcher's view that Helen Irlen's work has contributed substantially to both education and optometry. Educational practitioners were given a conceptual framework and diagnostic tool with which to address perceptual problems in reading. Her work provided additional impetus for researchers in optometry to investigate a relationship between visual function and reading. 
Garzia and Nicholson (1990) concluded that the totality of interactions between visual function and reading established the concept of learning related vision problems. An optometrist caring for a reading disabled patient is obliged to comprehensively evaluate visual functions, then take part in interdisciplinary efforts with educational personnel. In a rationale for optometric visual training of learning disabled children, solan (1981) stressed that such training should be part of an interdisciplinary effort. This is in keeping with the role of special educators and classroom teachers who are "primary care practitioners" for LD children (Solan, 1981, p. 572). It is they who must provide the proper mix of content and strategy to facilitate learning.

The visual training referred to by Solan (1981) was presented as a concept similar to that of vision therapy. Vision therapy involves activities such as distinguishing figures from ground, and responding to frequent stimulus adjustments. Some clinical reports have related the outcome of vision therapy to academic performance, especially in cases where the central therapy issue was the remediation of visual perceptual-motor skills. It is unclear whether functional deficiencies in the visual system are actually being corrected, or compensatory strategies are learned (Garzia \& Nicholson, 1990).

Dr. Gary Kappel, OD (personal contact, 1993), a local practitioner of vision therapy, reported that vision therapy is supported by several decades of clinical practice. However, it is regarded as innovative and controversial, and only 108 (approximately) of practicing optometrists are competent in its techniques. This 
researcher concluded that for many families, vision therapy would present more serious issues of cost and accessibility than would the Irlen techniques.

\section{Interdisciplinary studies}

The remaining four studies discussed here did little to resolve the controvergy between spectral modification as an educational intervention vs. optometric management of perceptual problems. The outcome of one study (Fricker, 1989) supported the effectiveness of Irlen lenses. Two supported the concept of spectral modification in general (Hannell, Gole, Dibden \& Rooney, 1989; Solman, Dain \& Keech, 1991). The study by Gole, Dibden, Pearson, Pidgeon (1989) did not support the use of tinted lenses.

Fricker's (1989) sample of 127 had been fitted with lenses according to Irlen procedures. The other three studies did not involve Irlen-designed assessment procedures. Subjects in Gole et al. (1989) and Hannell et al. (1989) had lenses and overlays prescribed by optometrists after trial of commercially available products. Filter assignment was based on spatial location judgments in the contrast sensitivity study by solman et al. (1991).

Sample size varied from a case study of two (Hannell et al., 1989) to Fricker's 127. Only the case study effort by Hannell et al. involved optometric evaluation as a procedural element. Fricker's (1989) sample of 127 school age children were fitted with Irlen lenses, then assessed at annual intervals on the Gray Oral Reading Test and the ACER silent Reading Test. This study included the administration of questionnaires to subjects, parents, and 
teachers; these were designed to elicit observations on degree of improvement in regard to reading ability and health indicators. Results on the Gray and ACER reading tests were positive and consistent over the three year period. Questionnaire responses from 208 to 308 of the parents indicated that the lenses led to a decrease in incidence and severity of headaches, migraine, asthma, and some psychosomatic complaints. The teachers who responded on the questionnaire reported improvements in reading accuracy that they attributed to the lenses. The children's responses to the questionnaire were that their reading had gotten a "lot better" (68-718), or a "little better" (27-30\%). This study did not include a control group of normal readers, making it impossible to compare reading gains or to assess motivational effects (Lea \& Hailey, 1990). SPELD (SA) Inc., sponsoring agency for Gole et al., is a non-profit organization that provides assessment and advice to dyslexic children and adults. This study (Gole et al., 1989) was designed as a randomized prospective controlled trial of the use of tinted lenses in the management of dyslexia. Selection criteria for the 24 subjects in Gole et al. did not include an attempt to identify symptoms associated with scotopic Sensitivity syndrome. Selection criteria included ages of 9 to 12 years, full scale IQ above 85, a reading delay of two or more years, and normal reading vision. Tinted lenses were prescribed by an optometrist, based on trials of four commercially available tints with variations in density for each tint. Subjects who responded that tints did not improve the appearance of print were given clear lenses 
and retained as subjects. All 24 were randomly assigned to an experimental group, which wore their lenses for two school terms, or to a control group which did not wear lenses for one term but wore them for two subsequent terms.

The outcome variable in Gole et al. (1989) was reading age as measured by the Neale Analysis of Reading Achievement. There was no significant change in total reading age, or in any subskill, for all subjects between first and second term assessments. Nor was there any significant difference between experimental and control groups following the first term assessment.

The Gole et al. (1989) study can be challenged on two points. First, there was no attempt to identify a subgroup of SPELD clients who had the type of symptoms or reading difficulties for which spectral modification is indicated. Secondly, four colors may be an insufficient range for the purpose of the study. Practitioners in the Irlen clinics maintain that the exactness of the tint is critical. Tint selection is assisted by a spectrophotometer and involves a wide range of color and density variations. Approximate tint cannot be assumed to indicate or counterindicate effectiveness (Pitluk, 1990). The SPELD endorsed research effort was extended to include the case study of two dyslexic brothers by Hannell et al. (1989). The brothers underwent an ophthalmic assessment, a reading analysis using the Neale Analysis of Reading, copying tests, and an interview on their visual perception of words and white space. Post testing with the Neale Analysis showed that both brothers improved in reading accuracy and comprehension when using the overlays, with large 
improvements observed for sentence and pattern copying. Hannell et al. (1989) concluded that the use of colored overlays and tinted lenses may be appropriate for a subgroup of dyslexics. Solman, Dain and Keech (1991) selected 40 fifth grade subjects on the basis of a standardized reading test. Their 20 poor readers, who scored in the lower 158 , were matched to 20 good readers who scored in the top 158. An additional inclusion criterion cited by these researchers was demonstration of average general ability. The critical indicator in this study was change in subjects' contrast sensitivity as measured without colored filters, then measured when the stimulus was viewed through the "best color" filter. Selection of best and worst color for each subject was based on spatial location judgments. It was found that contrast sensitivity decreased significantly for poor readers when they used their best color. The use of clear, worst color, and gray filters increased the contrast sensitivity of the poor readers. Filter use resulted in little change for the good readers. Working independently of Irlen procedures, Solman et al. (1991) found a positive correlation between color effects and visual perception as relevant to reading. The selection technique they used, taken with the results, implied that contrast sensitivity is a problem for all poor readers. This seems inconsistent with the more prevalent conclusion that spectral modification is indicated for a subgroup of individuals with reading difficulties. 
Applications to the Current study

Several conclusions were derived from the literature review, and applied to the current study. Of major importance was the apparent relationship between carefully executed assessment and conclusive results that support spectral modification techniques. This researcher committed equal time to the assessment and subject identification process as to the experimental intervention.

The literature on applied research also indicated that most efforts have occurred in clinical settings, in contrast to actual school settings. Some efforts were made to survey individuals who had used Irlen lenses in school or work environments (Fricker, 1989; Whiting \& Robinson, 1988). This study was an experimental application in the actual school setting.

Unlike most of the existing work in education and psychology, this study involved comprehensive vision examinations for subjects. This was greatly facilitated by the small sample size. Subjects were assessed for conditions found by some researchers to approximate the symptoms of Irlen Syndrome. These had been identified as accommodative, binocular, and ocular motor anomalies (Blaskey et al., 1990).

The Lea and Hailey (1990) monologue offered the following conclusion on Irlen methods:

It has the potential to be applied according to a controlled protocol, has relatively low cost and can easily be introduced, assuming a degree of support from teachers, families, and peers. (p. 26)

This researcher tested their statement, in that one operating variable was the support of subjects by others in the school environment. 
Table 3 provides a synopsis of technical features that were supported by previous studies, and applied to this one. Iea and Hailey (1990) also recommended four caveats for the implementation of spectral modification techniques. These four are listed here and were considered in designing this study:

1. Selection criteria for persons receiving the treatment should be carefully defined.

2. An assessment procedure should be clearly specified and in place.

3. A supportive teaching environment for those undergoing treatment should be ensured.

4. The outcome measures of treatment should be defined and observed.

One purpose of this survey of literature and applied research was to locate information that would aid in designing this study. Table 3 presents a synopsis of recommendations from several sources that were considered in designing this study.

Table 3

Applications of Source Material to the Methodology of this study

\begin{tabular}{lll}
\hline Source & Information & Application \\
\hline $\begin{array}{l}\text { Irlen, H.I. } \\
\text { (personal } \\
\text { interview, }\end{array}$ & $\begin{array}{l}\text { Previous otudies have } \\
\text { not focused on reading } \\
\text { performance indicators } \\
\text { that are established } \\
\text { and routine in the } \\
\text { school setting. }\end{array}$ & $\begin{array}{l}\text { Established and } \\
\text { routine performance } \\
\text { indicators were } \\
\text { selected for } \\
\text { measurement in this } \\
\text { study. }\end{array}$ \\
\hline
\end{tabular}


Table 3

Applications of Source Material to the Methodology of this study

(continued)

\begin{tabular}{|c|c|c|}
\hline Source & Information & Application \\
\hline $\begin{array}{l}\text { Irlen } \\
\text { Screening } \\
\text { Manual } \\
(1991)\end{array}$ & $\begin{array}{l}\text { Individuals with Irlen } \\
\text { syndrome report these } \\
\text { improvements when reading } \\
\text { with spectral modification: } \\
\text { 1. Increased speed } \\
\text { 2. Increased accuracy } \\
\text { 3. Better comprehension } \\
\text { 4. Increased reading time. }\end{array}$ & $\begin{array}{l}\text { Three performance } \\
\text { indicators measured } \\
\text { in this study were } \\
\text { rate, accuracy, and } \\
\text { comprehension. } \\
\text { observations of } \\
\text { reading time were } \\
\text { made. }\end{array}$ \\
\hline $\begin{array}{l}\text { Robinson \& } \\
\text { Conway (1990) }\end{array}$ & $\begin{array}{l}\text { Subjects' rate of reading } \\
\text { growth while under } \\
\text { treatment was compared } \\
\text { with their prior rate; in } \\
\text { this sense subjects served } \\
\text { as their own controls. }\end{array}$ & $\begin{array}{l}\text { Reading growth } \\
\text { indicated by test } \\
\text { histories, plus } \\
\text { baseline data, was } \\
\text { compared to trends } \\
\text { revealed during } \\
\text { treatment. }\end{array}$ \\
\hline $\begin{array}{l}\text { Hannell, Gole, } \\
\text { Dibden \& } \\
\text { Rooney et al. } \\
(1989)\end{array}$ & $\begin{array}{l}\text { Improvements in reading } \\
\text { accuracy and comprehension } \\
\text { were attributed to the use } \\
\text { of overlays, over a period } \\
\text { of time, in a case study. }\end{array}$ & $\begin{array}{l}\text { Overlays were used } \\
\text { in a single subject } \\
\text { experiment, for a } \\
\text { period of nine weeks; } \\
\text { the effect on rate, } \\
\text { accuracy and } \\
\text { comprehension was } \\
\text { measured. }\end{array}$ \\
\hline $\begin{array}{l}\text { Fricker } \\
(1989)\end{array}$ & $\begin{array}{l}\text { Improvements in reading } \\
\text { performance held up over } \\
\text { time ( } 3 \text { years) as } \\
\text { individuals used tinted } \\
\text { lenses in the school } \\
\text { setting. Results were } \\
\text { generated by survey } \\
\text { methodology. }\end{array}$ & $\begin{array}{l}\text { Subjects used colored } \\
\text { overlays consistently, } \\
\text { in the school setting, } \\
\text { for nine weeks. } \\
\text { Results were generated } \\
\text { by repeated } \\
\text { measurements and } \\
\text { observations. }\end{array}$ \\
\hline
\end{tabular}


Table 3

Applications of Source Material to the Methodology of this study

(continued)

\begin{tabular}{lll}
\hline Source & Information & Application \\
\hline $\begin{array}{l}\text { Mobinson \& } \\
\text { Miles (1987) }\end{array}$ & $\begin{array}{l}\text { Word recognition did not } \\
\text { improve when subjects } \\
\text { used overlays in a test- } \\
\text { retest experimental } \\
\text { design. }\end{array}$ & $\begin{array}{l}\text { Word recognition was } \\
\text { one component of } \\
\text { accuracy and measured } \\
\text { repeatedly over time } \\
\text { as subjects used } \\
\text { overlays. }\end{array}$ \\
$\begin{array}{l}\text { SofConnor, Kendall } \\
\text { \& Olsen (1990) }\end{array}$ & $\begin{array}{l}\text { Colored overlays were } \\
\text { employed in a test-retest } \\
\text { improvement in reading } \\
\text { rate, accuracy and } \\
\text { comprehension. }\end{array}$ & $\begin{array}{l}\text { overlays were employed } \\
\text { over time in the } \\
\text { school setting; } \\
\text { changes in rate, } \\
\text { accuracy and } \\
\text { comprehension were } \\
\text { documented. The test- } \\
\text { retest feature was } \\
\text { also incorporated. }\end{array}$ \\
\hline
\end{tabular}


CHAPTER III

METHODOLOGY

Design

This study was designed as a single-subject experiment having four strands (e.g. four subjects) and a multiple-baseline structure. Subjects served as their own controls, in that changes in their reading performance during experimental intervention were compared to their performance pattern during the baseline period and previously.

A single subject experimental design was selected for this study chiefly because Scotopic Sensitivity/Irlen syndrome can occur differently in each affected individual. This individuation is indicated by the five symptom categories of the syndrome (presented on pages 5 and 6 of Chapter I), and by the subjective response focus of the Irlen Differential Perceptual Interview Survey. As stated by Ary, Jacobs, and Razavieh (1985),

Single-case designs have been particularly useful in clinical applications in which the focus is on therapeutic value of an intervention for the client. (p. 290)

special education for learning disabled children has an individualized and therapeutic focus, and is an appropriate field for single subject research. 
Rationale for single Group Design

Omission of a control group is considered generally appropriate for a multiple baseline cross-subject design (Kazdin \& Kopel, 1975). Two additional grounds are offered here as rationale. First is the specificity of learning disabilities. Each ID child has a learning profile which cannot be reliably matched to that of a peer; this makes it problematic to attribute growth or change to a targeted intervention, based on a comparison between experimental and control groups.

A second characteristic of learning disabilities, in addition to their specificity, is that assessment cannot determine the origin or exact nature of the disability within each individual. Assessment allows us to predict interventions that may be effective, but these must be tried and the results evaluated on an individualized basis. To fully evaluate the effects of the experimental treatment on each subject, this researcher compiled and analyzed qualitative information from interviews, as well as quantitative data on subjects' reading performance.

Data on subjects' previous growth in reading were extrapolated from special education assessment reports. The existence of this achievement test data, compiled at three-year intervals, was partial justification for having subjects serve as their own controls. This researcher was unable to use the test instrument referred to in the reports, since it is reserved for initial evaluations and three-year re-evaluations. Other tests were selected for pre-test and post-test procedures in this study. It is acknowledged that results from 
different instruments were compared in an effort to analyze subjecta' rate of growth.

\section{Maturational Factors}

The search for subjects was undertaken among learning disabled students in the upper elementary grades four and five and among students with comparable disabilities in the high school grades nine, ten and eleven. Fourth and fifth grade subjects were enlisted for the following three reasons:

1. If this treatment is both feasible and effective, children should experience its benefits early in their school careers.

2. Grade four reading material typically has smaller print and less white space than that presented in earlier grades; fourth grade is likely to be the first level at which children with Irlen syndrome are actually hampered by its effects (H. L. Irlen, personal communication, November 7 , 1991).

3. Children in elementary grades are generally less defensive as a result of repeated failure in school than their adolescent counterparts. This makes them more open to innovations, especially those which are observable to others.

High school subjects were sought chiefly due to the assumption that they would be motivated to use adaptive techniques because of the academic demands placed on them. By the high school grades, students are likely to have experienced a reading disability as an actual threat to survival in school. It was therefore expected that spectral 
modification techniques would be a welcome innovation for older

students who need them.

Dependent Variable Indicators

Table 4 lists the indicators of reading performance which were examined for each subject. The table matches each indicator to the mode of measurement and individual responsible for taking it.

Table 4

Indicators of Reading Performance

Activity Meagurement Evaluation

1. Rate of oral

words per minute

Researcher reading

2. Accuracy in oral reading

Percentage of words stated in correct form and sequence

3. Comprehension of silent reading

4. On-task behavior for oral and gilent reading

5. General engagement in reading

6. Completion of written work on tinted paper

7. Pre- and postperformance on standardized reading tests answered correctly

Weekly observational check sheet

Observation

Weekly observational
Percentage of questions Researcher

Mainstream class teacher

Teachers and parents

Mainstream class teacher

San Diego Quick Assessment

Experimenter: San Diego

Slosson Word Recognition slosson, Brigance

Brigance Oral Reading

Portland Achievement Levels Test
Evaluation

Department: PALT 
The first three indicators (rate, accuracy, and comprehension) were selected in part because they were dependent variables in a number of previous studies (Adler \& Atwood, 1987; Blaskey et al., 1990; Fricker, 1989; Gole et al., 1989; Gregg, 1988; Hannell et al., 1989; 0'Connor et al., 1990; Robinson \& Conway, 1990; Williams, 1990). This supported their inclusion in the current study, and allowed for direct comparison of results to previous findings. The indicators of rate, accuracy, and comprehension are also reflected in the bank of reading goals which must be incorporated into the Individualized Educational Plans (IEPs) for learning disabled students in Portland. Subjects' IEPs were expected to address these three subskills. This both supported their relevance for inclusion and made it likely that subjects would have ongoing practice with oral reading and comprehension strategies as the study progressed.

The fourth and fifth indicators were selected so that subjects' reading practice could be monitored, as well as their actual use of overlays between sessions with the experimenter. Data were applied to the research question which addresses recommendations for the use of overlays in the school setting.

The sixth indicator, written assignment completion, was included in order to test the effectiveness of tinted writing paper. The use of tinted paper is a direct application of spectral modification, as is the use of transparent overlays. It is also a simple and low-cost innovation for students who have difficulties with glare and fluorescent lighting. Although this was principally a study of reading performance, it was felt that tinted paper was a related intervention that should also be examined. 
Standardized test performance, the seventh indicator, was selected for three reasons. First, test results could be compared to findings on reading rate and accuracy as measured informally at weekly intervals. Test data from the San Diego Quick Assessment (1977), Slosson (1963), and Brigance (1976) procedures would either confirm or challenge the results of interval measurements. The second justification is that results on this indicator could be compared to results from other pre- and post-test studies. The third reason is that students with disabilities are entitled to testing adaptations which would allow for the truest measurement of their achievement. Colored overlays and tinted paper can easily be incorporated into Portland Achievement Levels Tegt (PALT) procedures. It is appropriate to incorporate such adaptations, provided that they are routinely used and of demonstrated benefit to the student. Use of spectral adaptations on the PALT for these students was contingent on the outcome relevant to the other indicators.

\section{Multiple Baseline sequencing}

Baseline data on the pre-intervention rate, accuracy, and comprehension of each subject were collected during a four-week period. Subjects began intervention at four to seven-day intervals as follows:

Subject A - Day one, week two Subject B - Day five, week two Subject C - Day three, week three Subject D - Day one, week five 
Each subject demonstrated a baseline performance trend in five measurements. Mainstream teachers were interviewed for baseline observations of time-on-task and completion of written work on white paper. Subjects were asked to log their outside reading during one week of the baseline period.

Each subject was given the San Diego Quick Assessment (1977), Slosson (1963) Word Recognition Test, and Brigance (1976) Oral Reading Inventory at the beginning of the baseline phase. This information served as pre-test data, and was also used to determine the level of difficulty of reading material that would be used for baseline trials. Results of the most recent PALT administration, spring 1992 , was also entered as pre-test data.

Introduction of the experimental phase involved the following procedural changes for each subject:

1. Transparent overlays and tinted writing paper were provided for use during timed trials, at home, and in mainstream and resource classrooms.

2. Experimental trials were scheduled weekly, instead of two to four times per week as scheduled during baseline.

3. Experimental trials included a structured experimenter-subject interview.

The plan for collection and presentation of data on six indicators of reading performance is summarized by Table 5 . These specifications for procedures, scheduling and data management were adhered to as the study progressed. 
Table 5

Performance Data Management

\begin{tabular}{|c|c|c|c|}
\hline Measurement & $\begin{array}{l}\text { Procedures and } \\
\text { Instruments }\end{array}$ & Collection Intervals & Presentation \\
\hline Rate of oral reading & $\begin{array}{l}\text { Two minute timed reading } \\
\text { for words per minute }\end{array}$ & $\begin{array}{l}\text { Baseline: two to } \\
\text { four per week } \\
\text { Treatment: once } \\
\text { weekly }\end{array}$ & $\begin{array}{l}\text { Iine graph to show extent } \\
\text { and direction of change }\end{array}$ \\
\hline $\begin{array}{l}\text { Accuracy of oral } \\
\text { reading }\end{array}$ & $\begin{array}{l}\text { Word-for-word error } \\
\text { notation for percentage } \\
\text { of words stated } \\
\text { correctly and in } \\
\text { sequence }\end{array}$ & $\begin{array}{l}\text { Baseline: two to } \\
\text { four per week } \\
\text { Treatment: once } \\
\text { weekly }\end{array}$ & $\begin{array}{l}\text { Line graph to show extent } \\
\text { and direction of change }\end{array}$ \\
\hline $\begin{array}{l}\text { Degree of reading } \\
\text { comprehension }\end{array}$ & $\begin{array}{l}\text { Silent reading of } \\
\text { programmed material, } \\
\text { followed by oral } \\
\text { response questions, for } \\
\text { percentage of correct } \\
\text { responses }\end{array}$ & $\begin{array}{l}\text { Baseline: two to } \\
\text { four per week } \\
\text { Treatment: once } \\
\text { weekly }\end{array}$ & $\begin{array}{l}\text { Line graph to show extent } \\
\text { and direction of change }\end{array}$ \\
\hline $\begin{array}{l}\text { (a) On-task behavior } \\
\text { for } \\
\text { oral and silent } \\
\text { reading; } \\
\text { (b) Utilization of } \\
\text { overlays in } \\
\text { classroom; } \\
\text { (c) Extent of written } \\
\text { work completed on } \\
\text { tinted paper }\end{array}$ & $\begin{array}{l}\text { Check-sheet for } \\
\text { recording teacher } \\
\text { judgment on these three } \\
\text { factors }\end{array}$ & $\begin{array}{l}\text { Once during baseline } \\
\text { phase; } \\
\text { Weekly during } \\
\text { experimental phase }\end{array}$ & $\begin{array}{l}\text { Narrative summary of } \\
\text { teacher observations } \\
\text { recorded on check-sheet, } \\
\text { plus information gained } \\
\text { from experimenter- teacher } \\
\text { contact }\end{array}$ \\
\hline $\begin{array}{l}\text { General engagement in } \\
\text { reading }\end{array}$ & $\begin{array}{l}\text { Ss record description of } \\
\text { material and number of } \\
\text { pages read outside of } \\
\text { school hours }\end{array}$ & $\begin{array}{l}\text { Once during baseline } \\
\text { phase; } \\
\text { Weekly during } \\
\text { experimental phase }\end{array}$ & $\begin{array}{l}\text { Narrative summary based on } \\
\text { subject self-report and } \\
\text { experimenter-parent contact }\end{array}$ \\
\hline
\end{tabular}


Table 5

Performance Data Management (continued)

\begin{tabular}{|l|l|l|l|}
\hline \multicolumn{1}{|c|}{ Measurement } & \multicolumn{1}{|c|}{$\begin{array}{c}\text { Procedures and } \\
\text { Instruments }\end{array}$} & \multicolumn{1}{c|}{ Collection Intervals } & Presentation \\
\hline $\begin{array}{l}\text { Performance on } \\
\text { standardized test } \\
\text { with and without } \\
\text { overlay }\end{array}$ & $\begin{array}{l}\text { San Diego Quick } \\
\text { Assessment; Slosson Word } \\
\text { Recognition Test; Brigance } \\
\text { Oral Reading Inventory }\end{array}$ & $\begin{array}{l}\text { Pre-test: before } \\
\text { baseline; Post-test: } \\
\text { experimental week }\end{array}$ & $\begin{array}{l}\text { Tabular comparison of } \\
\text { pre- and post-test } \\
\text { scores }\end{array}$ \\
& $\begin{array}{l}\text { Portland Achievement } \\
\text { Levels Test in Reading }\end{array}$ & $\begin{array}{l}\text { PALT: District wide } \\
\text { spring administration }\end{array}$ & \\
\hline
\end{tabular}


Procedural Guidelines

This study incorporated five guidelines established for the

multiple baseline cross-subject design (Tawney \& Gast, 1984):

1. The outcome objective was established prior to initiating the study: subjects would demonstrate measurable and observable trends in reading performance before and during the implementation of spectral modification techniques.

2. Intervention was introduced only when all subjects exhibited stability in level and trend under baseline conditions.

3. A minimum of three subjects were identified.

4. Subjects were functionally independent. (They were in different schools and/or classroom environments.)

5. Subjects were similar in factors pertinent to the study. Utilization of this design format precluded returning to baseline conditions in order to establish experimental control, a requirement of the A-B-A-B design format (Tawney \& Gast, 1984). Re-establishment of baseline performance trends was unlikely due to the nature of the dependent variable (reading performance). Reading is a multi-faceted and cumulative skill that changes due to a variety of factors. It was not expected that spectral modification would be the sole contributing factor to the subjects' reading performance. The objective was to determine whether or not performance was significantly altered as a result of the intervention.

\section{Additional Control Factors}

This section concludes with a discusgion of control factorg which could affect the internal validity of the research plan. A major 
control was the replication of measurement, which should have counteracted environmental and measurement variables that could confound a single measurement. Measuring a variety of performance indicators could also control for spontaneous environmental or intra-subject factorg that would interact with one or more of the indicators. Information on these spontaneous factors, when provided by subjects or teachers, was entered as qualitative data. Measuring and observing at regular intervals also checked regression, and desensitized subjects to measurement effects.

A major control problem inherent in the time series format involves subjects' personal history during the baseline and experimental time periods (Ary et al., 1985). Events such as illness or family crisis could significantly impact results, or even lead to gubject mortality. It was hoped that the inclusion of four subjects would compensate for unforeseen personal issues. Selecting a small group of subjects allowed for some controls which could not be applied to a larger sample. They could be carefully screened for motivational, behavioral, and environmental factors that would make them unwilling to adapt to the treatment program over time. The willingness of teachers and parents to collaborate with the study was also assessed. A small sample made it possible for the experimenter to perform all or most measurements, which controlled for confounding measurement variables. The single subject design did preclude the generalization of results to a larger population. Irlen Syndrome was approached as a clinical problem for which individualized diagnosis and treatment was 
appropriate. However, if these subjects derived benefit from the intervention, it could be generalized that others with Irlen syndrome, in these school settings, would also benefit.

\section{Sample Selection Procedures}

Special education in the Portland District is organized into three areas for provision of services. Schools and resource teachers were recruited from Area II, to take advantage of these factors:

1. Support of the Area Coordinator was obtained for the project. 2. The researcher had worked as a special educator in this area, and was geographically and personally familiar with it.

\section{Criteria for selecting schools}

The schools selected for subject recruitment had program structures that were typical of the Portland District. The effort to select typical schools was guided by the second research question: "What recommendations for the implementation and continued use of spectral modification techniques in the public school setting can be derived from this study?" Results relevant to this question could be generalized to schools having program structures similar to those from which subjects were selected. The schools from which subjects were selected shared the following characteristics:

1. They had general education programs, geared to serve an attendance area rather than a special-interest or special-needs population.

2. Mainstream class sizes were typical for the District. 
3. Special education students receiving itinerant service spent the majority of their time in regular mainstream classrooms; they were served by special education on a pull-out basis and/or within the mainstream.

Procedure for selecting schools and Teacherg

The proposal for this study was shared with the special Education Coordinator for Area II. She recommended participating teachers of special education resource centers who served schools having the characteristics listed on the previous page, and who had demonstrated two attributes:

1. Effectiveness as a collaborator who could work with the researcher, and with mainstream teachers involved in the study;

2. Willingness to try new techniques with students, and to allow another professional (i.e., this researcher) to be involved in the trial.

The process of considering schools and teachers occurred simultaneously, and resulted in an initial list of eight schools and nine teachers; two of the teachers served the same high school. Included were six of the area's elementary schools and two of its three high schools. The sites were divided equally between the two geographical sections of Area II (North and Southwest Portland). Administrative support was enlisted from the Director of Instruction, and from building principals at the selected sites. This was accomplished by letters, followed by telephone contact, to the 
principals. The researcher made personal contact with the Area II Director of Instruction, and with each principal during an early site visit. Principals were also informed, in writing, of the outcome of the subject selection process.

The initial contact with each teacher was by telephone. Given an introduction to the researcher and brief description of the project, teachers could agree or decline to participate. The first procedure for participating teachers was a structured telephone interview which covered the following factors:

1. Size and structure of the special education (e.g. Resource Center) program for students identified as learning disabled in reading.

2. Mainstreaming activities engaged in by the resource teacher.

3. Resource teacher's perception of mainstream teachers' motivation to collaborate on behalf of special needs students.

4. Instructional methods for reading used by the resource teacher during direct contact with students.

5. Factors foreseen which could cause change in their program structure or instructional methods during the current school year.

6. The teacher's level of interest in the topic of this study.

7. The teacher's willingness to collaboratively try an experimental treatment with a small number of students.

The primary intent of this interview was to determine commonalities and differences in the special education services extended to potential subjects. The effects of these services, and of 
mainstream instruction, were expected to interact with the experimental intervention.

An informational packet was sent to the participating resource teachers during the fifth week of the school year. This included a list of 11 characteristics (see Appendix A), recommended for students who would be considered as subjects. The packet's introductory letter advised teachers to use this list as a guide, and identify three students who best demonstrated the recommended characteristics. The packet also provided teachers with a definition and brief description of Irlen Syndrome, plus an orientation to the symptoms. Five copies of Irlen's symptom observation form were included, with instructions to complete one for each student recommended. Also enclosed was a small sample of literature on the Irlen method, and on the theoretical base that supports it. A closing letter advised teachers that their only direct involvement would be to recommend students for pre-screening. Beyond that, teacher time commitment was expected to be minimal.

\section{Subject Characteristics}

The subjects were carefully selected in regard to attributes which can affect reading performance. The four attributes considered as basic requirements are listed in Table 6 , which pairs each characteristic with the rationale for making it a selection factor. The fourth attribute is stated "manifests scotopic sensitivity Syndrome to a significant extent" in recognition of the possibility that four suitable subjects having high-range Irlen syndrome might not 
be located. It would then be necessary to select a subject from the moderate-range prospects.

Table 6

Intersubject Attributes

\begin{tabular}{ll} 
Attribute & Primary Rationale Factor \\
\hline $\begin{array}{l}\text { Grade placement in } \\
4-5 \text { (upper elementary) } \\
\text { or 9-11 (high school) }\end{array}$ & $\begin{array}{l}\text { Material at fourth grade level present } \\
\text { type size and text format likely to } \\
\text { elicit symptoms of Irlen syndrome. }\end{array}$ \\
\hline & \\
Identified as learning & $\begin{array}{l}\text { Implementation of Individualized } \\
\text { disabled (LD) in } \\
\text { reading }\end{array}$ \\
& $\begin{array}{l}\text { established the need for interventions } \\
\text { which were specialized and } \\
\text { individualized. }\end{array}$
\end{tabular}

Placed in mainstream clasgroom with itinerant support from special Subjects had equal opportunity to Education reading instruction that is appropriate to their needs.

Manifests Scotopic Sensitivity/Irlen syndrome to a significant extent
This is the critical attribute the experimental intervention was designed to address.

Table 7 lists the intrasubject attributes, on which the four were expected to vary. Information relevant to each characteristic was obtained from student files, and through consultation with parents and teachers. The attributes on Table 7 were identified as factors which could compromise a subject's response to the intervention. 
Table 7

Intrasubject Attributes

\begin{tabular}{ll} 
Attribute & Primary Rationale Factor \\
\hline & \\
Visual functioning & Significant and uncorrected vision \\
within normal limits. & problems could cause false manifestation \\
& of the syndrome and/or confound effects \\
& of treatment.
\end{tabular}

Reading progress not significantly impacted by:

a. Behavioral characteristics

b. Emotional distress

c. Miscellaneous health factors (i.e., drug therapy, food allergies)
Any of these factors could influence the results, making it difficult to assess the effects of the experimental intervention.

NOTE: Irlen's screener training program acknowledged these as confounding influences.
Learning potential in the average range (full scale IQ 85 or above).
Subjects must be capable of demonstrating progresg in a cognitive skill (reading comprehension) and in the mainstream classroom.
History of reading achievement indicates limited growth.
Limited progress may involve a perceptually-based problem that remedial instruction has not addressed directly.
Regular school attendance was demonstrated.
Irregular attendance itself impedes progress, and would disrupt the schedule of data collection.
Records indicated limited movement between schools.
Frequent moves could be partially responsible for academic delays, and could also indicate environmental instability.
Mainstream teachers, resource teachers, and parents support inclusion of the student as a subject.
Voluntary consent of parents and participation of teachers, was required in order to initiate and conduct the study. 
Pre-Screening Procedures

An initial conference between the researcher and each resource teacher was scheduled. The major objective was for teachers to recommend specific students, but it allowed for questioning and discussion of teacher concerns. It was determined whether or not each recommended student demonstrated sufficient attributes to be considered as a subject. The researcher agreed to screen two to four students recommended by each teacher, provided that file reviews did not produce disqualifying information. Teachers were urged to complete symptom observation forms if they had not done so by the time of this conference.

The ensuing process was a file review of each recommended student. As an Area II special education employee (on sabbatical), the researcher had legal access to the cumulative files. The protocol for file access in place at each school was followed. One principal requested that written parent permission be obtained for the file review. For that building, permission for both file review and screening was combined into a single process. In general, parent contact was withheld until after the file review, when the decision to actually make contact with the student was finalized.

The file review form (see Appendix A) was structured to include information on vision screening and/or treatment, special education assessment results in reading, Portland Achievement Levels Test results in reading, general learning profile, school enrollment history, and behavioral and environmental issues that had impacted school progress significantly. Special education assessment reports 
contained most of the pertinent information on reading achievement and learning profile.

Parent Involvement

Teachers had the option of making the first informational contact with parents. This was in recognition of the established teacher-parent relationship. The researcher made a follow-up parent contact in order to explain Irlen syndrome, the treatment methodology, and the screening procedures. Verbal parent consent was followed by an initial researcher-student conference, at which students had the opportunity to sign a statement of consent to be screened. Those who consented were given a parent permission form (see Appendix B). Most parents of elementary students were contacted prior to student-researcher contact, and had been advised of the permission form. The researcher did not contact high school parents until after the respective students had agreed to be screened.

Parents were given IDPIS results by telephone as soon as possible after the screening. They were advised that overlays and written reports would be distributed to resource teachers after the four subjects had been selected. It was important to ensure all participants that each prospective subject who screened positive for Irlen syndrome would be given an overlay. Prospects who demonstrated low-range syndrome were given overlays immediately after screening, and were not considered as subjects.

An informed consent conference was scheduled for each student gelected as a subject. This was attended by one parent (although open 
to both if applicable), the student, the resource teacher, and the researcher. Fourth and fifth grade subjects had specially prepared informed consent documents written at their level (see Appendix B). The content paralleled that of the adult consent document (see Appendix B), and contained the following:

1. Introduction of the principal investigator.

2. Description of the project.

3. Potential risk to subjects.

4. Assurance of confidentiality.

5. Potential benefit to subjects.

6. Subject and parent rights.

The informed consent conference focused on these points, and allowed subjects and parents to pose questions and discuss concerns. All participants signed the informed consent document, and were given copies of the informational pages.

\section{Screening Procedures}

Twenty-aix potential subjects underwent complete administrations of the Irlen Differential Perceptual Interview Survey. The procedure involved 45 to 60 minutes for each student and is described in the validation discussion on pages 20 to 23 of Chapter II. Most students underwent the entire procedure in one sitting. Class schedule constraints were an issue for three of the high school students. They were given the interview (Section $I$ ) in one session, with tasks and overlay trial in a second session. Sections II (perceptual tasks) and III (overlay trials) were always given in the same session, due to the 
delayed onset characteristic of the syndrome. For the overlay trial to be accurate, the visual system had to be fatigued and functioning symptomatically.

IDPIS results for each student were synthesized into a written report format, a sample of which is included in Appendix c. The report was intended to provide the following information to students, parents, resource and mainstream teachers.

1. Definition of the syndrome and extent to which the student demonstrated it (or did not demonstrate).

2. A description of reading difficulties and strain/fatigue experienced by the student.

3. A description of the actual distortions of print and/or background as reported by the student during the perceptual task experience.

4. The apparent effects of the preferred overlay, as described by the student and observed by the researcher/examiner.

5. The color and density of overlay recommended for the student.

6. Strategies and environmental modifications that Irlen has recommended for light sensitive individuals.

As previously stated, reports and overlays for students who demonstrated a moderate to high degree of the syndrome were withheld until subjects could be identified. The purpose was to prevent early intervention on behalf of students who would become subjects. 
Final Subject Selection

Selection was based on three factors, listed below in descending priority.

1. Results indicated by the IDPIS in terms of:

a. Severity of Irlen Syndrome as indicated by the entire IDPIS procedure.

b. Immediate improvement in oral reading--as reported by the student and observed by the examiner--that occurred during trial with the colored overlay.

2. Degree of adherence to subject attribute variables (Tables 6 and 7).

3. The observed ability and inclination of resource teachers, mainstream teachers, and parents to facilitate the study. One parent of each prospective subject was interviewed by telephone prior to the informed consent conference. The purpose was to obtain information on factors of physical and mental health which could influence the child's current level of functioning. Factors of interest were previous vision care; drug, diet, psychological, or sensory motor therapy; and family history of learning problems and light sensitivity.

Enrollment of each subject was completed at the informed consent conference. Final subject selection and enrollment occurred between the fourth week of November and third week of December. 


\section{Vision Examination}

Pacific University's Family Vision Clinic provided the researcher with up to six comprehensive vision evaluations. These were offered free of charge to subjects of this study, and were completed during the month of January.

Although it would have been most ideal to make a vision examination part of the screening process for all candidates, it was not feasible to provide consistently executed professional evaluations for 26 students. Files were carefully reviewed for results of routine vision screening and for evidence of optometric examination and/or treatment.

subjects were professionally evaluated for three conditions which have been cited as correlating with Irlen syndrome characteristics (Blaskey et al., 1990). These are listed and defined as:

1. Accommodative anomalies: difficulty with focusing or shifting focus.

2. Binocular dysfunction: failure of eyes to team, resulting in nearpoint and/or farpoint double vision.

3. Ocular motor dysfunction: faulty coordination of eye muscles. These conditions are not routinely investigated in vision evaluations, and could stand undetected in students with reading difficulties. It was decided not to disqualify a subject should one or more of these conditions be present, but to consider the case wholistically. Vision therapy, if recommended, could be incorporated as a related intervention. 
Pre-Testing Procedures

By determining each subject's reading level prior to the experimental intervention, pre-testing served two purposes. First, and of primary importance, it assisted the researcher to select material at the appropriate level of difficulty. Material selection was based on pre-test results, historical test data, and on informal assessments of resource teachers. A second function of the pre-test procedure was to allow for pre-test/post-tegt comparison.

The following instruments were used to determine a grade level equivalent for each subject:

1. San Diego Quick Assessment (1977)

2. Slosson (1963) Oral Reading Test

3. Brigaince (1976) Diagnostic Inventory: Oral Reading Subtest The San Diego Quick Assessment (1977) and Slosson (1963) require subjects to read word lists of increasing difficulty, until a ceiling level of errors is reached. Two instruments were employed in order to circumvent the bias of one test. It was hoped that averaging the grade equivalent scores of two tests would provide a truer measure of word recognition skill.

The Brigance (1976) Oral Reading subtest involves passage reading to assess rate, accuracy and literal comprehension. The plan to assess these same indicators throughout the study was considered in selecting the Brigance as a pre-test tool. The Brigance does not assign a grade equivalent in terms of year and month, as do the san Diego and slosson tests. One Brigance passage represents an entire grade level range. 
An effort was made to select pre-test procedures that would have minimal stress impact on the subjects. These three could be given in a 30 minute time period. Administration of the Brigance (1976) subtest involved timed oral reading and oral response to questions based on the passage read. It was similar to actual data collection procedures, and was used to orient subjects to them.

An effort was also made to determine that each subject recognized all upper and lower case letters. Subjects responded orally to each symbol on a sheet of randomly distributed letters.

The most recent Portland Achievement Levels Test (PALT) administration was in April 1992. Scores for each subject could be loosely interpreted as pre-test data, and were compared to spring 1993 results. The post-test PALT was given near the latter end of the experimental phase. Since subjects had been using overlays for reading instruction, it was appropriate to give them the option of using them for the PALT.

Interval Measurement Procedures

Information on the sequencing and scheduling of data collection, for baseline and experimental phases, was incorporated into the discussion of experimental design (first section of this chapter). This section specifies the procedures employed during measurement sessions with the subjects. 
Selection of Reading Material

A reading grade level equivalent for each subject was determined by pre-testing, combined with analysis of other achievement information The researcher also queried each subject on personal interests, then attempted to locate material that would be moderately motivating and at the instructional level of each subject. Material was borrowed from school media centers, resource teachers, and the District's Teacher support Center.

The Fry Readability Graph (Fry, Fountoukidis, \& Polk, 1985) was used to determine the reading grade level of all material, unless readability was specified by the publisher. Although level of difficulty was of primary importance in assigning material, the researcher did monitor subjects' level of interest in the content. Expressed disinterest resulted in a change of content, with the level being held constant.

Comprehension passages were selected from the New Practice Reader (Anderson, stone \& Burton, 1978). This programmed series offered books at various grade levels, which would make it suitable for subjects having varied levels of skill. It also offered a consistent format of short, non-fiction passages with short-answer questions that could be administered orally. This minimized task variance from session to session. Answering five questions on each passage of approximately 100 words required the use of three strategies: recall of facts; (b) content verification, or stating whether information was included or not included; and (c) identifying the main idea when given four alternate choices. Reading instruction in the 
fourth and fifth grades involves application of these comprehension skills.

The New Practice Reader (Anderson et al., 1978) begins at the mid-second grade level. In anticipation of the possibility that a subject would be selected who read below this level, the researcher selected several passages from the Merrill Linguistic Reader Lift off (Wilson \& Rudolph, 1986). This test was written at the first grade level. Questions were modeled after those included in New Practice Reader.

\section{Subject orientation}

Two preliminary sessions with each subject involved pre-testing, and introduction to the procedures and expectations of the study. The letter recognition probe, San Diego Quick Assessment (1977), and slosson (1963) were given during the first session. The researcher encouraged question/answer interaction, and stressed the following four points to each subject:

1. The researcher's role was to observe the student read, not to teach skills.

2. The researcher would not be evaluating students for grades, rewards, or other outcomes to which they may have been accustomed.

3. The researcher would not provide students with evaluative feedback during the study. 
4. Students were not at fault if their reading skills did not improve during the experiment. They were asked to think of the technique as being tested, not them.

Each subject underwent an overlay retrial as an extension of one of the baseline sessions. The Dutch language page of the Irlen (1991) Screening Manual was used as a print sample. Subjects practiced letter reading with variations of overlay tint and density. The purpose was to confirm or modify their overlay prescription.

The Brigance (1976) Oral Reading subtest was used to simulate actual data collection during the second session. The researcher invited additional question/answer interaction and reviewed the four points.

\section{Trial Environment}

The lighting conditions and occupancy of the working environment were held constant for all sessions between subjects and the researcher. Both were seated at a table or desk at which materials could be comfortably arranged, with researcher facing the subject. Each trial room provided a window which was four to six feet from the working table. Blinds were kept open, and overhead fluorescent lights were on. The rooms provided for subject trials were a vacant multiuse classroom for subject A, a small workroom attached to the resource classroom for subjects $B$ and $C$, and a classroom used for a half-day kindergarten program for subject $D$.

All trials were conducted as private sessions between researcher and subject. There were no other occupants in the room for subjects 
A, B and C. A teaching assistant and one student occupied an opposite corner of the kindergarten classroom. The room was large enough to prevent this from interfering with trial procedures.

\section{Trial Process and sequencing}

Each measurement of both rate and accuracy was based on an oral reading trial of a pre-selected passage. The trial was taped, in order to minimize measurement error and interference the researcher might cause by marking during a trial (Griffen \& Jongsma, 1980). The researcher monitored subject reaction to the taping.

Rate was measured as words per minute, extrapolated from a two-minute timed reading. subjects were allowed to complete the paragraph they were reading at the two-minute point; exact timing could be confirmed by the tape. The subsequent timed trial would begin at the point in the text where the previous one ended unless the content or level of the material was changed.

Accuracy was measured as the percentage of words stated in correct form and sequence during the two-minute trial. Each word omission and substitution was counted as an error. Self-corrections were not marked as errors, but did affect rate. Errors were noted when two or more words were repeated, in that mistracking and repetition is symptomatic of Irlen syndrome.

Although major changes in reading level were not expected in a nine-week period, accuracy was used as the criterion for advancement to more difficult material. The Brigance (1976) Diagnostic Inventory establishes five errors in 100 words (958) as a mastery level. Three 
consecutive trials at 958 accuracy was adopted as the criteria for advancement in this study. A subject who gave five correct responses (1008) on three consecutive comprehension trials would also be advanced to the next level of New Practice Reader (Anderson et al., 1978).

Assessment specialists seem to vary in their recommendations on the length of an oral. reading trial. Brigance (1976) selections are 100 words, whereas scales (1980) recommended a passage of over 500 words that would elicit 25 miscues. Griffen and Jongsma (1980) withheld that length is secondary to the criteria that the passage be ". . completely meaningful in itself" (p. 2). This researcher selected a two-minute trial, on grounds that it is sufficient for examining a perceptual condition that impairs word recognition and fluency. If the purpose was to conduct an analysis of miscues or comprehension strategies, then a longer trial would have been appropriate.

The passages and related questions for the comprehension trials were taken directly from New Practice Reader (Anderson et al., 1978). Subjects were directed to read the passage silently, once through and at a comfortable rate. Silent reading was selected so that subjects would not be involved with performance concerns, but could apply all capacity to the meaning. The comprehension trial was not timed. Comprehension questions did not immediately follow the silent reading, but were given after the subject had completed the taped reading of different material. This adhered to the recommendation of a distraction time before retelling or questioning (Griffen \& Jorgsma, 
1980). The purpose of a distraction time is to insure that the reader has connected meaning to print, and is not reciting from short-term memory.

The measurement session for rate, accuracy, and comprehension had four segments as indicated here:

Step one: Subject "warmed up" by reading a passage orally, for a period of three minutes, without taping or any effort at assessment. This was to orient subjects to task, and to allow some degree of strain and fatigue to set in. Step two: Subject read a passage of approximately 100 words silently, untimed.

Step three: Subject read a third passage for the two-minute timed trial, which was taped.

Step four: Subject's attention was redirected to the passage read silently. He or she answered five comprehension questions based on that passage. Questions were read aloud to subjects, with researcher transcribing answers.

Since different material was used for the first three steps, the researcher oriented subjects by making a brief statement about the content of each passage. For the comprehension passage, this was merely a statement of the title. An effort was made to keep the steps proceeding in direct sequence, and to minimize distraction time between passages. Breaks could potentially relieve any Irlen syndrome symptoms that developed during actual reading time.

The procedures for measuring rate, accuracy, and comprehension remained constant through baseline and experimental phases. As stated 
previously, two changes were implemented for the experimental phase: (a) subjects used overlays for oral and silent reading; and (b) a subject-researcher interview preceded the reading trial.

\section{Text Format}

Material was presented to subjects in a straight text format, without illustrations. Text from books which utilized a primary-level format of fewer than 40 characters per line, illustrations around and between lines, and/or tinted paper was word processed for use in the reading trials.

The processed material was double-spaced, had 40 characters per line, and was enlarged 1218. It then presented a text density and type size (10 point) similar to New Practice Reader (Anderson et al., 1978) and other material pregenting a straight-text format and written at the second to fourth grade reading level.

One example of straight-text, non-illustrated, low-grade level material located by this researcher is the Merrill Linquistic Reader (Wilson \& Rudolph, 1986). Two- and three-page selections from this serieg were used by two of the subjects as warm-up material. An effort was made to provide higher interest material for timed trials. The justification for using Merrill as warm-up (and different material for the timed trial) was to limit the commitment to material preparation. This was especially important during the baseline phase, when two or more weekly measurements on each subject were taken. 
Interview and Observational Procedures

Qualitative data on the progress of each subject was generated through interview and observation processes. These processes were conducted regularly throughout the intervention phase, and according to protocol.

\section{Weekly Subject Interview}

This was conducted using the protocol form in Appendix D. The following points were included:

1. Extent to which the subject used the overlay in the mainstream classroom, in the resource room, and at home.

2. The subject's reasons for not using the overlays.

3. The subject's perception of the responses and reactions of others (teachers, parents, peers) to his or her use of the overlays.

4. Subjective and on-going assessment of the effect of the overlay on reading performance.

5. On-going critique of the overlays in terms of what subjects liked best and least about them.

6. Subjective and on-going assessment of the tinted paper as an aid to writing.

7. The subject's identification of, and reaction to, continuing and new reading activities. They were asked to state which activities, in the mainstream and resource classrooms, were most helpful. 
A complete subject-experimenter interview required 15 to 25

minutes, and taxed the attention span of subjects. Complete interviews were given at the beginning and end of the intervention

phase. Questions were otherwise alternated between sessions. Related observations and information, supplied by teachers and subjects, were entered weekly in an experimenter's log.

\section{Parent and Teacher Interviews}

An initial and concluding interview was conducted with parents, mainstream teachers, and resource teachers. The initial parent interview, conducted by telephone, was designed to elicit information on health and vision factors which could influence the interpretation of results. The content was adapted from the Irlen Institute's client intake form. The question/response form used for this procedure is attached in Appendix D.

A concluding parent telephone interview occurred near the end of the data collection process, and covered three points:

1. A review of results as indicated by the data on rate, accuracy, and comprehension.

2. Verbal parent permission for use of overlays and tinted answer sheets for the spring PALT administration.

3. Parent observation of subject's use of the overlay at home, plus observations of any changes in general engagement in reading.

Responses on points two and three were recorded in the researcher's $\log$. 
Early in the baseline phase, resource and mainstream teachers were interviewed for specific information on subjects' reading instruction in both settings. The question/response form for this procedure is included in Appendix D. This session was used to orient mainstream teachers to the "Teacher Progress Check" form (Appendix D), and to collaboratively develop a schedule for on-going data collection.

The researcher met separately with resource and mainstream teachers at the close of the experimental phase. Both were asked to review, verify, and expand upon observations that had been recorded weekly on the progress check. Included in the weekly progress check were the following points:

1. Extent of overlay use for both oral and oilent reading in the classroom.

2. Approximate percentage of time the subject appeared to be on task during silent reading activities.

3. Observable changes in rate and accuracy of oral reading as subject used the overlay.

4. Extent of the subject's use of tinted paper for completing written assignments.

5. Observable changes in the quality of written work as the subject practiced with tinted paper.

On-Going Teacher Observation

The progress check sheet was designed to have minimal impact on teacher time, while providing an on-going structure for the 
observation of subjects' overlay use and reading behavior in the mainstream classrooms. Teachers were asked to exchange a completed check sheet for a blank one on a weekly basis. The researcher viewed the check sheet as too cursory for resource teachers, who were in a position to observe subjects in a small group setting. The concluding teacher interview was the primary procedure by which resource teachers shared their observations. Comments of resource teachers made throughout the study were also recorded in the researcher's log.

Miscellaneous Support Procedures

\section{Provision of Materials}

Subjects were initially provided with three overlays, or overlay combination sets, to be used in the three settings of mainstream classroom, resource room and home. They were supplied with new overlays as needed, in cases of loss or damage. Tinted writing paper was produced from blackline masters copied onto blue, green, grey, and buff stock. Each subject was given separate paper supplies for resource and mainstream classrooms.

\section{Subject Reading Log}

Subjects were given a form on which they were instructed to record their outside reading. This was defined as any material read at home, either voluntarily or as assigned practice. The log form is included in Appendix $D$. 
Time Parameters

This study was initiated, conducted and concluded in the 1992-1993 school year. It proceeded within the time frame that is presented in Table 8.

Table 8

Timeline

\begin{tabular}{ll} 
Time Period & Study Emphasis \\
\hline September 1992 & $\begin{array}{l}\text { Enlistment of building } \\
\text { administrative support and } \\
\text { teacher participation }\end{array}$
\end{tabular}

October and November 1992

Pre-screening and screening procedures

December 1992

Subject selection and enrollment

January 1993

Adjunct screening activities, comprehensive vision examinations, pre-testing

January 28 to
February 18,1993

Baseline data collection

February 8 to

April 26, 1993

Intervention data collection

and post-testing

May 1993

Post-intervention data

collection 
CHAPTER IV

RESULTS

Pre-Screening Outcome

One itinerant (e.g. resource room) teacher was assigned to each of the six elementary schools that were recommended by the special Education Coordinator of Area II. All six teachers agreed to participate in the study, and followed through on recommending from two to four students for screening. Four teachers expressed a high level of interest in scotopic sensitivity/Irlen syndrome and its treatment; two expressed moderate interest along with a willingness to participate in the investigation.

Administrative approval from the principal in each building was also enlisted. Five principals agreed to the pre-screening and screening procedures as originally proposed. One requested that written parent permission be obtained for the file review as well as for actual screening. This was accomplished for the four students who were screened at that site.

Itinerant Program Characteristics:

Elementary

Teachers were asked to rate their programs on a one-to-five scale as "pull-out" (identified students served within the resource room) or "push-in" (special educators co-teach or assist students in the 
mainstream classroom). Four teachers claimed a three rating

indicating that their programs were in transition from the traditional "pull-out" to the more contemporary inclusion model. The remaining two teachers claimed a one (entirely "pull-out") and two rating. The implications of this, for the study, was that subjects could not be guaranteed to receive reading instruction within a resource room setting.

Considerable uniformity was found in the instructional methods employed by these six teachers. Five used multisensory methodology to teach structural phonics directly. Three teachers also offered whole language experienceg in order to support their students in the mainstream curriculum, which was whole language oriented. One teacher emphasized whole language techniques in the resource room, with structural phonics as a coordinate. This indicated that any specialized instruction received by subjects at different sites would be similar.

Similarity in the mainstreaming activities engaged in by these teachers was also indicated. Four cited teacher consultation and assisting within classrooms as the two activities upon which the most time was expended. The other two reported consultation and classroom observation as their major mainstreaming efforts. This finding indicated that special education teachers would be aware of subjects' overall behavior and progress as the study progressed. If necessary, they could also assist the research effort in the mainstream classroom. 


\section{Elementary Student Characteristics}

Seventeen of the eighteen students recommended for screening were in grades four and five. One third grader was accepted for screening, chiefly because the teacher could recommend only one suitable candidate in the upper grades. The three recommended subject attributes (presented in Tables 6 and 7) demonstrated by all eighteen were: (a) they received itinerant special education services for reading; (b) previous assessment indicated limited growth in reading; and (c) teachers, parents and the students themselves supported inclusion in the study. Each teacher who agreed to assist with the study was guaranteed a screening for two to four students. Because teachers were generally unable to recommend students who demonstrated all the recommended attributes, some deviation was allowed. Information to support students" "attribute status" was obtained from file reviews and resource teacher interviews. Table 9 presents the frequency of deviation, for both elementary and high school students, from the recommended subject attributes.

\section{High School Participation}

One high school in each geographical section (Southwest and North Portland) of Area II was originally recommended by the area supervisor. Administrative support for the study as proposed was obtained from each principal, and also from vice principals in charge of special programs. Although three itinerant special education teachers were invited to participate, two followed through on recommending students. One participating teacher was at each site. 
Table 9

Attribute Deviations Demonstrated by Prospective Subjects

\begin{tabular}{|c|c|c|c|}
\hline Attribute & $\begin{array}{l}\text { Knowr } \\
\text { Elementary }\end{array}$ & $\begin{array}{l}\text { Deviations } \\
\text { High School }\end{array}$ & $\mathbf{T}$ \\
\hline $\begin{array}{l}\text { Grade Placement } \\
(4-5)(9-11)\end{array}$ & 1 & 0 & 1 \\
\hline LD in reading & 3 & 2 & 5 \\
\hline $\begin{array}{l}\text { Qualified for itinerant } \\
\text { gpecial education }\end{array}$ & 0 & 0 & 0 \\
\hline $\begin{array}{l}\text { Moderate or high } \\
\text { Irlen Syndrome }\end{array}$ & 3 & 3 & 6 \\
\hline Normal visual function & 3 & 3 & 7 \\
\hline $\begin{array}{l}\text { No gignificant behavioral, } \\
\text { emotional or health factors }\end{array}$ & 3 & 4 & 7 \\
\hline $\begin{array}{l}\text { Average range IQ } \\
\text { (full scale 85-110) }\end{array}$ & 2 & 0 & 2 \\
\hline $\begin{array}{l}\text { History of limited gains in } \\
\text { reading }\end{array}$ & 0 & 0 & 0 \\
\hline $\begin{array}{l}\text { Regular attendance } \\
(90-100 \%)\end{array}$ & 2 & 2 & 4 \\
\hline $\begin{array}{l}\text { Limited movement between } \\
\text { schools }\end{array}$ & 1 & 1 & 2 \\
\hline $\begin{array}{l}\text { Teachers, parents, students } \\
\text { support inclusion in study }\end{array}$ & 0 & 1 & 1 \\
\hline Number screened & 18 & \multicolumn{2}{|l|}{8} \\
\hline Total Deviations & 18 & \multicolumn{2}{|l|}{15} \\
\hline
\end{tabular}

Only five students who were recommended for screening at these two sites consented to be given the IDPIS. The researcher, therefore, approached the resource teacher at a third high school, also in Area I, about participating in the study. The teacher at the third site expressed a high level of interest, and administrative support was obtained. Three students at this site consented to the IDPIS 
procedure, which brought the total number of potential high school subjects to eight.

Itinerant Program Characteristics: High School

High school teachers were also asked to rate their service delivery on a five-point scaie, with one being total "pull-out" and five being total inclusion. At one of the original sites, rated as three, the teacher co-taught subject matter for approximately half of the day and had students scheduled into the resource room for the balance. The other originally included site was rated as four, and was moving toward a total inclusion model. At the third site, rated as one, students were scheduled into the resource room throughout the day.

None of the high school resource teachers was involved in direct reading instruction. Their emphases were reported as teaching subject matter, the development of study skills, tutoring, scheduling, and counseling. This researcher concluded that these teachers were marginally involved in the development of students' reading skills. It was therefore more difficult for them to observe behaviors that indicate Scotopic sensitivity syndrome, and to make appropriate recommendations.

\section{High school student Characteristics}

The eight high school prospects shared three of the desired attributes: they qualified for itinerant special education services, had average range IQs, and had demonstrated limited achievement gains in reading. Table 9 shows the exient to which they deviated 
from other attributes as a group. In general, the high school students demonstrated more reluctance to participate in the study than their elementary counterparts.

\section{Attribute Deviationg}

The comparison of attribute deviations presented in Table 9 indicates that the high school sample demonstrated a proportionally higher incidence of deviations than did the elementary sample. Fifteen deviations were noted for the eight high school students, compared to eighteen for the larger sample of elementary students.

The three attributes for which there were five or more known deviations were "learning disabled in reading" (5), "moderate or high Irlen Syndrome" (7), and "no significant behavioral, emotional, or health factors." The five students who were not identified in special education records as reading disabled did demonstrate significantly delayed reading skills. In these cases, the discrepancy between assessed reading skills and learning potential was less than the 15 points (one standard deviation) required by the District for identification as learning disabled. This is most likely to occur with students who are assessed as low average for verbal IQ; seven of the 26 students screened were in the low average IQ range of 80 to 90. The five students not identified for reading were learning disabled in mathematics or written language, and did receive itinerant special education.

of the two attributes having seven deviations, one (degree of Irlen syndrome) could not be determined by pre-screening. It is 
notable that three of the eight high school students screened demonstrated low to negligible Irlen syndrome. Health factors accounted for four of the seven "significant factor" deviations. These included childhood leukemia, and asthma and other conditions requiring current medication. One candidate had behavioral goals on his Individual Educational Plan. Emotional and environmental (family) igsues were documented in the files of two students.

Table 9 documents four known deviations in visual function. Two of these belonged to subjects in the study, and were not known until after the comprehensive vision examinations.

Teacher Obgervation of Irien Syndrome symptoms

Teachers submitted symptom observation forms, designed by the Irlen Institute, for 15 of the 26 students who were screened. These 15 forms were grouped according to severity of Irlen syndrome demonstrated by students, and analyzed for the number of notations in each symptom category. The objective was to assess the usefulness of the observation form as a pre-screening tool.

Forms submitted on three high-syndrome prospects yielded a mean of 26 symptoms observed. Given the small number of forms, it could not be concluded that symptoms of high-syndrome students were more apparent to teachers than symptoms of moderate-range prospects. The eight forms on moderates yielded a mean of 22.25 symptoms observed. The mean of observed symptoms for low-syndrome students (four forms submitted) was 17.75 . 
The symptom categories noted most frequently by teachers were "Types of Reading Difficulties" (92 notations overall) and "Observations while Reading" (99 notations). Total notations for the other categories are listed in descending order:

Table 10

Symptoms Noted by Teachers

\begin{tabular}{lc}
\hline Category & Total Notations \\
\hline Wiriting & 49 \\
Complaints (of strain and fatigue) & 32 \\
General Characteristics (of light sensitivity) & 26 \\
Mathematics & 16 \\
Depth Perception & 12 \\
Complaints on Computers & 4 \\
Appearance of Eyes & 2 \\
\hline
\end{tabular}

The researcher concluded that symptoms were observable to teachers, primarily in categories that interface with instruction. However, symptom observation by a teacher was not a reliable predictor of the severity of Irlen syndrome in an individual student.

\section{Screening Results}

Table 11 presents the screening results in terms of demonstrated severity of Irlen syndrome, for the 26 prospective subjects who were given the IDPIS. Four of these cases (15\%) demonstrated a high level 
of scotopic Sensitivity/Irlen syndrome on the IDPIS. Three of these four participated in the study as subjects. The incidence of students demonstrating a low to negligible level was $27 \%$ (seven cases.)

Table 11

Demonstrated Severity of Irlen syndrome in Prospective Subjects

\begin{tabular}{|c|c|c|c|}
\hline Degree & $\begin{array}{c}\text { Elementary } \\
\text { Candidates }\end{array}$ & $\begin{array}{c}\text { High School } \\
\text { Candidates }\end{array}$ & Total \\
\hline High & 3 & 1 & 4 \\
\hline Moderate & 11 & 4 & 15 \\
\hline $\begin{array}{c}\text { Low to } \\
\text { Negligible }\end{array}$ & 4 & 3 & 7 \\
\hline
\end{tabular}

Fifteen cases, or 588 of the total screened, exhibited a moderate level of Irlen syndrome. One of these became a subject in the study. The assessment as moderate was tentative in two of these 15 ; these two exhibited significant symptoms but expressed a weak preference for their chosen overlay. One of these had a history of childhood leukemia, which itself can cause light sensitivity. The other wore glasses to correct focusing difficulties, and preferred an overlay only when he was not wearing the glasses. It appeared to the researcher that a goldenrod overlay and the glasses, working separately, addressed the same vision problems for this student.

\section{Selection of Four Subjects}

The original intent was to locate four subjects who demonstrated all of the intersubject attributes, including a high level of Irlen syndrome. The intrasubject attributes would be considered on a 
case-by-case basis. Since a high syndrome manifestation was a

priority attribute, all four of the "high" students were originally enrolled. Their grade levels were fourth (two students), fifth (one student) and tenth (one student.)

The tenth grade student qualified for special education as learning disabled in written language, but not in reading. she had previously been identified as reading disabled, but did not demonstrate the required ability-achievement discrepancy at the time of her most recent re-evaluation. This student also reported being on a temporary medication which frequently caused headaches during the school day. These factors were of concern, but not judged as grounds for disqualification.

The decision to discontinue this student's participation was based chiefly on the outcome of her overlay re-trial. For the other subjects, this re-trial process confirmed symptoms identified during screening and allowed the researcher to refine the prescription of color and density. This subject did not demonstrate a preference for using her yellow overlay during the re-trial. on this occasion, the researcher was also unable to observe a difference in performance when she read a line of small print with versus without the overlay. This made the original assessment of Irlen Syndrome tentative, and the tenth grade subject was withdrawn from the study. Another tenth grade student, one with moderate syndrome, was offered the chance to participate but declined.

A fifth subject was enrolied, in anticipation that problems would develop with at least one subject. This was a fifth grader who demonstrated Irlen syndrome in the moderate range. He was selected, 
from a field of 15 "moderates," chiefly because he attended the same school as a high-syndrome subject whose attendance was judged as borderline ( 808 from September through Aprj.l of the current year). This would allow for constructive data collection at that site in the event that the high-syndrome subject was absent. These students were in different mainstream classrooms, socialized in different peer groups, and were not grouped together in the resource room. It was therefore felt that selecting both of these subjects did not violate the experimental design.

The final roster included four subjects who participated throughout the study. These were one male and one female student in each of grades four and five. Although there were some attribute concerns in regard to the first subject (Jeremy) and the third (Samantha), none of these four presented deviations which barred fruitful results.

The next section summarizes screening results for the subjects. They were randomly assigned a position in the multiple baseline sequence, and are discussed in the following order.

1. Subject "A", Jeremy; grade four, site one; began overlay intervention at the beginning of week two.

2. Subject "B", Jered; grade five, site two; began overlay intervention at the end of week two.

3. Subject "C", Samantha; grade five, site two (same school as Jered); began overlay intervention at the end of week three.

4. Subject "D", Melisøa; grade four, site three; began overlay intervention at the beginning of week five. 


\section{Subject Screening Profile日}

Table 12 allows direct comparison of screening profiles for the four subjects. There were numerous parallel outcomes in the following areas:

1. Symptoms that were reported both by students in the interview portion of the screening, and marked by teachers on observation forms.

2. Distortions of printed lines and symbols reported by the students following visual task exercises.

3. Instability of white space, also reported following the visual task exercises.

Symptoms exhibited by all four were losing place in the text, skipping words and/or lines, repeating words and/or lines, and inaccurate or incomplete comprehension. Signs of the "labored tracking" noted for all four were as follows:

1. Jeremy: complained of lines and symbols being too close together and of being distracted by surrounding print; used of his finger or a marker.

2. Jered: hesitated when counting or reading; "stop and go" cadence.

3. Samantha: complained of lines and symbols as being too close together, and of being distracted by surrounding print; observable hesitation, "stop and go" cadence.

4. Melissa: also complained of lines and symbols being crowded and of being distracted by surrounding print; observable head movements; "stop and go" cadence. 
Table 12

Screening Profileg of Selected Subjects

\begin{tabular}{|c|c|c|c|c|}
\hline $\begin{array}{l}\text { Screening } \\
\text { Outcome }\end{array}$ & Jeremy & Jered & Samantha & Melisøa \\
\hline $\begin{array}{l}\text { Level of } \\
\text { Syndrome }\end{array}$ & High & Moderate & High & High \\
\hline $\begin{array}{c}\text { Overlay } \\
\text { Prescription }\end{array}$ & $\begin{array}{c}\text { Single density } \\
\text { turquoise }\end{array}$ & $\begin{array}{c}\text { Single density } \\
\text { turquoise }\end{array}$ & $\begin{array}{l}\text { Double density, } \\
\text { green with } \\
\text { turquoise }\end{array}$ & $\begin{array}{c}\text { Single density } \\
\text { green }\end{array}$ \\
\hline $\begin{array}{l}\text { Prominent observed } \\
\text { and reported } \\
\text { symptoms }\end{array}$ & $\begin{array}{l}\text { Loses place } \\
\text { Skips \& repeats } \\
\text { Labored tracking } \\
\text { Prefers dim light } \\
\text { Bothered by glare, } \\
\text { moves \& shades } \\
\text { page } \\
\text { Poor comprehension } \\
\text { Reading } \\
\text { deteriorates }\end{array}$ & $\begin{array}{l}\text { Loses place } \\
\text { Skips \& repeats } \\
\text { Labored tracking } \\
\text { Prefers dim light } \\
\text { Bothered by glare, } \\
\text { blinks \& squints } \\
\text { Poor comprehension } \\
\text { Reading } \\
\text { deteriorates }\end{array}$ & $\begin{array}{l}\text { Loses place } \\
\text { Skips \& repeats } \\
\text { Labored tracking } \\
\text { Headache } \\
\text { Fatigue, } \\
\text { eyestrain, } \\
\text { blinks \& squints } \\
\text { Poor comprehension } \\
\text { Reading } \\
\text { deteriorates }\end{array}$ & $\begin{array}{l}\text { Loses place } \\
\text { Skips \& repeats } \\
\text { Labored tracking } \\
\text { Headache } \\
\text { Shades page, } \\
\text { blinks \& squints } \\
\text { Poor comprehension } \\
\text { Frequent breaks }\end{array}$ \\
\hline $\begin{array}{l}\text { Task-induced print } \\
\text { instability }\end{array}$ & $\begin{array}{l}\text { Lines jiggled } \\
\text { Symbols moved } \\
\text { Print blurred } \\
\text { Lines of periphery } \\
\text { waved, crossed, } \\
\text { disappeared }\end{array}$ & $\begin{array}{l}\text { Symbols in line } \\
\text { moved apart } \\
\text { Print blurred } \\
\text { Lines on periphery } \\
\text { waved, spread } \\
\text { apart }\end{array}$ & $\begin{array}{l}\text { Symbols danced } \\
\text { Print rose up } \\
\text { Print blurred } \\
\text { Lines on periphery } \\
\quad \text { waved, flickered }\end{array}$ & $\begin{array}{l}\text { Symbols jiggled, } \\
\text { danced, moved } \\
\text { Print blurred } \\
\text { Print rose up }\end{array}$ \\
\hline $\begin{array}{l}\text { Task-induced } \\
\text { background } \\
\text { instability }\end{array}$ & $\begin{array}{l}\text { White space } \\
\text { appeared to rise } \\
\text { Flickering \& } \\
\text { flashing }\end{array}$ & $\begin{array}{l}\text { Space between } \\
\text { lines appeared } \\
\text { to grow }\end{array}$ & $\begin{array}{l}\text { White space } \\
\text { appeared to rise } \\
\text { Flickering \& } \\
\text { flashing }\end{array}$ & $\begin{array}{l}\text { White space } \\
\text { appeared to rise } \\
\text { Flashing } \\
\text { Brightened \& } \\
\text { dimmed }\end{array}$ \\
\hline $\begin{array}{l}\text { Demonstrated span } \\
\text { of focus }\end{array}$ & Undetermined & Very limited & Extremely limited & Undetermined \\
\hline
\end{tabular}


These students either admitted being bothered by glare or showed signs such as squinting or shading the page. Jeremy, Jered, and Samantha were observed by teachers as deteriorating in fluency as oral reading progressed. It was reported by both teacher and parent that Melissa could read for very short durations and needed frequent breaks. Jeremy and Jered stated a preference for reading in dim light, and were observed as preferring it. The occurrence of headaches was claimed as a significant problem by Samantha, Melissa and each of their teacher observers. Melissa's screening was discontinued during the visual task portion because of a headache. It was decided to repeat selected tasks and conduct her overlay trial on a different day. The print instability problem experienced by all four was intermittent blurring. As Table 12 indicates, there was slight variation in other perceived distortions. Jered was unique in describing a dot he was directed to focus upon--and also printed words--as splitting and moving apart. All students except Jered described white as appearing to rise up, to flash, and/or become brighter. Compared to the others, Jered appeared to have minimal problems with background instability. Jeremy's demonstrated span of focus is marked "undetermined" on Table 12 because he was unable to complete the task that was designed to assess it. He indicated that none of the symbols surrounding a point appeared clear; all were blurry or doubled. Jered and Samantha were able to see some surrounding symbols clearly, but scored low on this task. Melissa was not given the point-of-focus exercises because 
of the headache problem. All four were observed by both teachers and this researcher as reading word for word and being unable to skim. On the overlay trial portion of the screening, each student expressed a definite preference for reading a line of small print letters and a short passage with the chosen overlay(s). The researcher noted observable changes in fluency in the screening reports for Jeremy, Jered, Samantha and Melisøa. Each stated that the overlay corrected the blurring and made them considerably more comfortable by reducing glare on the page.

\section{Adjunct Screening Activities}

Two procedures were conducted in order to enrich the screening data on each subject. One was an overlay re-trial, the purpose of which was to allow the researcher to refine the density and tint of prescribed overlays prior to the intervention phase. It also served to reconfirm symptoms identified in screening, which it did for these four students.

For Jered and Melissa, the retrial indicated that no change in overlay prescription should be made. Jeremy stated a tentative preference for the addition of yellow to his turquoise during the retrial session. He was given a yellow to experiment with, but chose not to use it at home or in his classroom. The yellow overlay was not used for any of Jeremy's intervention trials.

Samantha also elected to add yellow to her previously selected overlays. She was more decisive in this choice than Jeremy, stating that the yellow enabled her to "see better." For the first five weeks 
of the study, Samantha used triple overlays (turquoise, green, and yellow) independently and for her trials. Prior to her fifth trial, Samantha read orally to the researcher with and without the yellow. At that point a difference was neither observed nor experienced, and Samantha discontinued use of the yellow overlay. The researcher concluded that the retrial procedure had no significant effect on intervention. However, it did serve to confirm the outcome of screening for these four students.

The second adjunct activity did not involve subjects directly. It was a telephone interview with parents, the purpose being to complete the "Subject Intake Data" form (see Appendix D). This yielded information on each subject that was pertinent to interpreting the results of the reading intervention. The parent contacted on Jeremy's behalf, throughout the study, was a stepmother with whom he had lived for one and one-half years. Jeremy's natural father was also in the home. Jeremy's stepmother reported several health, vision and family history factors which were relevant to this study. Jeremy was a premature baby who had open heart surgery during his first year. His natural mother had been on drug therapy during gestation. It is recognized that this could have contributed to his attentional difficulties and distractibility. Jeremy's visual health was documented as normal. He had been screened at school and by the family physician.

Jeremy had undergone counseling following a nine-month stay in the home of his natural mother. Problematic circumstances involving the natural mother led to a regression in school progress and personal 
adjustment. Jeremy continued to have intermittent periods of emotional difficulty which were attributed to his relationship with this parent.

Jeremy's father had experienced reading problems very similar to Jeremy's. He was also assessed by an Irlen Screener (not by this researcher) and found to have Irlen Syndrome. The father'g overlay prescription was for turquoise.

The health, vision and family information on Jered was supplied by his mother, who was the parent contacted throughout the study. Jered lived with both natural parents and two older brothers. There were no health and vision factors reported that were relevant to Jered's functioning as a subject in this study. Jered had previously been examined by the same vision clinic to which the four subjects were referred. It was found that his vision was within normal limits. Jered's mother reported that his father was light sensitive and that his two brothers demonstrated below-average reading skills. The brothers exhibited attention deficit, which school records had documented as a possible problem for Jered in the primary grades.

Samantha lived with her mother and two sisters in a single-parent home. Samantha's natural father, though not in the home, was centrally involved in some problematic circumstances that influenced Samantha's psycho-emotional adjustment and school attendance. This factor was the researcher's major concern in considering Samantha as a subject.

Samantha had received specialized tutoring outside of school, as had Jeremy and Jered. None of the subjects were involved in outside 
tutoring during the study. Samantha had also been examined by a commercial optometric outlet and provided with glasses for reading. Samantha said that the glasses magnified print slightly, but they did not help her significantly and she did not like to use them. Samantha's family history, like Jeremy's and Jered's, was positive for learning problems. Her mother had epilepsy, and experienced learning difficulties. The reading problems of both siblings were described as similar to Samantha's. The maternal grandmother was recognized as light sensitive.

Melissa's natural mother supplied the intake information, and was the home contact for this study. Melissa lived in a two-parent family, with siblings both older and younger. The mother reported no health, vision, or psycho-emotional factors for which Melissa had received treatment, and which would be relevant to her participation as a subject.

Melissa's school vision screening had indicated normal acuity. She had received no vision evaluation outside of school. Melissa's maternal grandmother, described as light sensitive, had prescription glasses designed for wearing in sunlight and for night driving. Melissa's mother reported that no one else in the family had reading or learning difficulties that were recognized.

Summary of Subject Attribute status

Each of the four subjects demonstrated the desired intersubject attributes (see Table 6): placed in grades four or five, identified as learning disabled in reading, eligible for itinerant (resource 
room) services, and significant manifestation of Irlen syndrome. Jeremy's attention deficit was documented as a learning disability, in addition to reading. There was concern that this would affect his performance on experimental trials. It was documented that he was able to consciously control both his attentional focus and his behavior, and did not take medication. off-task behavior and distractability had also been cited as a factor in Jered's profile. Jered too had not been medicated, and demonstrated the problem to a lesser extent than Jeremy.

Each subject did deviate from one or more of the recommended intrasubject attributes (see Table 7). Table 13 compares their statug on all attributes except the following two:

1. Significant behavioral, emotional, and health factors;

2. Support of teachers, parents, and students to inclusion in the study.

No difficulties were encountered in regard to number two above. The enlistment of support from the named parties, informed consent process, and enrollment of these four subjects went smoothly and according to plan.

None of these students exhibited significant and consistent behavior problems in the school or home. Some variation in the attitude and classroom performance of Jeremy and Samantha was observed by their teachers, and attributed to the family issues that were discugsed in the previous section. The divorce between Samantha's parents--and difficulties presented by the absent parent--contributed to a school enroliment and attendance pattern which was at variance 
Table 13

Attributes Demonstrated by Selected Subjects

\begin{tabular}{|c|c|c|c|c|}
\hline Attribute & $\begin{array}{c}\text { A } \\
\text { Jeremy }\end{array}$ & $\begin{array}{c}\text { B } \\
\text { Jered }\end{array}$ & $\begin{array}{c}\text { C } \\
\text { Samantha }\end{array}$ & $\begin{array}{c}\text { D } \\
\text { Melissa }\end{array}$ \\
\hline Grade & 4 & 5 & 5 & 4 \\
\hline $\begin{array}{l}\text { Area (s) of } \\
\text { Learning } \\
\text { Disability }\end{array}$ & $\begin{array}{l}\text { Reading } \\
\text { Attention Deficit }\end{array}$ & $\begin{array}{l}\text { Reading } \\
\text { Written Expression }\end{array}$ & $\begin{array}{l}\text { Reading } \\
\text { Written Expression } \\
\text { Mathematics }\end{array}$ & $\begin{array}{l}\text { Reading } \\
\text { Written Expression } \\
\text { Mathematics }\end{array}$ \\
\hline $\begin{array}{c}\text { Delivery of } \\
\text { special Education } \\
\text { Services }\end{array}$ & $\begin{array}{l}135 \text { minutes } \\
\text { direct service } \\
\text { per week; daily } \\
\text { half-hour } \\
\text { sessions in } \\
\text { Resource Room }\end{array}$ & $\begin{array}{l}90 \text { minutes direct } \\
\text { service per week; } \\
3 \text { half-hour } \\
\text { sessions in } \\
\text { Resource Room }\end{array}$ & $\begin{array}{l}\text { Collaboration } \\
\text { between RC and } \\
\text { mainstream teacher } \\
\text { for direct service } \\
\text { as needed }\end{array}$ & $\begin{array}{l}90 \text { minutes direct } \\
\text { service per week; } 3 \\
\text { half-hour sessions } \\
\text { in Resource Room }\end{array}$ \\
\hline $\begin{array}{c}\text { Scotopic } \\
\text { Sensitivity/Irlen } \\
\text { Syndrome }\end{array}$ & High & Moderate & High & High \\
\hline Visual Functioning & $\begin{array}{l}\text { Normal acuity; } \\
\text { binocular } \\
\text { dysfunction }\end{array}$ & $\begin{array}{l}\text { All functions } \\
\text { normal }\end{array}$ & $\begin{array}{l}\text { All functions } \\
\text { normal }\end{array}$ & $\begin{array}{l}\text { Minor hyperopia and } \\
\text { focusing difficulty }\end{array}$ \\
\hline Learning Potential & Average & $\begin{array}{l}\text { slightly above } \\
\text { average }\end{array}$ & Low Average & $\begin{array}{l}\text { slightly above } \\
\text { average }\end{array}$ \\
\hline $\begin{array}{l}\text { Prior Reading } \\
\text { Achievement }\end{array}$ & $\begin{array}{l}11 / 90-1.4 \mathrm{GE} \\
2 / 93-2.5 \mathrm{GE} \\
3.5 \text { mos. growth } \\
\text { per year }\end{array}$ & $\begin{array}{l}1 / 90-1.7 \mathrm{GE} \\
1 / 93-3.2 \mathrm{GE} \\
5 \text { mos. growth per } \\
\text { year }\end{array}$ & $\begin{array}{l}5 / 88-1.0 \mathrm{GE} \\
4 / 91-2.0 \mathrm{GE} \\
3 \text { mos. growth per } \\
\text { year }\end{array}$ & $\begin{array}{l}5 / 89-1.2 \mathrm{GE} \\
4 / 92-2.1 \mathrm{GE} \\
3 \text { mos. growth per } \\
\text { year }\end{array}$ \\
\hline $\begin{array}{c}\text { Prior School } \\
\text { Enrollment ( } 8 \text { ) } \\
\text { and Attendance } \\
\text { Pattern }\end{array}$ & $\begin{array}{l}\text { Two schools } \mathrm{K}-4 \\
948 \text { attendance } \\
\text { current year }\end{array}$ & $\begin{array}{l}\text { Two schools } \mathrm{K}-5 \\
948 \text { attendance, } \\
\text { current year }\end{array}$ & $\begin{array}{l}\text { Five schools } \mathrm{K}-5 \\
808 \text { attendance } \\
\text { current year }\end{array}$ & $\begin{array}{l}\text { One school } \mathrm{K}-4 \\
898 \text { attendance } \\
\text { current year }\end{array}$ \\
\hline
\end{tabular}


from the others. Samantha did attend the same school through her fourth and fifth grade years. Off-task behavior was of concern to Jered's mainstream teacher, and may have affected the rate at which he progressed in the classroom. For the baseline and intervention trials with the researcher, each subject appeared consistently attentive to tagk and behaved cooperatively.

Table 13 notes vision anomalies for Jeremy and Melissa. These were not known prior to the comprehensive vision evaluations. The probable impact of these conditions on the outcome of this study is discussed in other sections.

The inclusion of these four students as subjects was carefully considered, in light of the family and learning issues discussed above. It was decided that given the degree of Irlen syndrome demonstrated by each child, the conflicting factors would not be severe enough to negate treatment. The experimental plan would allow the researcher to determine whether or not spectral modification techniques were effective for each of these students.

Learning Objectives in Special Education and Mainstream Classrooms

The special education and mainstream teachers involved in this study were polled for their opinions on the importance of rate, accuracy, and comprehension as performance indicators. Their responses demonstrated concurrence that these are key subskills and should be assessed. Adequate rate and accuracy were generally regarded as prerequisites for comprehension. Subjects' Individual 
Educational Plans (IEPs) included objectives on the mastery of phonetic patterns, which would directly impact accuracy. Mainstream teachers included oral reading practice and improving fluency as learning objectives for these students.

All teachers stated that it was important to assess different levels of comprehension, which was attempted in the experimental reading trials. Comprehension objectives were included in IEPs for Jeremy, Jered and Samantha. Reading activities in the mainstream classrooms reflected the District's fourth and fifth grade curriculum goals for comprehension. It was therefore probable that each subject would experience on-going practice and instruction in the subskills of rate, accuracy and comprehension.

\section{Regults of Vision Examinations}

Each subject received a comprehensive vision evaluation at Pacific University College of Optometry's Family Vision Center. Care was taken to assess for conditions that have been associated with Irlen syndrome: focusing ability (accommodation), eye movements (oculomotor skil1s), and eye coordination (binocularity). Subjects were also assessed for their ability to manage horizontal eye movements (saccades and smooth pursuits).

\section{Visual Functioning: Jeremy}

Jeremy described intermittent blur at near point and in the distance, and doubling of letters when reading as entering concerns. His unaided visual acuity was $20 / 20$ at near and far point. He 
demonstrated low level nearsightedness (myopia) when the focusing muscle was active, low farsightedness (hyperopia) when focus was relaxed. Neither of these minor refractive conditions responded to lenses. Jeremy also demonstrated slightly reduced accommodative ability, especially in regard to changing focus at a normal reading distance. The most serious defects in Jeremy's visual functioning were in areas of ocular motor skills and binocularity. His eye movements were found to be full, rough, and inaccurate with definite deviations from normal. Jeremy's saccadic eye movements (the horizontal flow of movement and fixation required for reading) were found to be very low, in the tenth percentile for his age group. Smooth pursuits refers to the ability to visually track a moving target. Jeremy's smooth pursuits were highly inaccurate for his age. Jeremy also demonstrated deficient binocularity. In other words, he was unable to consistently converge his eyes for single vision at normal reading distance. The final assessment was of abnormal visual functioning with low hyperopia, convergence insufficiency, and oculomotor dysfunction. It was felt that glasses would not be appropriate, but that a regular program of vision therapy should be implemented to correct his visual deficiencies.

Jeremy was retained as a subject, chiefly on grounds that it would be possible for an individual to have Irlen syndrome in addition to ocular motor difficulties. The fact that his father had responded positively to spectral modification for reading was considered. Since Jeremy's parents were willing to provide him with the vision therapy, it was agreed that he would begin therapy three weeks after commencing 
use of the colored overlays. The vision therapy would be considered as an additional intervention for this subject.

Visual Functioning: Jered

Jered had been examined at this clinic two years previously. At that time he was assessed as slightly farsighted (though within normal limits) and as slightly below average on convergence. This examination indicated that both conditions had improved. Jered's visual acuity was $20 / 20$ at near and far point. His total accommodative power was normal, and ability to change focus at normal reading distance was assessed as very good. Oculomotor skills were also in the normal range. Jered's horizontal saccades were assessed as slightly low, but the lag was not statistically significant. Also slightly reduced was Jered's ability to change "eye pointing" at a normal reading distance and maintain single vision for reading (a binocularity function). However, his binocularity was assessed as within normal limits. The final assessment was that Jered required no glasses or therapy for clear and comfortable nearpoint vision.

\section{Visual Functioning: Samantha}

Prior to the examination Samantha complained of minor blur in the distance, and that her reading glasses seemed to give her headaches when she used them. Her visual acuity was assessed as 20/20 at near and far point, with very low hyperopia. She exhibited slightly reduced total accommodative power. Her ability to change focus at a normal reading distance was assessed as very good. 
Samantha's oculomotor skills were evaluated as normal, with no deviations in saccades or smooth pursuits. She demonstrated strong binocularity, and normal ability to adjust "eye pointing" and maintain single vision for reading. The final assessment was of a normal ocular and visual state, with low hyperopia that was also normal for her age. This clinic's conclusion was that reading glasses were not necessary for Samantha at this time.

Visual Functioning: Melissa

This was Melissa's first eye examination. An entering concern, as she presented it, was that print appeared to blur and fade with reading. Melissa demonstrated $20 / 20$ visual acuity at near and far point. Also detected was low hyperopia that was within normal limits. Total accommodative power was assessed as slightly reduced, as was her ability to change focus at normal reading distance. Melissa's focusing posture was described as too relaxed for clear vision at near point.

Melissa's oculomotor skills were basically normal, with no deviation in smooth pursuits. Her saccades were evaluated as somewhat inaccurate. Binocularity was within normal limits. However, her ability to adjust "eye pointing" and maintain single vision at normal reading distance was slightly reduced.

Each of Melissa's visual difficulties occurred to a minor degree. Their cumulative effect created a visual system described by the examining doctor as under stress. The final assessment was that Melissa required reading glasses for clear and comfortable near point 
vision. This was attributed to her farsightedness and the accommodative elements.

The decision to retain Melissa as a subject was based on the fact that many Irlen lens wearers do have optometric prescriptions incorporated into their tinted lenses. Melissa's use of an overlay with glasses allowed the researcher to assess whether or not the combination enabled this subject to read with maximum efficiency. Melissa was provided with her glasses in the middle of the intervention phase. Different trends were apparent for the use of overlay alone, and for the use of overlay and glasses combined.

Commonalities in Visual Functioning

Comparison of the vision profiles of these four subjects revealed four commonalities. Of note was that each student demonstrated $20 / 20$ acuity, and was identified as having normal vision by school screening records. Each of the other three commonalities were shared by three subjects. Jeremy, Samantha, and Melissa demonstrated farsighted tendencies, which were classified as within normal limits by the examining optometrists. The same three also demonstrated below average accommodation, or focusing capacity. This was very minor in Samantha's case, more significant for Jeremy and Melissa.

Below normal performance on horizontal saccades (eye movements and fixations required for reading) was noted for Jeremy, Jered, and Melissa. This finding can be considered in relation to the theory on magnocellular deficiency that was presented in chapter II. 
Historical Achievement Test Data

Each subject had been given the Woodcock-Johnson Pyschoeducational Battery (WJPB) as a part of initial assessment for special education eligibility. Jered, Samantha and Melissa had two WJPB administrations on record: initial assessment and a re-evaluation of three years later. Jeremy had not yet undergone a re-evaluation.

The three-year interval results were used to determine an approximate rate of growth per year for three subjects. Growth demonstrated during the study could then be compared to previous growth. The WJPB is reserved for re-evaluation of special education students, and was not available for use as a pre- and post-test instrument in this study. It was therefore necessary to compare growth patterns as indicated by results of different tests.

\section{Previous Growth: Jeremy}

As indicated above, Jeremy had undergone only one administration of the WJPB reading achievement test. This was given during his gecond grade year, fourth month. His grade equivalent score was 1.4, indicating that his reading achievement at that time was one year below actual grade placement.

Jeremy's calculated rate of growth, from beginning first grade level, would be one month of skill-level gain in 3.2 months of school time. His annual rate of growth, as determined by historical test data, would be approximately three months per year. 
Previous Growth: Jered

Jered was re-evaluated with the WJPB following his enrollment as a subject, but prior to experimental intervention. His grade equivalent score was 3.2 , indicating that his reading achievement was approximately 2.3 years below actual grade placement at the time of this study.

Jered's grade equivalent score three years earlier was 1.7 . His skill level gain was 1.5 years in three years of school time, or approximately five months for each year.

Previous Growth: Samantha

Samantha's most recent WJPB reading assessment was April, 1991, when her grade placement was 3.8. Her grade equivalent score in reading was 2.0 , indicating that her reading skill at the time was one year, eight months below actual grade placement. Samantha had scored 1.0 three years earlier, at the time of her initial evaluation. This indicated one year's skill growth in the three years of school time, or approximately three months per year.

Previous Growth: Melissa

Melissa was re-evaluated in the eighth month of her third grade year. Her grade equivalent score was 2.1, for a lag of one year, seven months below actual grade placement. The reading grade equivalent was 1.2 at the time of her initial evaluation, which had occurred three years earlier (May 1989). Melissa repeated first grade following her initial evaluation, which made possible the three-year interval. The WJPB indicated that Melissa's reading skill progressed 
nine months in three years of school time. This computed to a yearly gain of slightly less than three months.

Portland Achievement Levels Test (PAIT)

PALT scores from the spring of 1992 were on record for each subject except Melissa. Melissa's Spring 1992 results were invalid, indicating a correct response rate of under 25 percent. The PALT had been administered both Fall and spring in the 1991-1992 school year. Melissa had a Fall 1991 score of 171 on record. This was classified as a low score, as were the spring 1992 scores of the other subjects. These were 170 for Jeremy, 192 for Jered, and 172 for Samantha.

\section{Pre-Test Results}

\section{Letter Recognition}

It was determined that each subject could recognize all upper and lower-case letters of the alphabet. The letter-reading task did elicit some perceptual difficulties. Jeremy transposed a few letters, commenting that they appeared to jump. Samantha described the lower-case letters as blurring, the background as flashing. The examiner/researcher observed that her fluency deteriorated as she proceeded in the letter-naming task.

Although Jered and Melissa did not report visual distortions, performance aberrations were observed. Jered's cadence slowed as he read through the final row of lower-case letters. Melissa reversed the "b" and "d" symbols. 
Word Recognition and Oral Reading

Table 14 includes pretest results, in addition to the reading material each subject was placed in at the start of the study. As previously stated, the assignment of reading material was guided by pre-test results but not ruled by it.

The heading "GE/WR" in Table 14 refers to grade equivalent in word recognition. The score entered is an average of two scores earned from two instruments: the San Diego Quick Assessment (1977) and Slosson (1963) Oral Reading Test.

Each subject's oral reading level ("OR Level", Table 14) was indicated by the Oral Reading subtest of the Brigance (1976) Diagnostic Inventory. A word recognition accuracy rate of 95 percent is mastery criterion for this subtest. Included on the table are the accuracy and rate at which each subject read the passage.

Jered and Samantha did demonstrate 958 and 1008 accuracy respectively. Jered's word recognition pre-test score, and his recent Woodcock-Johnson Total Reading score of 3.2 , indicated that his actual reading level was in the third grade range. Samantha's accuracy of 1008 on the second grade Brigance passage was offset by the fact that she read the passage at the rate of 56 words per minute. This could be compared to Jeremy's pre-test rate of $106 \mathrm{w} . \mathrm{p} . \mathrm{m}$. , and Jered's rate of 84 w.p.m. Samantha's resource teacher provided an informal achievement assessment of late second grade. Material in the second grade range was found suitable for samantha throughout the study. 
Table 14

Pre-Test Results and Selected Reading Trial Material

\begin{tabular}{|c|c|c|c|c|}
\hline subject & GE/WR & $\begin{array}{c}\text { OR } \\
\text { Level }\end{array}$ & Reading Material & Comprehension Material \\
\hline Jeremy & 2.2 & $\begin{array}{c}\text { Grade } 2 \\
938 \\
106 \text { w.p.m. }\end{array}$ & $\begin{array}{c}\text { Nate the Great } \\
\text { (Sharmat, 1984) } \\
2.0-2.5 \\
\text { readability }\end{array}$ & $\begin{array}{c}\text { New Practice Reader } \\
\text { (Anderson, stone \& } \\
\text { Burton, 1978) } \\
\text { Level A } \\
2.5-2.9 \\
\text { readability }\end{array}$ \\
\hline Jered & 3.1 & $\begin{array}{c}\text { Grade } 3 \\
958 \\
84 \mathrm{w} \cdot \mathrm{p} \cdot \mathrm{m}\end{array}$ & $\begin{array}{l}\frac{\text { Angel, } \mathrm{Me}_{\mathrm{g}}}{\text { Bayside Bombers }} \\
\text { (Auch, 1989) } \\
3.5-3.9 \\
\text { readability }\end{array}$ & $\begin{array}{c}\text { New Practice Reaader } \\
\text { (Anderson, Stone \& } \\
\text { Burton, 1978) } \\
\text { Level B } \\
3.0-3.4 \\
\text { readability }\end{array}$ \\
\hline Samantha & 2.0 & $\begin{array}{l}\text { Grade } 2 \\
1008 \\
56 \text { w.p.m. }\end{array}$ & $\begin{array}{c}\text { Nature's Wonders } \\
(\text { Rally) } \\
\text { (Simons, 1979) } \\
2.0-2.5 \\
\text { readability }\end{array}$ & $\begin{array}{c}\text { New Practice Reader } \\
\text { (Anderson, Stone \& } \\
\text { Burton, 1978) } \\
\text { Level A } \\
2.5-2.9 \\
\text { readability }\end{array}$ \\
\hline Melissa & 1.5 & $\begin{array}{c}\text { Grade } 1 \\
858 \\
56 \text { w.p.m. }\end{array}$ & $\begin{array}{c}\text { Days with Frog and Toad } \\
\text { (Lobel, } 1978) \\
1.5-1.9 \\
\text { readability }\end{array}$ & $\begin{array}{c}\text { Lift off } \\
\text { (Merrill Linguistic) } \\
\text { (Wilson \& Rudolph, } \\
1986 \text { ) } \\
2.0 \\
\text { readability }\end{array}$ \\
\hline
\end{tabular}


Reading Trial Resultg--Jeremy

\section{Graphic Data Analysis}

Table 15 presents the subject's numerical scores for 17 reading trials. Figures 1,2 and 3 show this subject's performance trends during his three trial phases: baseline without overlay, intervention with overlay, and post-intervention. The post-intervention trials were conducted without the overlay, after Jeremy had been practicing vision therapy for seven weeks.

Table 15

Numerical Trial Data--Jeremy

\begin{tabular}{|c|c|c|c|c|}
\hline Date & Rate & Accuracy & Comprehension & Baseline \\
\hline $1 / 28 / 93$ & 80 & 78 & 80 & 1 \\
\hline $2 / 1 / 93$ & 86 & 83 & 60 & 2 \\
\hline $2 / 2 / 93$ & 83 & 84 & 60 & 3 \\
\hline $2 / 5 / 93$ & 58 & 65 & 20 & 4 \\
\hline \multirow[t]{2}{*}{$2 / 8 / 93$} & 113 & 85 & 60 & 5 \\
\hline & & & & Intervention \\
\hline $2 / 8 / 93$ & 122 & 93 & 60 & 6 \\
\hline $2 / 11 / 93$ & 97 & 90 & 20 & 7 \\
\hline $2 / 16 / 93$ & 95 & 91 & 80 & 8 \\
\hline $2 / 24 / 93$ & 84 & 95 & 60 & 9 \\
\hline $3 / 3 / 93$ & 91 & 94 & 100 & 10 \\
\hline $3 / 10 / 93$ & 78 & 92 & 80 & 11 \\
\hline $3 / 16 / 93$ & 67 & 91 & 100 & 12 \\
\hline $3 / 31 / 93$ & 101 & 95 & 60 & 13 \\
\hline \multirow[t]{2}{*}{$4 / 7 / 93$} & 81 & 93 & 40 & 14 \\
\hline & & & & Post \\
\hline $5 / 10 / 93$ & 101 & 89 & 80 & 15 \\
\hline $5 / 12 / 93$ & 93 & 93 & 80 & 16 \\
\hline $5 / 14 / 93$ & 95 & 94 & 60 & 17 \\
\hline
\end{tabular}




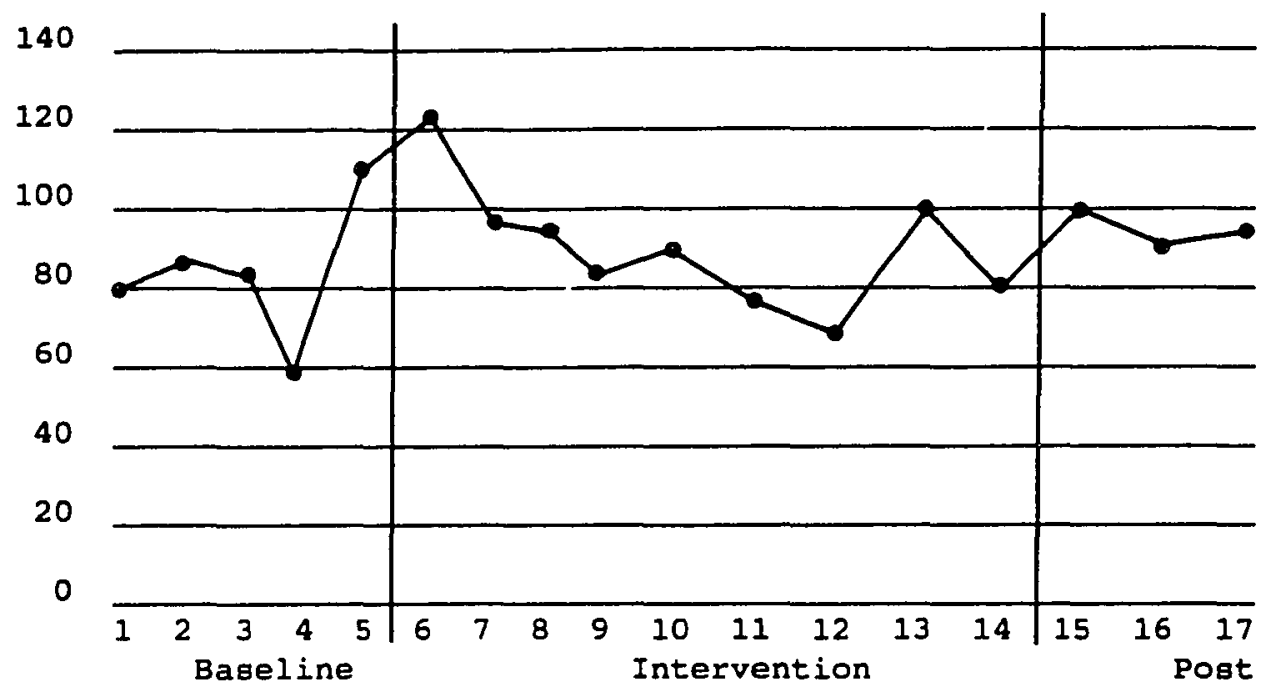

Fiqure 1. Graphic representation of Jeremy's oral reading rate across three experimental phases.

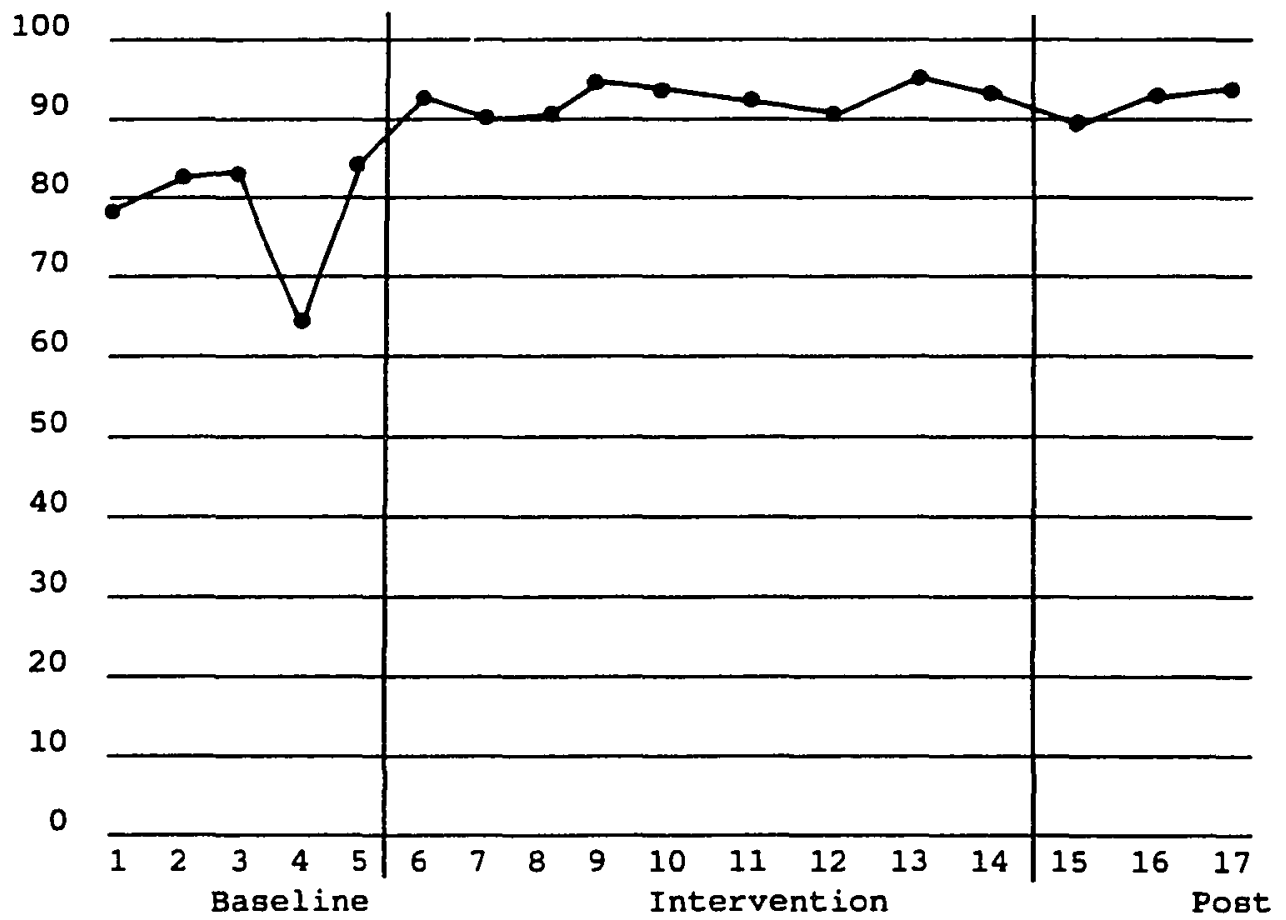

Fiqure 2. Graphic representation of Jeremy's oral reading accuracy across three experimental phases. 


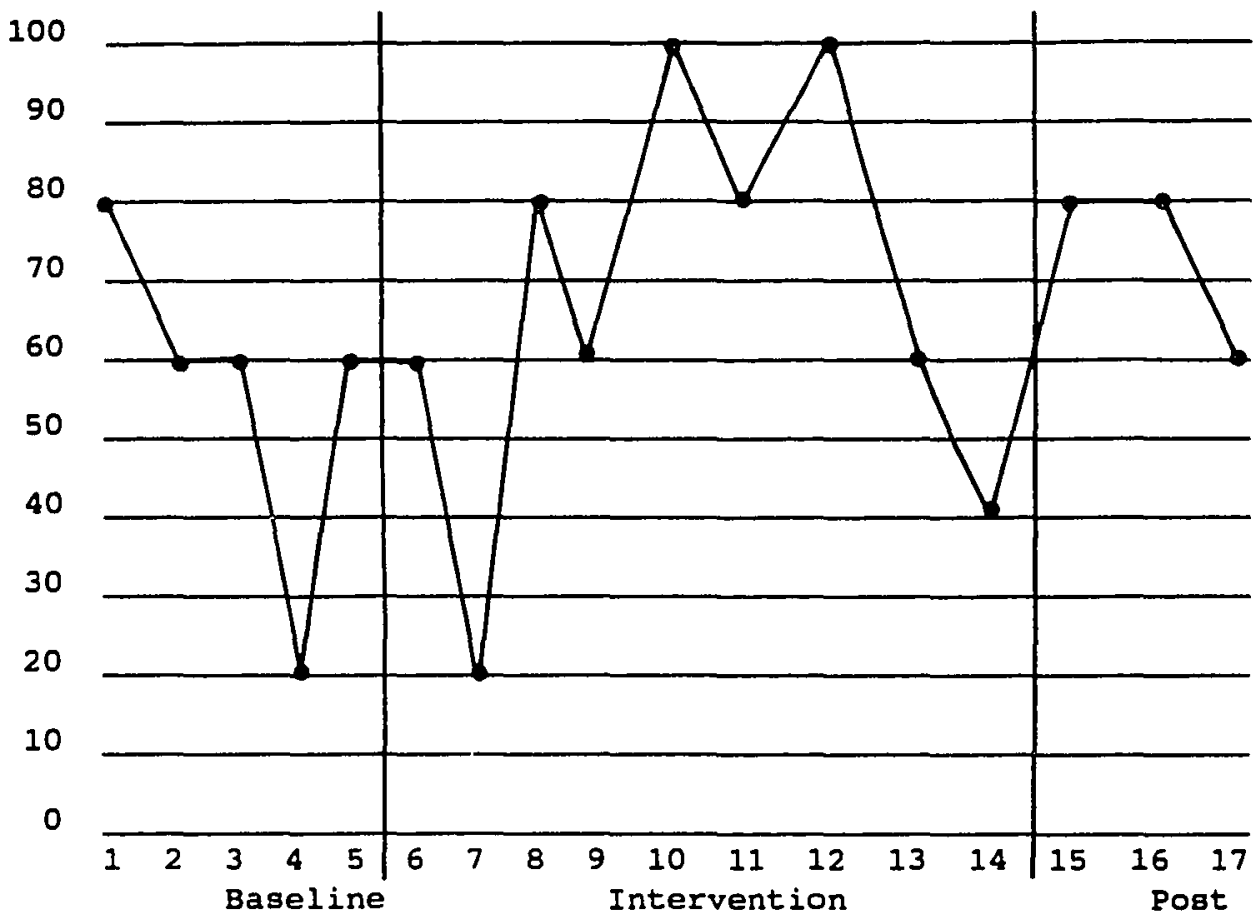

Fiqure 3. Graphic representation of Jeremy's silent reading comprehension across three experimental phases.

Baseline Phase

The timeline for this study required that the first subject to begin intervention with overlay (Jeremy) do so during the gecond week of data collection. This allowed for five baseline trials, which was the number conducted for each subject. The performance stability demonstrated by Jeremy on three of his five baseline trials must be interpreted as tentative, given the small number of trials. He performed within the following range on his first three trials:

1. Rate of 80 to 86 words per minute (w.p.m.);

2. Accuracy of 788 to 848 of words stated in correct form and sequence;

3. 608 to 808 correct response to comprehension questions. 
Low performance on all three indicators was demonstrated during the fourth trial. Jeremy complained of being unable to focus and see print clearly on that day. This was offset by comparatively good performance on the fifth trial, when his rate and accuracy were at their highest level of the baseline phase. Jeremy's mean performance for all five trials was:

1. Rate of 84 (w.p.m.);

2. Accuracy of 798 ;

3. Comprehension of 568 .

\section{Intervention Phase}

Jeremy's performance changed significantly in the area of oral reading accuracy, as shown in Figure 2. His most frequently occurring error during baseline was skipping or rereading lines, the incidence of which was greatly reduced during intervention. The level of accuracy was stable throughout intervention, varying from 908 to 958 . It did not fluctuate as did performance on the other indicators. Mean accuracy during intervention was 92.678 , compared to 798 during baseline. The gain was 13.678 more words stated in correct form and sequence.

Jeremy's performance in oral reading rate (see Figure 1 ) and silent reading comprehension (see Figure 3) fluctuated considerably during intervention with the overlay. Trend analysis of these performance indicators did not reveal change that could be attributed to experimental intervention. There were slight changes in the mean 
performance for rate $(90.67 \mathrm{w} \cdot \mathrm{p} \cdot \mathrm{m}$. for intervention, $84 \mathrm{w} \cdot \mathrm{p} \cdot \mathrm{m}$. for baseline) and for comprehension ( 66.678 intervention, 568 baseline).

\section{Post-Intervention Trials}

Jeremy's post-intervention trials were delayed until five weeks after the conclusion of intervention. This was to allow his practice of vision therapy exercises to have a cumulative effect. He did not actually begin the exercises until after the twelfth trial, since the first three weeks of the vision therapy program were devoted to assessment.

Trials 15, 16, and 17 comprised the post-intervention phase. The subject continued in the reading material he had used on trial 14, but did not use his overlay. Jeremy's performance on these three trials was similar to that demonstrated during intervention. Postintervention meang were:

1. Rate of 96.33 w.p.m. (intervention 90.67 , baseline 84);

2. Accuracy of 928 (intervention 92.678, baseline 798);

3. Comprehension of 73.338 (intervention 66.678 , baseline 568)

\section{Conclusions}

Reading trial results did indicate the following conclusions for Jeremy :

1. The overlay intervention and the vision therapy, taken separately, allowed this subject to achieve the same level of reading accuracy. 
2. Use of the overlay alone produced gignificant improvement in accuracy, and insignificant change in the areas of rate and comprehension.

Reading Trial Regultв--Jered

\section{Graphic Data Analygis}

Two trial phases were conducted for Jered: baseline, and intervention with a turquoise overlay. Post-intervention trials were not conducted for Jered or Samantha, since they did not undergo prescribed vision treatments. Table 16 is a numerical tabulation of Jered's reading trial results. Figures 4, 5, and 6 represent graphic analysis of Jered's reading performance during baseline and intervention phases.

Table 16

Numerical Trial Data--Jered

\section{Date}

$2 / 1 / 93$

$2 / 3 / 93$

2/ $5 / 93$

2/ $9 / 93$

$2 / 10 / 93$

$2 / 11 / 93$

$2 / 17 / 93$

$2 / 24 / 93$

$3 / 3 / 93$

$3 / 10 / 93$

$3 / 16 / 93$

$3 / 31 / 93$

$4 / 7 / 93$

$4 / 14 / 93$
Accuracy

96

93

77

88

87
73

56

50

59

70
76
56
80
86
88
99
94
94

100

100

100

100

80

80

100

80
Bageline

1

2

3

4

5

Intervention

6

7

8

9

10

11

12

13

14 


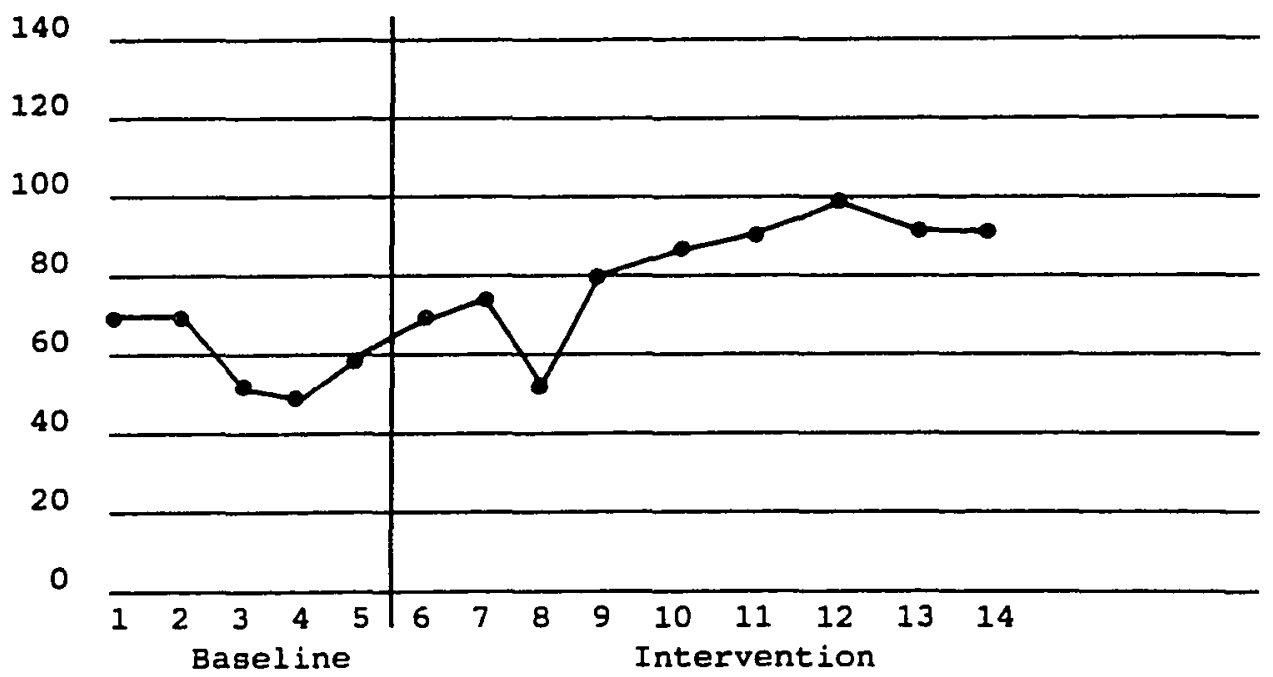

Figure 4. Graphic representation of Jered's oral reading rate across two experimental phases.

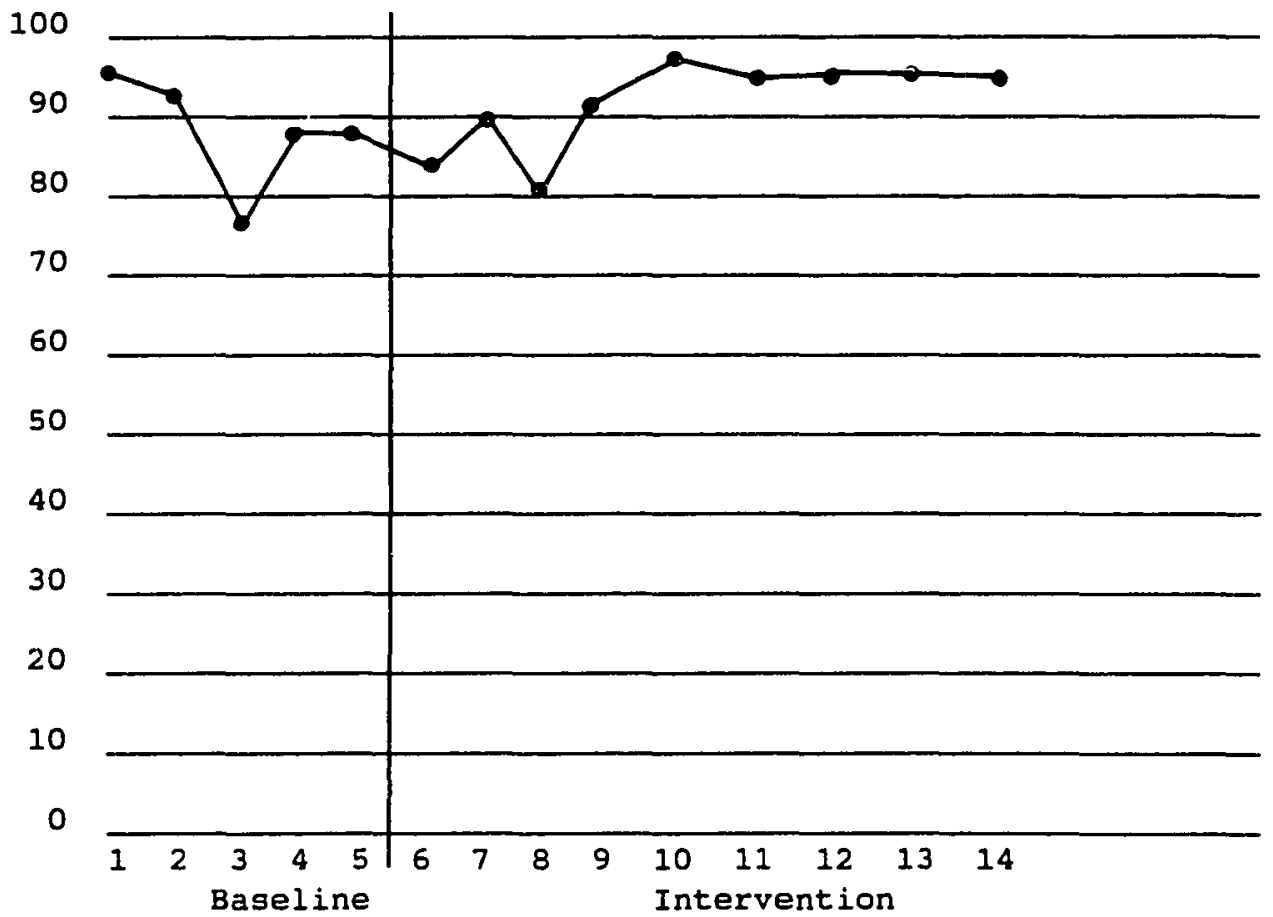

Eigure 5. Graphic representation of Jered's oral reading accuracy across two experimental phases. 


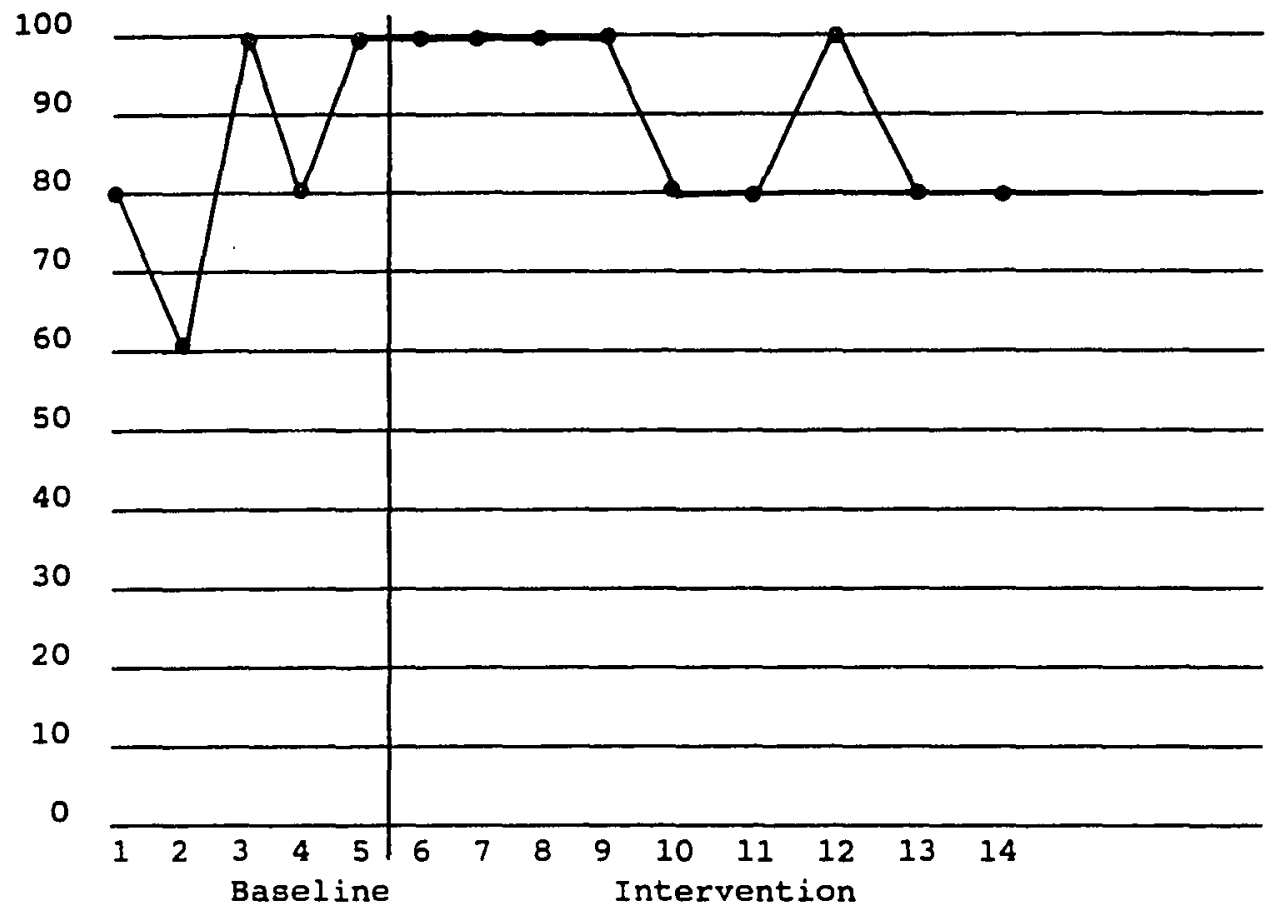

Fiqure 6. Graphic representation of Jered's silent reading comprehension across two experimental phases.

\section{Baseline Phase}

Jered demonstrated the most consistent performance on trials

three, four and five of his baseline phase. Rate ranged from 50 to 59 words per minute on these trials, accuracy from 778 to 878 , comprehension $80 \%$ to 1008 . Jered's rate and accuracy were elevated on his first two trials, as shown on Figures 4 and 5 . Comprehension was more consistent throughout, although depressed to 608 on trial two. Jered's mean scores for the five baseline trials were:
a. Rate of 62 w.p.m.;
b. Accuracy of 88.28 ;
c. Comprehension of $84 \%$. 


\section{Intervention Phase}

Jered's lowest reading rate of the intervention phase was 56 w.p.m. on trial eight: six words per minute less than his baseline mean. This subject had complained to the researcher about the material he was given for oral reading on the first eight trials, on grounds that the story was boring and he disliked it. An effort was made to substitute material having different content but the same level of difficulty. Due to this adjustment, the performance trend for trials 9 through 14 should be considered separately. Jered's highest rate, on trial 12, was 99 w.p.m. Material at the third level was used for trials 1 through 12 .

Because accuracy was $95 \%$ or more on trials 10,11 and 12 , the subject advanced to fourth grade material for the final two trials. The level of rate and accuracy remained stable for the final two trials, and did not appear to be affected by the level change. Jered's mean intervention rate of 83 w.p.m. represented a mean increase of 21 words per minute while the overlay was in use.

Oral reading accuracy ranged from a low of 818 (trial 8) to a high of 978 on trial 10. His mean intervention accuracy was 92.438 , compared to 88.28 during baseline. The researcher did not interpret this as a significant gain, given the changes in reading and extent of the difference.

Jered demonstrated a $100 \%$ correct response rate to comprehension questions on the first three intervention trials. He was given passages at the beginning fourth grade level, for silent reading, for the remainder of this phase. Responses were 808 or $100 \%$ correct on 
all trials employing the fourth grade comprehension material ( 9

through 14). His mean comprehension score for trials 9 through 14 was 86.67\%. This was slightly higher (2.67\%) than the baseline mean which represents silent reading comprehension of third grade material. Although this was a slight increase over the baseline mean, the trend was not decisive enough to conclude that use of the overlay improved silent reading comprehension for this subject.

\section{Conclusions}

Analysis of results from Jered's reading trials allowed the following conclusions:

1. The subject demonstrated a stable upward trend in rate of oral reading while the overlay was in use.

2. At the end of the intervention phase, this subject was able to comfortably read material at a slightly higher level of difficulty than was indicated at the beginning.

Reading Trial Results--Samantha

\section{Graphic Data Analysis}

Table 17 provides Samantha's numerical trial data, while Figures 7, 8 , and 9 show performance trends during baseline and intervention. Samantha used her prescribed combination of overlays for the intervention trials 6 through 14 . 
Table 17

Numerical Trial Data--Samantha

\begin{tabular}{lcccc}
\hline Date & Rate & Accuracy & Comprehension & $\frac{\text { Baseline }}{1 / 52}$ \\
\hline $2 / 5 / 93$ & 58 & 90 & 40 & 2 \\
$2 / 9 / 93$ & 51 & 85 & 40 & 3 \\
$2 / 10 / 93$ & 53 & 85 & 60 & 4 \\
$2 / 12 / 93$ & 61 & 88 & 80 & 5 \\
$2 / 17 / 93$ & 47 & & & \\
& & & & Intervention \\
& & 93 & 80 & 6 \\
$2 / 17 / 93$ & 56 & 89 & 60 & 7 \\
$2 / 24 / 93$ & 48 & 91 & 60 & 9 \\
$3 / 3 / 93$ & 54 & 84 & 40 & 10 \\
$3 / 10 / 93$ & 48 & 89 & 60 & 11 \\
$3 / 16 / 93$ & 59 & 87 & 60 & 12 \\
$3 / 31 / 93$ & 35 & 92 & 60 & 13 \\
$4 / 7 / 93$ & 71 & 93 & 70 & 14 \\
$4 / 14 / 93$ & 56 & 91 & 80 & \\
$4 / 21 / 93$ & 51 & & & \\
\hline
\end{tabular}

\section{Baseline Phase}

Samantha's reading rate was most similar for baseline trials 1,2 and 3 , ranging from 53 to 58 w.p.m. High and low extremes were demonstrated on trials 4 (61 w.p.m.) and 5 (47 w.p.m.). The first

three trials yielded the same score for correct response to comprehension questions: 408. Comprehension for trials 4 and 5 was higher, 608 and 808 respectively.

Baseline stability for accuracy was not achieved on the first three trials, but was at a similar level for trials 3 through 5 (see Table 17). This inconsistency in baseline data was recognized as a weakness in the trial data for all three subjects. 


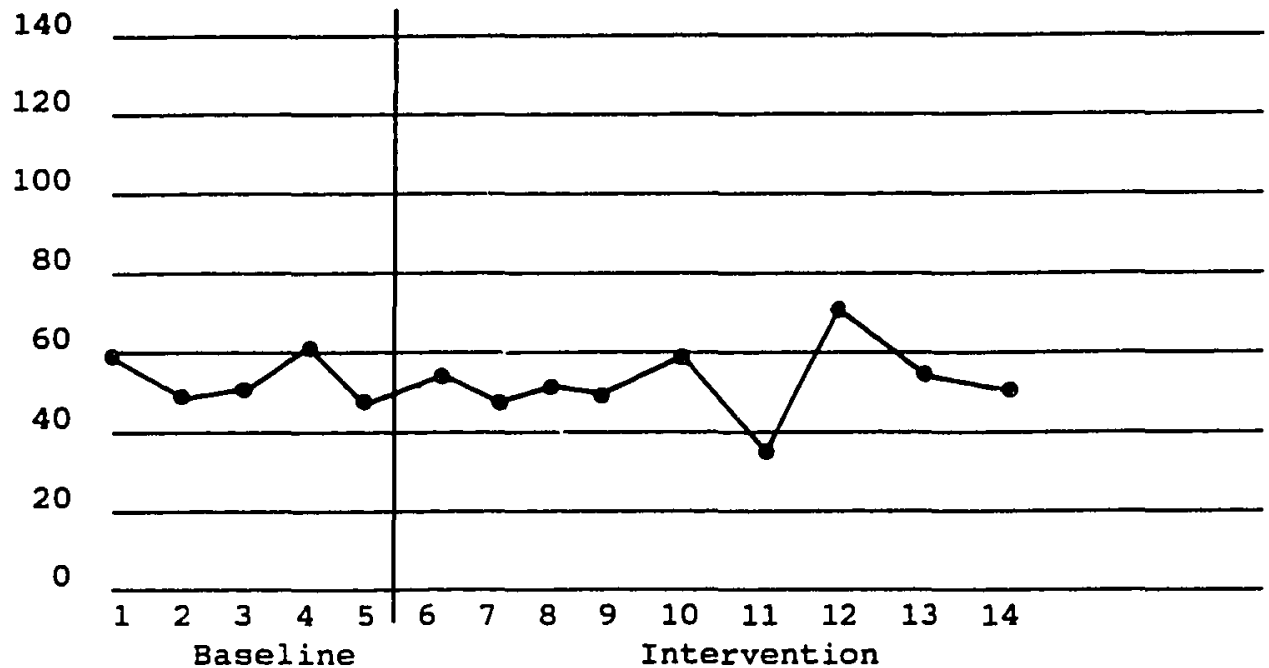

Figure 7. Graphic representation of Samantha's oral reading rate across two experimental phases.

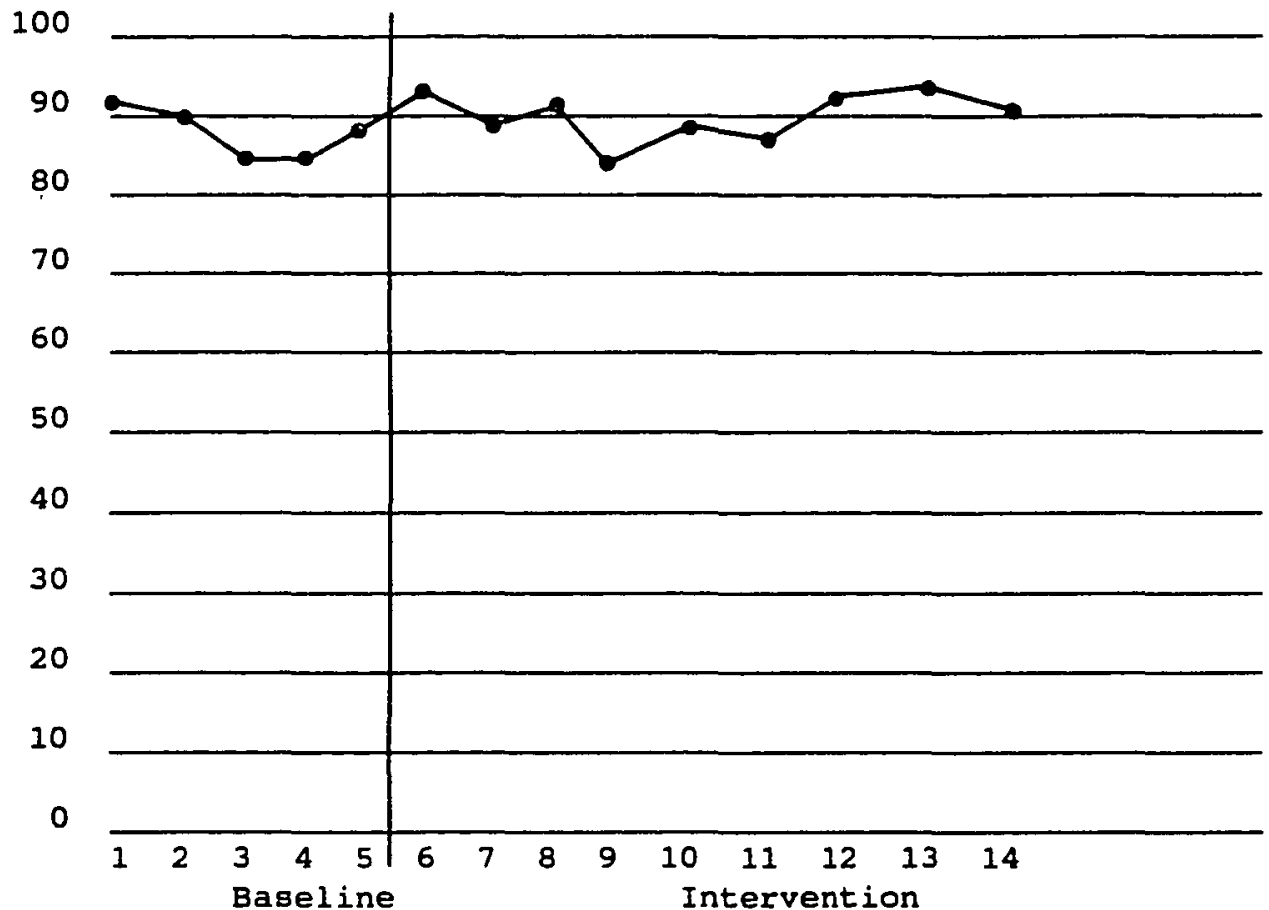

Figure 8. Graphic representation of Samantha's oral reading accuracy across two experimental phases. 


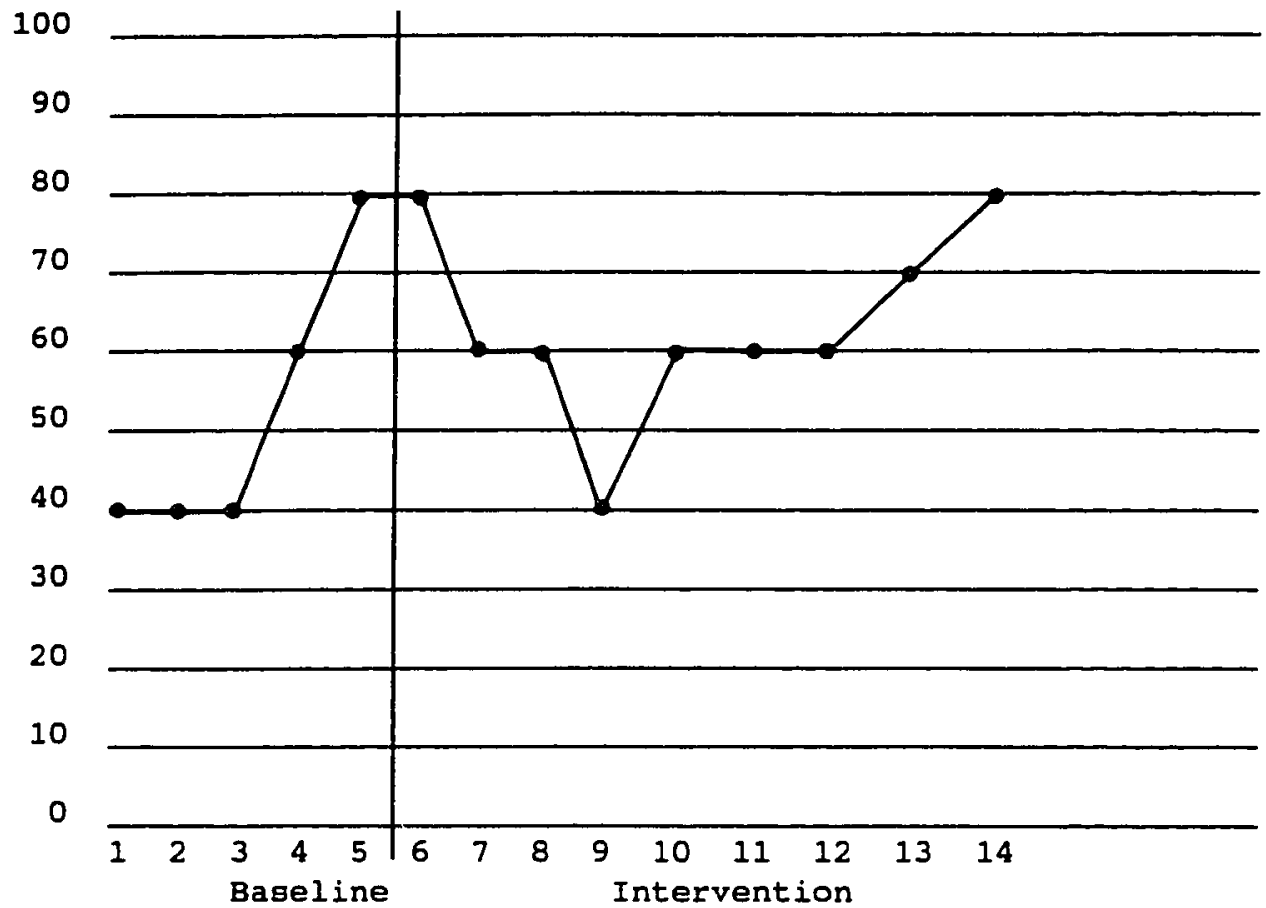

Figure 9. Graphic representation of Samantha's silent reading comprehension across two experimental phases.

Mean baseline scores for the three indicators were:

a. Rate of 54 w.p.m.;

b. Accuracy of $88 \%$;

c. Comprehension of 528 .

\section{Intervention Phage}

Samantha's reading rate varied from an extreme low of $35 \mathrm{w} \cdot \mathrm{p} . \mathrm{m}$. (trial 11) to an extreme high of 71 w.p.m. (trial 12). Samantha'B mean intervention rate of $53.14 \mathrm{w} \cdot \mathrm{p} . \mathrm{m}$. changed little from her baseline mean of 54 w.p.m.

Accuracy ranged form 848 (trial 9) to 938 (trials 6 and 13). The mean intervention accuracy was 92.298 , representing a slight but insignificant improvement from the bageline mean of $88 \%$. 
A positive change in Samantha's comprehension scores was more apparent than for the other two indicators. It must be cautiously interpreted, since results were in the same range (408 to 808 ) as during her baseline phase. The subject scored 408 on only one of the intervention trials, 608 on five trials, and 808 on two trials. Her score of 708 on trial 13 reflected a partially correct response to a fact recall question. The intervention mean for comprehension was 638, compared to a baseline mean of 528 .

\section{Conclusions}

Reading trial results suggested the following conclusions for this subject:

1. The trend for oral reading rate and accuracy was flat throughout baseline and intervention phases; intervention with overlays did not produce change in this subject's oral reading performance.

2. There was a weak upward trend in this subject's silent reading comprehension which must be interpreted as tentative.

Reading Trial Results--Melissa

\section{Graphic Data Analysis}

Table 18 presents the numerical results for this subject. Melissa's reading trial performance is graphically represented in Figures 10, 11 and 12. The trials were conducted in three phases: baseline (1 through 5), intervention (6 through 14 ), and post-intervention (15 and 16$)$. 
Table 18

Numerical Trial Data--Melissa

\begin{tabular}{lcccc}
\hline Date & Rate & Accuracy & Comprehengion & Baseline \\
$2 / 4 / 93$ & 45 & 80 & 80 & 1 \\
$2 / 9 / 93$ & 39 & 99 & 40 & 2 \\
$2 / 11 / 93$ & 44 & 97 & 40 & 3 \\
$2 / 16 / 93$ & 46 & 91 & 20 & 4 \\
$2 / 18 / 93$ & 33 & 88 & 20 & 5
\end{tabular}

Intervention

\begin{tabular}{lllrl}
$2 / 22 / 93$ & 45 & 97 & 60 & 6 \\
$3 / 3 / 93$ & 37 & 81 & 60 & 7 \\
$3 / 8 / 93$ & 47 & 91 & 80 & 8 \\
$3 / 15 / 93$ & 36 & 86 & 100 & 9 \\
\hline & & & & \\
$3 / 29 / 93$ & 32 & 91 & 80 & 10 \\
$4 / 8 / 93$ & 42 & 93 & 80 & 11 \\
$4 / 12 / 93$ & 53 & 95 & 80 & 12 \\
$4 / 22 / 93$ & 59 & 98 & 60 & 13 \\
$4 / 26 / 93$ & 74 & & 80 & 14 \\
& & & & Post \\
$4 / 19 / 93$ & 46 & 92 & 100 & 15 \\
$4 / 27 / 93$ & 46 & 92 & 80 & 16
\end{tabular}

Melissa obtained her prescription reading glasses between trials 9 and 10, as indicated by a horizontal line in Table 18. This effectively divided her intervention phase into two parts, for which different trends were observed. Part one, trials 6 through 9, involved intervention with the green overlay only. The second part, trials 10 through 14, involved the combined use of overlay and reading glasses. Melissa used only the overlay for one of the post trials (15), the glasses only for the other post trial (16). 


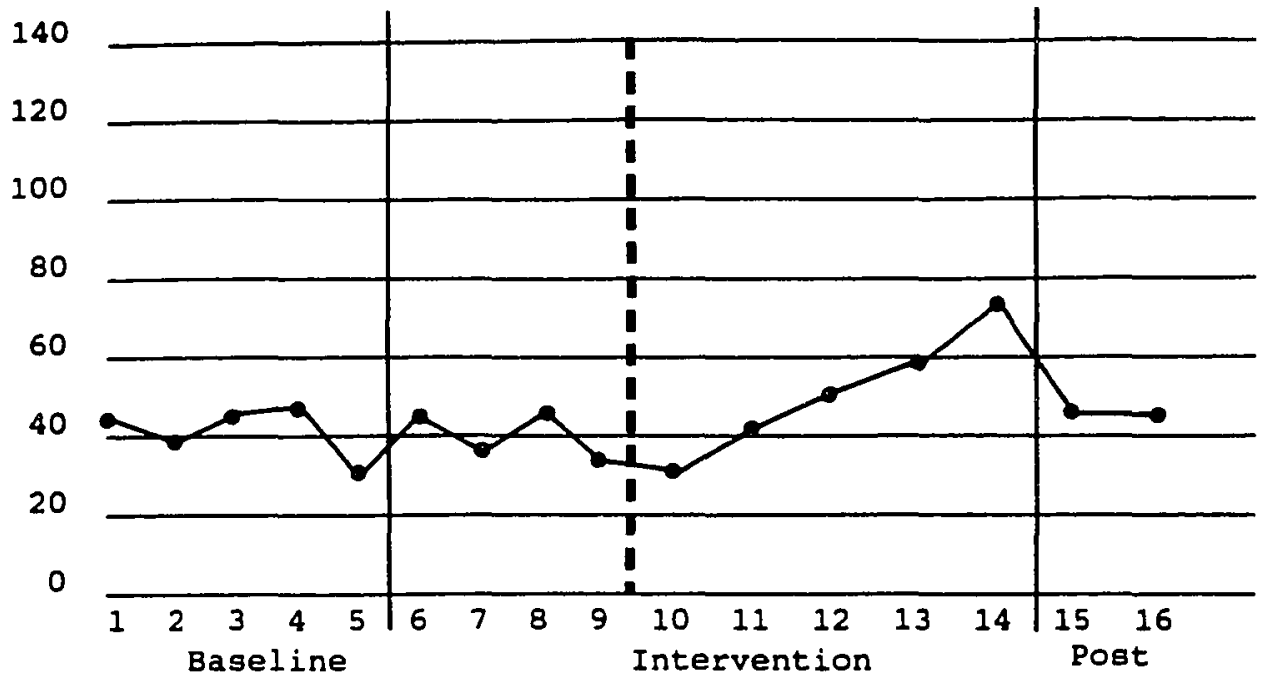

Figure 10. Graphic representation of Melissa's oral reading rate across three experimental phases. Broken line indicateg addition of glasses for Figures 10,11 , and 12 .

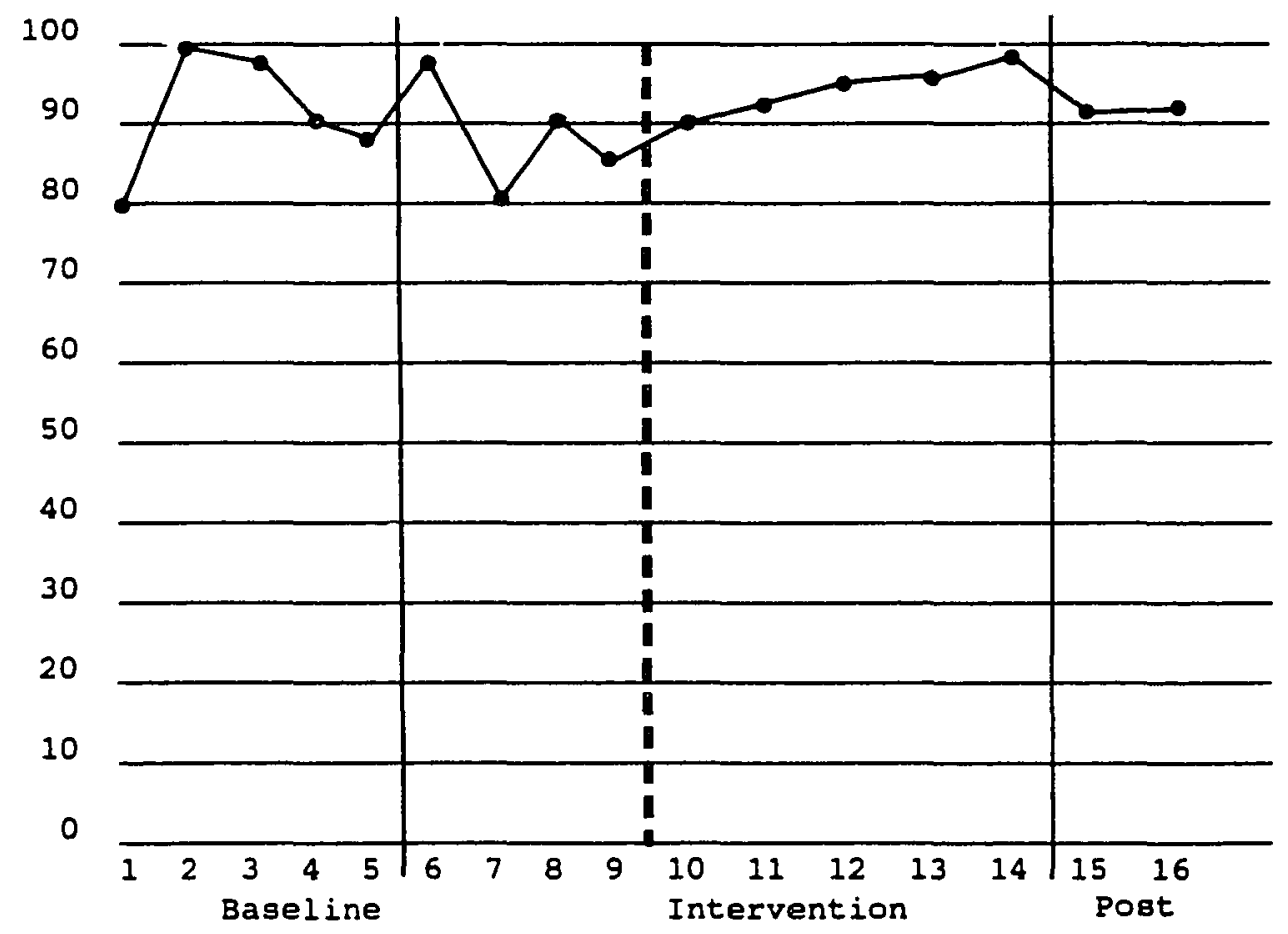

Fiqure 11. Graphic representation of Melissa's oral reading accuracy across three experimental phases. 


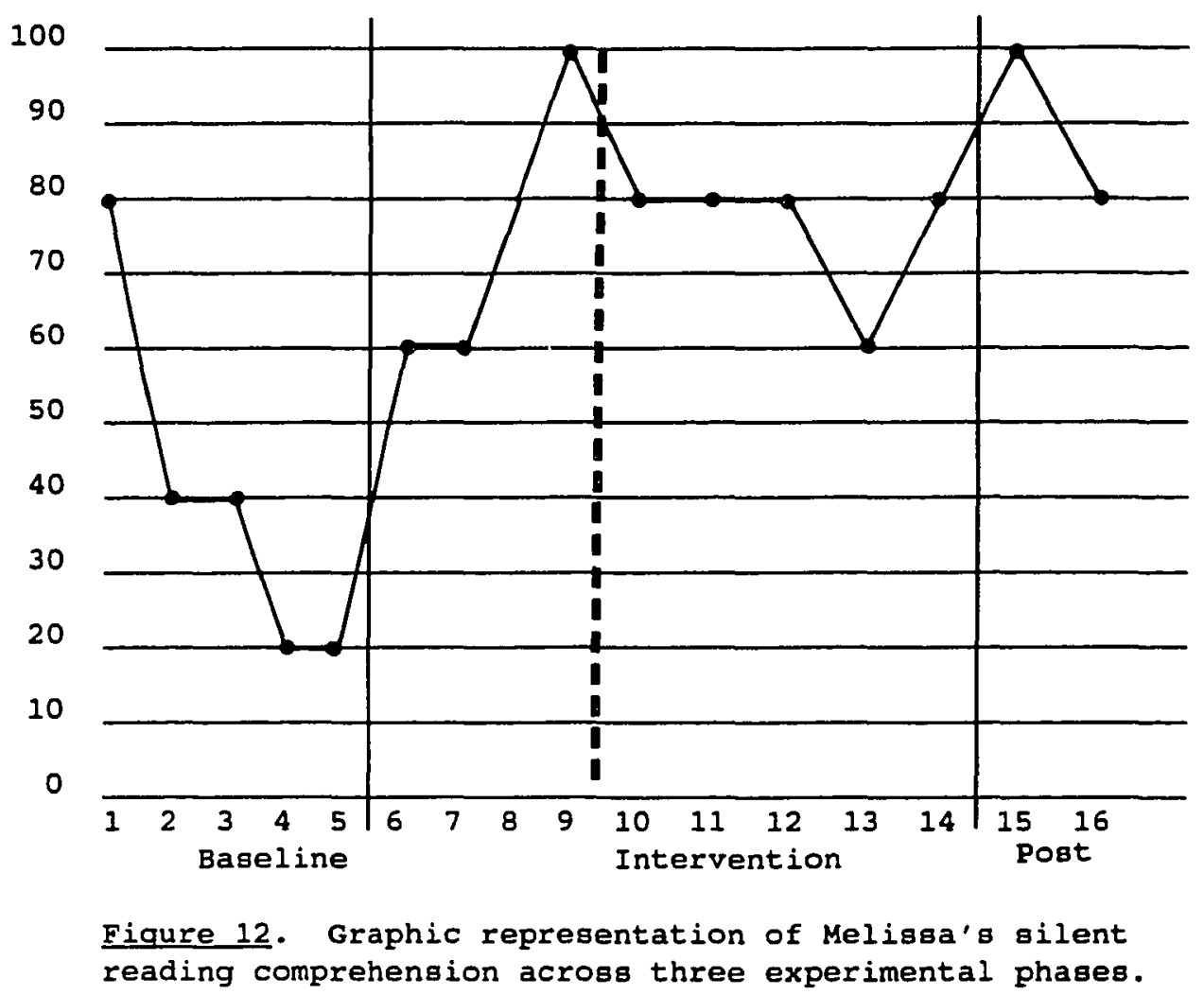

\section{Baseline Phase}

For three of her baseline trials $(1,3$, and 4), Melissa

demonstrated a similar rate of 45 to $46 \mathrm{w} . \mathrm{p} . \mathrm{m}$. Her rate was at a

lower level on trials 2 (39 w.p.m.) and 5 (33 w.p.m.). Melissa's oral

reading accuracy was unstable throughout the baseline phase.

Melissa's first trial score for silent reading comprehension was 808, which was uncharacteristic of her other baseline scores. The percentage of correct responses was 408 on trials 2 and 3 , 208 on

trials 4 and 5. Melissa's mean scores for the three indicators were:
a. Rate of 41.4 w.p.m.;
b. Accuracy of 918 ;
c. Comprehension of 408 . 


\section{Intervention Phase}

Separate trends for rate and accuracy were demonstrated for subphases of Melissa's intervention. The subject used a green overlay only for the first of these subphases, trials 6 through 9. Her rate on these four trials fluctuated in an up-and-down pattern, from a low of 36 to a high of 47 words per minute. The mean rate for these four trials was 41.35 w.p.m., which represented no significant change from the baseline rate.

Accuracy on 6 through 9 fluctuated in a similar alternating pattern, ranging from 818 to 978 . Higher scores in rate on these four trials corresponded to higher scores in accuracy. The mean accuracy of 89.758 for this period was down slightly from 918 during baseline.

A distinctly upward trend emerged for trials 10 through 14, when the overlay was combined with glasses. Rate began at an extreme low of $32 \mathrm{w.p.m}$. on trial 10, then climbed steadily and progressively to a high of 74 w.p.m. on trial 14. The subject demonstrated a similar progressive increase in accuracy, which progressed from 918 on trial 10 to 988 on trial 14. Separate computation of means for rate and accuracy on trials 10 through 14 produced the following:

1. Mean rate of 52 w.p.m., representing an increase of 10.6 from the baseline mean of 41.4 w.p.m.

2. Mean accuracy of 94.68 , representing a negligible increase of 2.68 from the baseline mean of 918 .

Melissa's trial result for silent reading comprehension revealed a pattern distinctly different than for rate and accuracy. An immediate increase was demonstrated at the beginning of the nine-trial 
intervention, and held constant through trial 14. The percentage of correct responses was 808 on five trials, 608 on three trials, and 1008 on one trial for an intervention mean of 75.568 . There was a negligible difference between a mean for the overlay-only subphase (758) and the overlay/glasses subphase (76\%). Melissa's mean increase for comprehension was 35.568 from the baseline mean of 408 .

\section{Post-Intervention Trials}

One post-intervention trial was conducted under each of two conditions:

1. The overlay was used without the glasses (trial 15).

2. The glasses were used without the overlay (trial 16).

Melissa demonstrated identical performance in rate and accuracy for both of these trials. Her rate of $46 \mathrm{w} . \mathrm{p} . \mathrm{m}$. indicated a reversion to the baseline level. The accuracy of 928 was more similar to baseline performance than to the level of her final three intervention trials when accuracy was at the mastery level of 958 and above.

Melissa's comprehension scores on the post-intervention trials were consistent with her intervention level of performance. The percentage of correct responses was $100 \%$ for the overlay-only trial, 808 for the glasses-only trial.

\section{Conclusions}

Analysis of Melissa's reading trial results ouggested four conclusions:

1. The performance trend for rate and accuracy was flat through five baseline trials and four trials with the overlay; 
intervention with the overlay alone did not result in a change for thege indicators.

2. An upward trend for oral reading rate was demonstrated when the prescription glasses were combined with the overlay.

3. The upward trend for oral reading rate reverted when the overlay or glasses were used singly; performance was enhanced only when both were used.

4. Use of the overlay alone resulted in a significant increase in silent reading comprehension on the intervention trials; this improvement did not accelerate when glasses were added.

\section{Procedural Adjustments}

\section{Taping of Oral Reading}

Subjects were not taped for any procedures except the two-minute timed trial. Timed trials of all four were taped consistently throughout the baseline phase. This was to allow the researcher to become familiar with the articulation and reading patterns of each subject, and to determine whether or not rate and accuracy could be measured without the opportunity to replay. Jeremy was taped throughout the study due to two characteristics. The first was his incomplete articulation of some words, due to a sinus condition that became apparent as he read orally. The second factor involved his error pattern of skipping lines or phrases. Both factors made replay necessary for accurate measurement. 
The other subjects articulated clearly and maintained rates that were not too rapid for simultaneous error notations. They were questioned and observed for possible taping effects, of which none were claimed or detected for Samantha and Melissa. The two female subjects were taped throughout the study.

Jered stated that the tape made him nervous. His errors were mainly single word omissions and substitutions. This factor, plus the previously mentioned ones of rate and articulation, made accurate measurement without taping possible for this subject. Following trial 9. Jered was taped intermittently. Jered's performance trend was consistent on trials 10 through 14 , and did not indicate a taping effect.

\section{Reading Material}

There were two primary requirements for reading material: (a) it must be at the correct level of difficulty for the subject, and (b) it should be of sufficient interest that the subject not demonstrate aversion. Material adjustments were guided by trial results for accuracy, and by observation of each subject's reaction.

Jered was the only subject who expressed dislike of his trial material. This was noted on the seventh and eighth trial, the eighth being a low performance point for Jered. The subject stated that he did enjoy the material from the Rally! series (Simons, 1979), he was given for warm-up. Material from the Rally! serieg was matched to the difficulty level of the discontinued book and given to Jered for trials 9 through 12. The performance trend maintained a consistent 
direction on these four trials and did not fluctuate significantly as it did on the first three intervention trials (see Figures 5 and 6 ). Jered was given a Rally! story at a slightly higher level of difficulty for trials 13 and 14, due to his demonstrated accuracy on the previous three.

As stated previously, subjects could be advanced one level in New Practice Reader (Anderson et al., 1978) if they responded 1008 correct to comprehension questions on three consecutive trials. Jered was again the only subject who met this criterion. He was advanced from levels "B" (beginning third grade level) to "C" (beginning fourth grade level) starting with trial 9. He maintained a consistent performance in level " $C$ " of 808 or above on trials 9 through 14, indicating that this level was appropriate for silent reading comprehension. Jered did not advance to oral reading material at the beginning fourth grade level until trial 13.

Post-Test Results

Portland Achievement Levels Test

Each subject used prescribed overlay(s) for reading the test booklet during the spring 1993 administration of the Portland Achievement Levels Test (PALT). The reading subtest of the PALT required multiple choice responses, with choices marked onto a separate bubble sheet. Subjects also used bubble sheets which had been prepared on paper of their preferred tints. Table 19 compares subjects' PALT reading scores of spring 1992 and spring 1993. Each subject's net gain is also compared to the 
District's mean gain for students who were in the third/fourth or fourth/fifth grades in springs 1991 and 1992. Melissa's gain is for an 18 month period, Fall 1991 to spring 1992. Her spring 1992 score was invalid. The District's mean gain given for Melissa's comparison is also for an 18 month period.

Table 19

PALT Reading Results

\begin{tabular}{|c|c|c|c|c|}
\hline Subject & $\begin{array}{c}\text { Spring } \\
1992\end{array}$ & $\begin{array}{c}\text { Spring } \\
1993\end{array}$ & Gain & $\begin{array}{c}\text { District } \\
\text { mean gain } \\
\text { for } \\
\text { same- } \\
\text { grade } \\
\text { peers, } \\
1991-1992\end{array}$ \\
\hline Jeremy & 170 & 175 & 5 & 9.9 \\
\hline Jered & 192 & 198 & 6 & 6.3 \\
\hline Samantha & 172 & 176 & 4 & 6.3 \\
\hline Melisga & $\begin{array}{c}\text { Invalid } \\
\text { Fal1 '91 } \\
171\end{array}$ & 179 & 8 & 15.3 \\
\hline
\end{tabular}

It is recognized that multiple influences, in addition to spectral modification, could have affected the skill development of these subjects during a full year's time. Growth on the PALT could not be attributed to a short-term intervention. Spring 1993 scores for all subjects were classified as low, and their gains were less than comparable District mean gains (excepting Jered). Despite these limitations, the use of overlays and tinted answer sheets were modifications that:

1. Were workable in the testing situation;

2. Were acceptable to parents, teachers, and subjects themselves. 
Word Recognition

The San Diego Quick Asgessment (1977) and slosson (1963) Oral Reading tests were readministered after intervention, with subjects using overlays to read the word lists. Results are summarized in Table 20 .

Table 20

Word Recognition Post-Test Assessment

\begin{tabular}{|c|c|c|c|c|}
\hline Subject & $\begin{array}{c}\text { Grade } \\
\text { Equivalent } \\
1 / 93\end{array}$ & $\begin{array}{c}\text { Grade } \\
\text { Equivalent } \\
4 / 93\end{array}$ & Gain & $\begin{array}{c}\text { Previous } \\
\text { Annual } \\
\text { Gain }\end{array}$ \\
\hline Jeremy & 2.2 & 2.7 & .5 & .3 \\
\hline Jered & 3.1 & 3.6 & .5 & .5 \\
\hline Samantha & 2.0 & 3.1 & 1.1 & .3 \\
\hline Melissa & 1.5 & 1.9 & .4 & $<.3$ \\
\hline
\end{tabular}

The word recognition gair for each subject is compared to the average annual gain that was extrapolated from special education assessment histories. This comparison is limited by the fact that this average annual gain represents total reading skills, not merely the recognition of words in isolation. Post-testing did indicate that each subject's gain in word recognition exceeded previous annual gains in total reading skills.

\section{Oral Reading}

The Brigance (1976) oral Reading subtest was also readministered following intervention. Each subject demonstrated the ability to read a sample passage that was classified as one instructional grade level above the level of difficulty at which they had begun baseline 
trials. Jered and Melissa read their post-test passage at 948 accuracy, which was slightly below the mastery criterion of 958 . However, each read at the previous rate (Melissa) or at an accelerated rate (Jered) and answered five literal comprehension questions at $100 \%$ accuracy. Each subject was given a comprehension probe in order to confirm mastery of the post-test passage. Table 21 provides comparative results of the Brigance assessment.

Table 21

Oral Reading Post-Test Assessment

\begin{tabular}{|c|c|c|c|c|c|}
\hline Date & $\begin{array}{c}\text { Mastery } \\
\text { Level }\end{array}$ & Jeremy & Jered & Samantha & Melisga \\
\hline $1 / 93$ & $\begin{array}{c}\text { Passage } \\
\text { Level }\end{array}$ & $\begin{array}{c}\text { Grade } \\
2 \\
\end{array}$ & $\begin{array}{c}\text { Grade } \\
3 \\
\end{array}$ & $\begin{array}{c}\text { Grade } \\
2 \\
\end{array}$ & $\begin{array}{c}\text { Grade } \\
1 \\
\end{array}$ \\
\hline $1 / 93$ & Rate & 106 & 86 & 54 & 56 \\
\hline $1 / 93$ & Accuracy & 938 & 958 & 1008 & $85 \%$ \\
\hline $4 / 93$ & $\begin{array}{c}\text { Passage } \\
\text { Level }\end{array}$ & $\begin{array}{c}\text { Grade } \\
3\end{array}$ & $\begin{array}{c}\text { Grade } \\
4\end{array}$ & $\begin{array}{c}\text { Grade } \\
3\end{array}$ & $\begin{array}{c}\text { Grade } \\
2\end{array}$ \\
\hline $4 / 93$ & Rate & 84 & 94 & 70 & 56 \\
\hline $4 / 93$ & Accuracy & $98 \%$ & 948 & 998 & 948 \\
\hline $4 / 93$ & $\begin{array}{l}\text { Compre- } \\
\text { hension }\end{array}$ & 808 & 1008 & 808 & 1008 \\
\hline
\end{tabular}

Interview and Observational Data

Observations of each subject'g reading behavior and work completion patterns were enlisted from teachers once during baseline, and regularly throughout the intervention phase. This information was augmented by the researcher's recorded observations, structured 
subject-researcher interviews, and parent observations of reading behavior at home.

Summaries of interview and observational data relevant to the use of colored paper, observed changes in reading behavior, and personal history factors are included here. Appendix E contains additional information on each subject's adaptation to the experimental procedures.

\section{Use of Colored Paper}

Teachers in the mainstream classrooms reported that each subject used colored paper consistently and without teacher prompting. The researcher concluded that subjects demonstrated a more decisive preference for colored paper than for their overlays, due to temporary lapses in the independent use of overlays in the classroom. (Appendix E includes patterns of overlay use for each subject.)

Melissa was the only subject who used colored paper regularly in the resource room as well as in the mainstream setting. This was apparently due more to program characteristics than to student preference. Jeremy's resource teacher explained that direct oral instruction and group interaction were more routine in that setting than writing. Jered received assistance with classroom assignments in the resource room, and he was observed bringing uncompleted work on blue paper. Samantha was not required to attend the resource room on a regular basis.

Each subject was given lined paper in a tint similar to the prescribed overlay, plus some in a neutral tint. Jeremy and Jered, 


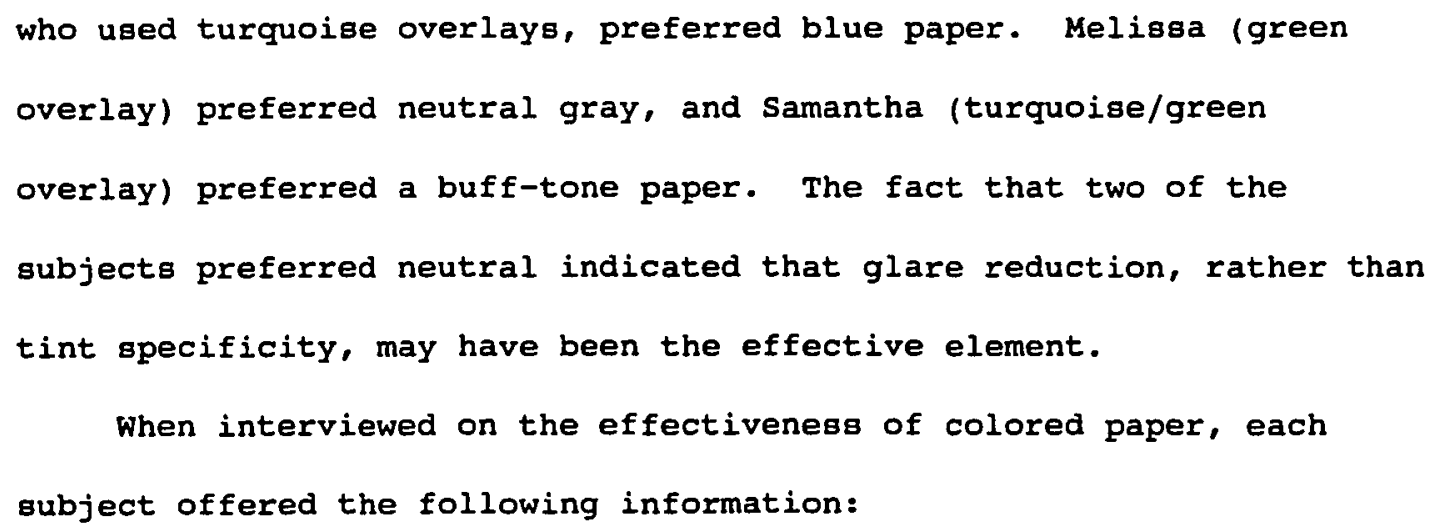

1. Jeremy: It was not necessary to erase as much with blue paper. It was also easier to read what he had written.

2. Jered: Blue paper was easier to look at, and made it easier to stay on the lines.

3. Samantha: Lines appeared to jiggle on white paper, but not on colored. She also liked colored paper because other students did not tease her about using it. (Samantha did report a small amount of teasing in regard to her overlay use.)

4. Melissa: Gray paper was easier to look at and made it a little easier to line numbers up for math. It was still hard for her to read numbers, however.

Teachers provided mixed reports on the effectiveness of the tinted paper intervention. Jeremy's classroom teacher reported that his quality of work continued to be inconsistent; it appeared to reflect his state of mind, and the influence of distracting elements. Jered's fifth grade teacher regarded the preference for blue paper as psychological, and not contributing to observable change. Melissa's 
mainstream teacher also felt that the tinted paper was not a critical intervention.

Melisga was rotated to another teacher's classroom for math. He offered decisive praise of the gray paper, stating that the neatnesg of Melissa's work had improved during the weeks of this study. Melissa's resource teacher also provided a positive assessment, stating that it appeared to help the subject focus on her work. An endorsement of tinted paper was also given by Samantha's mainstream teacher. She reported that it seemed to positively affect both the quality of written work and the extent of assignment completion.

\section{Observed Performance Changes:} Jeremy

Information addressing performance changes was supplied by the "Teacher Progress Check" forms, initial and final teacher interviews, and parent observation. Jeremy's fourth grade teacher completed four check sheets during the intervention weeks. These indicated no observable improvement in the rate and accuracy of oral reading when he used the overlay.

This teacher did not provide a baseline estimation of his percentage of time on task for silent reading, explaining that he was in the resource room during the silent reading period. Two of the check sheets did indicate an assessment of this factor, however. He was observed as on task 75-1008 on one week, which decreased to 50-758 during one of the weeks when general deterioration of behavior and attitude was noted. This "deterioration" was due to external personal history factors, which are discussed in the next section. 
The mainstream teacher provided a baseline estimate of 508 completion for reading-based written assignments. She stated that he would willingly begin all assigrments, but failed to complete half of them. At the end of the study she reported that he was completing all of his work when present. However, a combination of factors such as family events, vision therapy, and special services were interrupting his classroom routine to a problematic extent.

The purpose of the reading log was to guage the extent of reading done outside the school setting. Logs and parent reports were intended to indicate changes in independent reading behavior. This subject returned one reading log on which he had recorded his own outside reading. It did indicate daily reading activity, although he did not attempt to show the amount read. Jeremy's stepmother reported that all of his outside reading was accomplished during the daily homework time. No additional log sheets were returned, although Jeremy expressed remorge that he had forgotten them. Both teachers stated that getting information and material from school to home and back was often problematic.

During the concluding parent interview, Jeremy's stepmother cited a noticeable and positive change in his attitude toward school since the early weeks of the year. He appeared to be less frustrated by school work, and generally better able to cope with school requirements. 
Observed Performance Changes:

Jered

The mainstream teacher provided a baseline assessment that Jered was on task 508 or less during silent reading activities. He did complete all written assignments, but the quality was consistently below grade level.

Jered's teacher completed five observational check sheets during intervention. It was noted that the percentage of time on task continued to be 508 or less until the week of the twelfth trial. It was then observed as 50-75\%. It was also noted that the quality of Jered's written work had increased at that point. The teacher attributed this to the year-long effort to communicate high expectations and to steady parent support. In other words, it had taken Jered most of the year to begin achieving at the level of his potential, and improvements were not attributed to a single intervention such as the overlay or the blue paper.

Improvement in Jered's oral reading with the overlay was not observed by teachers in the fifth grade classroom or the resource room. His mother said it was difficult to be objective in regard to an increase in the amount of reading done at home, due to variations in the family schedule. Jered himself did not return any reading log sheets, so there was no documentation of outside reading activity. The parent stated in the concluding interview that he would no longer "fight" reading as he had done prior to the study. since beginning to use the adaptations of dimmer lights, tinted paper, and the overlay, Jered's attitude toward reading had become more positive. 
Observed Performance Changeg:

Samantha

The mainstream teacher's baseline assessment was that Samantha remained on task 508 or less during silent reading activities. This changed to 50-758 during the intervention phase. Her baseline level of work completion was also noted as 508 or less. Work completion was seen as 50-758 during intervention, when assignments were completed on colored paper. Samantha's general productivity fell to its baseline level during the week of trial 7 , when the teacher had observed a heightened stress level that was attributed to external influences. There was teacher-observed improvement in this subject's oral reading during the first three weeks of overlay use, described as increased ease and confidence. The use of text printed on buff toned paper was noted as producing similar improvement, whether or not the overlays were added. This change was seen as sustained throughout intervention, but not as increasing beyond the initial period.

Samantha's mother reported increased reading activity at home once the overlays were introduced. The subject provided some self report of outside reading by returning two reading logs (weeks of trials 8 and 9). These indicated daily practice from two books. Each book had been practiced from consistently for one week. The amount read varied on week 8: one or two pages on three days, 10 pages on one day, 25 pages or more on four days. The log from week 9 indicated that she had read 10 pages daily. 
Observed Performance Changes:

Melissa

The mainstream teacher rated Melisвa's on-task behavior and work completion as 75-1008 throughout the study period. There was no change from baseline to intervention. If this studeist did not complete an assignment, it was usually because she was absent. The resource teacher would probably have assessed Melissa as 1008 on task, given the comments that were made about her work habits in that setting.

Improvement in oral reading upon introduction of the overlay was noted by the maingtream teacher. The improvement appeared to be enhanced by the addition of the glasses. This observation was qualified by the statement that there were few opportunities to observe a single gtudent in a large group setting. The resource teacher did not report observable changes in Melissa's oral reading. This should be considered in light of the oral reading trials, which did not assume an upward trend until the final three weeks. Melissa's mother reported a definite increase in reading engagement during the intervention period. She had begun to read voluntarily, without parent direction. She was also able to maintain her interest in a book or story, and would sometimes want to continue reading after bedtime. Prior to getting overlay and glasses, which were used at home, Melissa would read for short periods and lose interest readily. Talking to family members about what she had read was also noted as a new development. 


\begin{abstract}
Melissa returned two reading logs, one during baseline and one when she reported for the eighth trial. Despite Melissa's demonstrated work habits, she did not demonstrate the ability to regularly maintain and submit a $\log$ of outside reading. The baseline log indicated that she had read the same book on four nights, five pages each night. On a fifth night, she read 14 pages from something she identified as her favorite book. The $\log$ returned on the eighth week indicated nightly reading of 4 to 13 pages, averaging nine pages per night. This corroborated the parent's report of increased independent reading.
\end{abstract}

\title{
Personal History Factors
}

Teachers and subjects were interviewed for information on peer responses (to overlays and colored paper), and on-going reading instruction. These variables, operating within the school environment, could potentially affect subjects' independent practice with overlays and reading performance.

The subjects themselves revealed little about external influences that affected their emotional stability and/or adjustment to school. Teachers provided insight into these factors. There were temporary influences that affected the overall school performance of Jeremy, Samantha, and Melissa. These are discussed below as external influences. 


\section{Influences Within School Environment}

On-going reading instruction was an environmental variable which could have affected subject performance on both reading trials and post-testing. However, subjects and teachers provided little evidence that on-going instruction affected performance significantly during the weeks of this study.

A comparison of the learning objectives, specialized instruction, and classroom reading activities of the four subjecis is attached as Appendix F. The learning objectives on Individualized Educational Plans, and in the mainstream classroom, were similar for all four. Reading activities presented in the mainstream classrooms were also similar, and included oral reading, discussion, book reports, and work involving comprehension strategies. It is probable that materials and strategies presented in the regular classroom were at or near grade level, whereas the subjects were significantly below grade level in reading skills.

The most gignificant instructional variation was in the area of special education. Two of the four subjects (Jeremy and Melissa) received regular reading instruction, in the resource room, that was geared to their level. Only Melissa used her overlay and colored paper in that setting. Jeremy and his resource teacher reported an emphasis on group discussion and comprehension strategies during the time of this study. This could not have accounted for the most significant change in Jeremy's performance: a decrease in repetitions and omissions, resulting in improved accuracy. 
Melissa worked directly on word recognition skills and oral reading in the resource room. It is possible that her demonstrated performance changes, especially on the post-test, could have been partly due to on-going instruction. Instructional effect would be an unlikely explanation for the change in comprehension scores, or for the changes accompanying the glasees-overlay combination.

Jered and Samantha did not receive direct reading instruction in the special education setting. Given the fact that they were both significantly below grade level, it is unlikely that mainstream instruction could have been the significant contributor to the changes they did demonstrate.

Peer response was an environmental variable having the potential to affect the subjects' independent use of overlays and colored paper. There was no evidence from either male subject, or from their teachers, that this was an issue. Jeremy's experience with peer involvement is discussed in the Chapter $V$ section "Experimenter Effect." Jered's fifth grade teacher demonstrated precise classroom management, and maintained a strictly enforced "no put-down" policy. This teacher publicly acknowledged the use of overlays, glasses, and any aвsistive device as positive.

Samantha reported teasing from peers during two subject interviews. The teacher reported that Samantha herself engaged in derisive behavior in some situations; this was attributed to her low self esteem. The teacher was not aware of teasing directed toward Samantha's use of overlays. She observed that a few peers seemed intrigued with Samantha's overlays and asked to borrow them. 
Peer group reaction to Melissa's use of the overlay and the glasses was a more significant factor for her than for the other subjects. The students in her fourth grade class were described by the resource teacher as the "worst in the building" for denegrating behavior. This problem was also acknowledged by the mainstream teacher. Melissa reported that she was teased, mostly by boys, when she first got both the overlay and the glasses. This was a complaint until the last four weeks of the study. A gradual decline in the subject's independent use of both overlay and glasses was documented as teacher observation, and may have been attributable to negative peer reaction. Another possible explanation is that Melissa sought teacher intervention as attention and support.

Melissa reported getting some positive reinforcement from female peers. This was in the form of compliments on the appearance of her glasses, and one friend's desire to borrow and use an extra overlay.

\section{External Influences}

There were influences beyond the school environment that affected the overall school performance of two subjects: Jeremy and Samantha. In Jeremy's case, the mainstream teacher reported a negative change in behavior and attitude during the sixth and seventh week of intervention (trials 11 and 12). Uncharacteristic behaviors included leaving the classroom without permission, submitting papers of deteriorating quality, and associating with peers who demonstrated behavior problems. Through consultation with the stepmother and school counselor, it was determined that Jeremy was emotionally upset 
over developments between his natural mother and the brother who remained in her home. Jeremy was able to resolve this emotional gtress, given help from his teachers and the counselor. His behavior had normalized by the eighth week.

For trial 12, Jeremy's reading rate was slower than four of his baseline trials and all other intervention trials (Figure 1). Accuracy was slightly depressed on that trial (Figure 2). This was, however, one of two occasions when he scored $100 \%$ on the comprehension exercise (Figure 3). A possible explanation is that the subject was aware of his stress level, and was being careful.

Samantha presented the most troublesome environmental issues, and these surfaced during the study. To this researcher's knowledge, the chief problem with the home environment involved a parent (father) who did not reside in the home. Samantha's parents had been divorced for several years. There was evidence of abusive behavior from the absent parent, whose continuing efforts to contact the home were at issue. Intervention by the school counselor had revealed that Samantha's gelf-confessed reason for being truant from school on some days was to protect her mother from possible harm.

During the seventh trial week, the classroom teacher observed that samantha appeared to be troubled and distracted. For the following two weeks the subject did demonstrate behavior problems in the classroom and considerable task avoidance. Samantha was absent on the morning of the ninth trial day. An effort had been made to contact the home, but the phone had been disconnected. Samantha arrived at school in time for her reading trial; during her interview 
she explained to the researcher that the phone had been changed to prevent the father from calling.

Samantha did not demonstrate recalcitrant behavior or overt distress to the researcher. However, her trial performance on trials 7 and 9 was comparatively low. The only intervention trial that produced poorer results than 7 and 9 was trial 11, which was conducted following the spring break. Prior to the break, samantha had told the researcher that she expected to see her father. It is possible that unsettling events contributed to Samantha's low performance on trials 7,9 and 11 .

\section{Generalizations Based on Interview and Observations}

Synthesis of the information derived from observations and interviews has resulted in the researcher's projection of the following points.

1. Performance changes that were demonstrated in reading trails were not, in all cases, observable to teachers.

2. There was no reliable correlation between changes that were observed by teachers and demonstrated improvements on reading trials. For example, Samantha's teacher observed improvements that were not demonstrated in her trials. Improvements that were demonstrated by Jeremy and Jered were not noticed by their teachers.

3. Parents attested to more positive change in reading behavior--which they attributed to spectral modification techniques--than did teachers. 
4. During the course of this study, each teacher documented some degree of positive change in on-task behavior and work completion for each subject.

5. These subjects did not demonstrate the organizational skills and follow-through necessary for the reading log procedure; undeveloped organizational skills were also cited by teachers of Jeremy and Jered as interfering with the management of overlays.

6. Subjects used colored paper more independently and consistently than overlays.

7. There was no evidence that on-going instruction had a significant impact on performance, for any of the subjects, during the course of this study.

8. There was evidence that personal history factors affected reading trial performance for two subjects; however, the effects were temporary. 


\section{CHAPTER V}

\section{Discussion}

This study was intended to address two primary questions, and to do so in the school setting from a practitioner's point of view. The first (and primary) inquiry probed the extent and direction of change in the reading performance of four subjects who used colored transparent overlays consistently for a nine-week period. Reading performance, indicated as oral rate, oral accuracy, and silent comprehension, was assessed at weekly intervals. Subjects read orally and silently from materials that were available and in use in Portland schools, and care was taken to select materials at the instructional reading level of each subject. The experimental intervention therefore involved reading tasks that were familiar to subjects and commonly observed by teachers.

The reading trial process indicated measurable performance changes for three subjects as they used transparent colored overlays. Variance in the decisiveness and pattern of these changes was considerable, and apparently dependent on intrasubject characteristics. An additional finding was that the optometric diagnosis and treatment for two subjects le.g. vision therapy and glasses) interacted with the diagnosis and treatment of Irlen Syndrome. 
The actual consistency of overlay use was examined through teacher observation and subject-researcher interviews. Overlays were used by all four, at school and at home, between the weekly reading trials with the researcher. However, a variety of environmental and inirasuiject factors caused periodic lapses of use by each student. Issues involving consistency of use were relevant to the second research question: "What recommendations for the implementation and continued use of spectral modification techniques can be derived from this study?"

These recommendations are enumerated in the section "Specific Contributions of the Dissertation." They were derived from three processes. First was the identification of students who were appropriate for screening with the Irlen Differential Perceptual Interview survey. It was found that teacher identification of symptoms was satisfactory for referring students in the elementary grades. However, it was not generally effective for the identification of high school students affected by perceptual dysfunctions in reading.

Teachers were a key source of recommendations for the effective use of overlays and related interventions in the classroom. These were generated mainly by mainstream classroom teachers as they engaged in an on-going process of subject observation. Weekly subject-researcher interviews revealed some user-oriented recommendations, which were generally born out by teacher observations. 


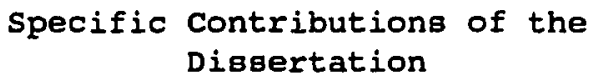

The previous studies reviewed for this work did not employ experimental techniques to monitor changes in reading performance that occurred over time. Two efforts involved the use of survey methodology to generate data on the effectiveness of Irlen lenses for individuals who had used them for one year or longer (Fricker, 1989; Whiting \& Robinson, 1988). Other experimental studies endeavored to assess the effectiveness of overlays or lenses through pre- and post-test procedures in clinical settings (Blaskey et al., 1990; Gole et al., 1989; Gregg, 1988; Hannell et al., 1989; O'Connor et al., 1990; Robinson \& Conway, 1990). Adler and Atwood (1987) had subjects using Irlen lenses over time in a secondary vocational environment. However, their assessment was oriented more toward changes in visual processing than to the outcome of reading performance.

This study differed primarily on two counts. First, it was conducted within the elementary school environment. Secondly, the reading performance of subjects was monitored over time as they used overlays. It was intended that a study having these variations would generate the following specific contributions:

1. Data indicating changes in reading performance as special education students used overlays in school.

2. Conclusions relative to the benefits of overlays for these students. 
3. Information that would guide practitioners toward identification of students who could benefit from spectral modification techniques, and also toward implementation of these techniques.

\section{Changes in Reading Performance}

Table 22 was developed to elucidate changes in performance that were demonstrated by each subject. Entries for oral reading rate, oral reading accuracy, and silent reading comprehension indicated the difference between mean baseline score and mean intervention score (rounded to whole numbers and whole percentages) for each subject. Although the post-test information was provided by previous tables 120 and 21 ), it is repeated here to allow comparison of post-test results to changes demonstrated in weekly reading trials.

Instability in the baseline data did compromise the effort to analyze trends in reading performance. As mentioned in chapter IV, the baseline phase was restricted by time limitations. Two other considerations influenced the researcher to limit the number of baseline trials to five. First was the possibility that extending the baseline phase would not result in performance stability for developing readers. Another concern was the possibility that subjects would lose interest or become negatively motivated to participate. Most performance changes as indicated by weekly trials were gradual. Immediate improvements in Jeremy's accuracy and Melissa's comprehension occurred with the introduction of overlays, and were gustained throughout the intervention phase. Jered's gains, and those 
Table 22

Cross-Subject Summary of Demonstrated Changes in Reading Performance

\begin{tabular}{|c|c|c|c|c|c|c|}
\hline Subject & $\begin{array}{l}\text { Oral } \\
\text { Reading } \\
\text { Rate }\end{array}$ & $\begin{array}{c}\text { Oral } \\
\text { Reading } \\
\text { Accuracy }\end{array}$ & $\begin{array}{l}\text { Silent } \\
\text { Reading } \\
\text { Compre- } \\
\text { hension } \\
\end{array}$ & $\begin{array}{c}\text { Previous } \\
\text { Achievement } \\
\text { Gain } \\
\text { (WJPB) }\end{array}$ & $\begin{array}{c}\text { Post-Test } \\
\text { Change: } \\
\text { Word } \\
\text { Recognition } \\
\end{array}$ & $\begin{array}{l}\text { Post-Test } \\
\text { Change: } \\
\text { Passage } \\
\text { Reading } \\
\end{array}$ \\
\hline Jeremy & $\begin{array}{l}+7 \text { w.p.m. } \\
(88 \text { gain) }\end{array}$ & +148 & +118 & $\begin{array}{c}+3.5 \text { mos. } \\
\text { (Annual) }\end{array}$ & $\begin{array}{c}+5 \text { mog. } \\
\text { (Quarterly) }\end{array}$ & $\begin{array}{c}\text { Progressed } \\
1 \\
\text { grade } \\
\text { level } \\
\end{array}$ \\
\hline Jered & $\begin{array}{l}+21 \text { w.p.m. } \\
(348 \text { gain) }\end{array}$ & +48 & $\begin{array}{c}+168 \\
\text { (at grade } 3 \\
\text { level) }\end{array}$ & $\begin{array}{l}+5 \text { mos. } \\
\text { (Annual) }\end{array}$ & $\begin{array}{c}+5 \text { mos. } \\
\text { (quarterly) }\end{array}$ & $\begin{array}{c}\text { Progressed } \\
1 \\
\text { grade } \\
\text { level } \\
\end{array}$ \\
\hline Samantha & $\begin{array}{l}-1 \text { w.p.m. } \\
\left(\begin{array}{ll}2 \% & \text { loss }\end{array}\right)\end{array}$ & +48 & +118 & $\begin{array}{l}+3 \text { mos. } \\
\text { (Annual) }\end{array}$ & $\begin{array}{l}+11 \text { mos. } \\
\text { (Quarterly) }\end{array}$ & $\begin{array}{c}\text { Progressed } \\
1 \\
\text { grade } \\
\text { level }\end{array}$ \\
\hline *Melissa & $\begin{array}{l}+11 \text { w.p.m. } \\
(278 \text { gain })\end{array}$ & +38 & +368 & $\begin{array}{l}+3 \text { mos. } \\
\text { (Annual) }\end{array}$ & $\begin{array}{c}+4 \text { mos. } \\
\text { (Quarterly) }\end{array}$ & $\begin{array}{c}\text { Progressed } \\
1 \\
\text { grade } \\
\text { level }\end{array}$ \\
\hline
\end{tabular}

* Data entered for Melissa's rate, accuracy, and comprehension represents the reading trials during which Melissa used her reading glasses plus the overlay. Both innovations were also used for Melissa's post-test administration. 
of Melissa in rate and accuracy, indicated an accelerating trend that

was not evident during the first four intervention trials.

Results of post-testing, as presented in Table 22, were

decisively different than pre-test results. Despite the short time

lapse between pre and post-testing, each subject demonstrated gains in

word recognition and oral reading that equaled or exceeded the

calculated previous annual gain in total reading skills.

Relationship of Performance Changes

to Use of Overlays

The potential for experimenter effect on subjects' performance is acknowledged, and discussed in the next section. Since this study was conducted over time in the natural setting, a wide range of variables was allowed to operate. One purpose of the observation and interview efforts was to illuminate these variables as they impacted each child, and to assist the researcher in determining their probable effect on reading performance.

The reading trial data did indicate change on one or more performance indicators for each subject. It is projected that changes in accuracy for Jeremy, rate for Jered, and comprehension for Melissa were sufficiently decisive and consistent to be attributed to the gpectral modification intervention.

Jeremy's level of accuracy was consistent throughout intervention, as opposed to his erratic performance in rate and comprehension. Since accuracy remained stable, it did not appear to be affected by the subject's progress in vision therapy. However, Jeremy was able to maintain his oral reading accuracy without the 
overlay after seven weeks of vision therapy. The implication was that for oral reading, the overlay provided "instant vision therapy" for this student.

Jered's most significant change was in the area of oral reading rate. It is probable that rate would have improved as the subject grew more familiar with trial procedures. The extent of Jered's improvement, and the consistency of his performance trend during the last five trials, indicated that the intervention was effective for him.

The changes demonstrated by Samantha in reading trials were not decisive enough to indicate that the overlay was the significant element for her. One indication that it had some positive impact was repeated testimony that overlays prevented her from getting headaches when attempting to read.

Samantha demonstrated gains through post-testing, if not during the weekly reading trials. Given the testing procedures used in this study, each subject exceeded the growth demonstrated on previous achievement testing. This must be interpreted with caution for several reasons:

1. Previous achievement growth was inferred from the results of an instrument not used for this study (the Woodcock-Johnson Psychoeducational Battery). Tests used for this study were not designed to measure global reading gkill, as was the WJPB.

2. The Brigance (1976) Oral Reading subtest indicates a grade level range; a student who successfully reads the grade 3 
Brigance passage could teat at 3.2 grade equivalent, or 3.9 grade equivalent on a different test. It could not be concluded that each of these subjects advanced by one grade level in reading skill, based on Brigance performance.

3. A post-test represents a single measurement, vulnerable to environmental and intrasubject variables that could be operating when taken. Repeated measurements, such as the reading trials, are likely to present a truer indication of the student's performance level.

A key purpose of pre and post-testing for this study was to confirm or contra-indicate changes that were demonstrated on reading trials. Subjects who demonstrated improvement on the trials had these improvements confirmed by post-testing.

The fourth subject, Melissa, demonstrated an immediate change in silent reading comprehension when she began using the overlay. This trial data, taken with information from observation and interviews, indicated that overlays provided Melissa and Samantha with similar relief from atrain (in the form of headaches) and fatigue. However, Melissa demonstrated marked improvement on the other two indicators when she combined reading glasses with her overlay. The possibility that the glasses were chiefly responsible for these additional improvements was contra-indicated by a post-trial with glasses only. Melisвa's rate reverted to baseline level on that trial, and she complained of a headache. The inclusion of additional trials with glasses only could have provided a truer picture of the effect of glasses plus overlay for this subject. 
Interaction of optometric and

Spectral Intervention

other studies that were reviewed by this researcher, and which originated in the fields of education and psychology, did not include optometric evaluation as a procedural element for subjects. Its inclusion in this study, and findings that resulted, was a contributing factor.

Some of the results generated by this study had relevance to several reservations which were proposed by Irlen's critics from the medical field. First is the projection that individuals who demonstrate Irlen syndrome are likely to have vision anomalies not routinely detected by optometric examination. This statement applied to two of the four subjects, which was significant. However, one subject's results (Jered's) indicated that spectral modification alone was beneficial.

The assertion that appropriate vision care for these individuals (e.g. Jeremy and Melissa) should be medically provided was possibly accurate for Jeremy. The possibility that Jeremy had Irlen syndrome in addition to convergence deficiency was undetermined at the conclusion of this study. Of significant interest was the implication that convergent-deficient students who lack access to vision therapy could be helped by carefully prescribed colored overlays. The effect of Irlen overlays on other convergent-deficient students could be explored in future research.

In Melisga's case, results indicated that optometric intervention alone (with untinted reading glasses) would have been insufficient. 
This subject presented a case for the constructive interaction of optometric and spectral technology. Her results also countered a third critical assertion: that given appropriate vision care, patients (who demonstrate Irlen syndrome) are unlikely to need overlays or tinted lenses.

Recommendations for Practitioners

As the study evolved, two important recommendations for the implementation of spectral modification techniques emerged. Firgt, different methods should be employed for the identification of students in elementary and secondary schools. The identification of appropriate students by special education teachers, as proposed for this study, worked well in the elementary schools from which subjects were recruited. The elementary students themselves posed little resistance to the subject selection procedures, with only one out of 19 refusing to be screened. The researcher's initial assumption that elementary students are less sensitized to risk and failure--hence more open to innovation--was not refuted.

The proposed subject identification procedure was, however, not effective in any of the three high schools available to the researcher. Teachers had a difficult time recommending a sufficient number of appropriate students, which was attributed to their limited involvement with direct instruction and observation of reading behavior. As a group, the high school students who were recommended offered a higher level of resistance than did their elementary counterparts. Of ten students recommended, two refused screening. 
One tenth grader who demonstrated moderate Irlen syndrome and otherwise favorable attributes refused to be enrolled. Another tenth grader was enrolled, as discussed briefly in Chapter IV. She demonstrated questionable compliance on the post-intake requirements of overlay re-trial and vision exam, and was dropped from the study. The original assumption that high school students would be motivated to use a procedure which requires little user effort, and could assist them in managing school demands, was not confirmed. The researcher developed a short questionnaire with which older students could identify key symptoms in themselves. This was first tried at the third high school where subject recruitment was attempted. It did assigt in the identification of students for screening, although the screening process did not indicate a suitable subject at that site.

As the subject selection process was nearing completion, the researcher came in contact with a high school reading instructor (not a special educator) who was interested in spectral modification. It was decided to try the student self-selection approach with a sample of this teacher's students, to further test its effectiveness. of 40 students given the one-page questionnaire, 14 gave responses indicating a high level of symptoms. Eight of these students were selected for interviews with the researcher, which were conducted with individuals or pairs of students. The researcher provided an overview of the Irlen process, explained the significance of the students' responses, and asked if they would be interested in screening. Each of the eight agreed to a screening, and was directed to have the 
screening permission signed by a parent or guardian. Five of the eight obtained the parent permission and were given the screening, for which each demongtrated a high or moderate degree of Irlen syndrome. These five otudents were given overlays, along with orientation on their use, care, potential benefits and limitations. The otudents were advised to use their overlays for four weeks, after which the researcher would return and question them on how they had worked. Although these five students exhibited a promising array of symptoms, some also displayed characteristics which could have made them unsuitable as subjects. These included related vision problems, other manifestations of dyslexia, and general low motivation. The researcher concluded that the self-selection process was effective for identification of students, at the high school level, who could be helped by spectral modification.

The second primary recommendation is to provide students with some degree of on-going support and structure, in the school environment, that is geared to consistent practice with overlays. The evidence was that most students who had been screened, but who did not become subjects, did not maintain their practice with overlays and consequently derived no real benefit. This was indicated by the researcher's casual observation of five non-subjects who attended subjects' schools, and was confirmed by special education teachers. Four of the five used overlays for one or two weeks after receiving them, then gradually discontinued. One student continued to use a goldenrod overlay, which the resource teacher attributed to an improvement in her oral reading. This student was in the unusual 
circumstance of having her mother as a teaching assistant in the resource room. This may have been a variable that influenced her motivation to continue.

As mentioned above, the five high school students from the reading program were later questioned about their experience with overlays. The four who were present on the follow-up day gaid they liked reading with overlays, which were effective for relieving strain and clarifying print. However, only one of these students used an overlay at school. The others preferred to keep them at home for homework and other reading tasks. This was in keeping with the reports of subjects and their parents: overlays were used regularly at home, and there was little need for parent prompting. Lapses in the consistency of overlay use at school were reported by each subject, and verified by their teachers. Reasons given for not using overlays at school included being too hurried to get them out (Jeremy), forgetting (all four), losing track of them (all four), letting others borrow all overlays (Samantha), losing them (Samantha, Melissa), and that overlays became too scratched and dirty (Melissa). Samantha and Melissa also reported slight difficulty with peer teasing. The possibility that experimenter effect was a performance-influencing variable will be discussed in the next section. The point is here projected that subjects did derive some genuine benefit from spectral modification, which may have been realized because they participated in the experiment. The structure designed into the experiment may have kept subjects using overlays in all settings long enough for gains to actually be realized. The 
graphic trend analysis indicated that some gains took several weeks to become apparent.

This section conciudes with a small number of recommendations that were given by teachers and implied by subjects. The seven teachers were asked open-endedly to provide recommendations for the use of overlays in school. Their suggestions, which did not reveal a strong consensus, are listed below:

1. The responsibility for overlay use resta chiefly with the student; teachers and others should not be expected to assist or remind consistently (two teachers).

2. Teachers should prompt students to use overlays, and assist in other ways, according to the developmental level of the student (two teachers).

3. A peer support group should be in place for overlay users (one teacher).

4. Overlays themselves should be perfected to reduce glare and vulnerability to scratching (one teacher).

Suggestion one was not given by mainstream teachers only, but was projected by one regular and one special educator. The same applied to the second suggestion. The subjects' recommendations were derived from their weekly interview responses. The researcher felt that the students themselves would offer these recommendations:

1. Students may need help with protecting overlays from scratching, denting, bending; special envelopes or files could help. 
2. Students should develop a system for keeping track of overlays and having them wherever needed.

3. Teachers and peers should help gtudents deal with teasing when it comes up.

4. They should make overlays less shiny, even on the dull side.

5. The shiny side of the overlay is useful for working math problems, which can then be wiped off.

Experimenter Effect

It was recognized that the researcher (e.g. experimenter) could have projected a heightened sense of expectation in regard to the overlays and their possible effect. This may have been offset by the time lapses between screening and subject enrollment (five to ten weeks), again from enrollment to the start of data collection (seven to nine weeks). During these periods, contact between the researcher, subjects, and parents was limited to the informed consent conference and instructions for the vision examination.

The informed consent conference was used to orient participants to the researcher's non-teaching role, and to the possibility that overlay use would not prove beneficial to any or all subjects. This was specified in the informed consent document (Appendix B). As the study progressed, these four students did not openly demonstrate an expectation for the researcher to teach skills or provide evaluative feedback.

The major safeguard against experimenter effect was that reading trials were carefully structured, and this structure was adhered to as 
each subject repeated the procedure 14 to 17 times. Interaction between researcher and subject was permitted during the interview, but minimized during the actual reading trial. It was the researcher's objective to have subjects read consigtently throughout the trial, and not experience breaks which might relieve any operating symptoms. Observations of teachers and the researcher indicated a need for two types of experimenter feedback, which were given to each of the four. The first involved word prompting, provided by the researcher, as subjects read orally. The effort to measure rate required that subjects progress through a passage without stopping. To ensure this, the researcher read single words for a subject if he or she paused for longer than five seconds, or stated that the word was unknown. The five second criterion was adopted from the Brigance (1976) oral reading assessment procedure. Prolonged hesitation upon sounding a word out or guessing was followed by a correction or the prompt "good." Teacher observation prompted the second type of feedback provided by the researcher. The mainstream teachers of two subjects (Jeremy and Jered) reported throughout the study that they were unable to detect improvement in oral reading that could be attributed to the overlays. These two did not use overlays regularly in the resource room; teachers explained that this was due mainly to their frequent involvement in small group oral activities (Jeremy) and math tutoring (Jered). Mainstream teachers of Melissa and Samantha did report observable improvement in these subjects' oral reading when they used overlays. The only subject who used her overlay regularly in the resource room was Melissa. 
Given evidence that two subjects did not get teacher feedback, the researcher decided to provide some objective information on performance changes prior to the end of the study. It was felt that an absence of feedback would hamper one intended procedure: subjects' practice with overlays between trials. The term "objective" was applied because the shared observations could be verified by the data. No attempt was made to influence teacher behavior toward subjects. During the fourth week of intervention, each subject was given the following feedback:

1. Jeremy: He did not skip or repeat lines as often when he used the overlay.

2. Jered: He was doing comprehension exercises in a book that was one level higher than the one he had started in.

3. Samantha: Since using the overlay, she had answered more of her comprehension questions correctly.

4. Melissa was given the same performance feedback as samantha. Information from interviews and observations was examined for evidence of the researcher's influence on the performance and behavior of each subject. A variety of issues surfaced, and are disclosed here relative to each child.

\section{Jeremy}

During the first subject interview, Jeremy initiated a request that the project be explained to his class. This request was repeated during each subsequent interview. It was decided that denying this reque日t, given its source and frequency, could be more contaminating 
to the study than compliance. The classroom teacher was asked to explain the study, but this did not get results. The researcher therefore agreed to speak briefly to Jeremy's peers during the fourth intervention week.

The talk was three to five minutes in length, during which the concept of research was presented in terms appropriate for a fourth-grade audience. It was explained that the overlays had helped some people's vision work better for reading, and that Jeremy was participating in the research by testing overlays for a period of time. The students were invited to borrow and try out extra overlays, which Jeremy had in his desk envelope.

Jeremy's classmates eagerly accepted the invitation, and took turns experimenting with his overlays during the two weeks following the talk. The resource teacher, who visited the classroom regularly, reported that he appeared to be using his overlay much more consistently during this period. Other students would model returning the overlays to their correct place, which may have helped Jeremy with the materials management aspect.

The District-wide spring break occurred between the seventh and eighth week of Jeremy's intervention. Both teachers observed that peer involvement decreased following the break, as did Jeremy's independent use of the overlay.

\section{Jered}

The researcher responded to this subject's reaction to the taping procedure and also to some of the oral reading material. Jered 
appeared nervous when he began his sixth timed trial (first one with

the overlay). He was observed as more at ease during trial 7. Following the ninth trial, Jered was questioned about his reaction to taping. He responded that he would prefer not to be taped. As discussed previously, taping was intermittent for the balance of intervention. These signs of aversion to reading for an audience may account somewhat for the fluctuations in rate and accuracy on baseline and first three intervention trials.

The change in the content of Jered's reading material between trials 8 and 9 presented an opportunity for experimenter effect. The subject expressed dislike of the story he had been reading for $t$ imed trials, addirg that he enjoyed the story he had been reading for warm-up, which was from the Rallyl series (Simons, 1979). The researcher's response was to discontinue the disliked book and substitute Rally! material that was at the same level of difficulty.

\section{Samantha}

Samantha exhibited intrasubject issues in regard to self esteem (oee Appendix E, Samantha, Intrasubject Characteristics). There was also evidence of emotional stress, apparently prompted by circumstances in the home environment. Samantha shared little of her personal circumstances with the researcher, even though the one-on-one interview provided an opportunity. The extent to which the external influences affected Samantha's performance could not be determined. Given factors in Samantha's learning profile, plus the environmental problems, it is possible that her results on the 
original screening were prompted by a desire for attention and recognition. The range of learning problems that Samantha demonstrated may also have compounded both the true extent of her Irlen syndrome, and her difficulty with the reading trial tasks.

\section{Melissa}

The researcher did adjust the procedure for administering Melissa's comprehension questions. This was in response to the observation that she had difficulty interpreting the question itself. Beginning with trial 8 , the subject was given a copy of the questions, and guided through each one as it was read slowly by the researcher. This provided visual as well as auditory input. For the sake of consistency, the other subjects were also given the opportunity to read along. Each of the other three demonstrated a preference for watching the researcher instead of the question sheet. Melissa continued with the read-along procedure, using her overlay. Because Melisвa's reading grade level was below that of the beginning New Practice Reader (Anderson et al., 1978), it was necessary for the researcher to prepare questions based on a passage that was written at her level. An effort was made to model questions after those presented in the programmed material. However, there was the possibility of interaction between subject performance and question preparation.

There were two indications that Melissa's improvement on the comprehension task was attributable to the planned intervention. One was her level of performance before the read-along procedure was introduced (trials 6 and 7), which was still above that of four 
baseline trials. The second was the researcher's observation that her speed of recall seemed to increase during the last four trials. She also began to voluntarily supply information from the passage that was not needed to answer the question. This was in marked contrast to baseline trials, and also an indication that she was not relying on clues from the questions or her prior knowledge.

\section{Conclusiong}

This researcher concludes that experimenter effect is not likely to have invalidated the results for any of the subjects. This was based on two factors:

1. Performance changes could be represented as trends which maintained a direction through several trials.

2. Improvements in reading performance that were demonstrated in reading trials were corroborated by post-test results.

However, it may have been a significant factor for one subject who demonstrated little performance change during the trial process (Samantha). The factors of personal insecurity and low self esteem were demonstrated during the study (and are described in Appendix E). The chance for personal attention may have biased this subject's response to screening, and resulted in the inappropriate inclusion of her as a subject. Evidence in favor of benefit from the intervention was provided by teacher observation, and by the subject's persistent self-reports that the overlay relieved headaches.

For Jered, the researcher concluded that his baseline and early intervention trial performance could have been influenced by 
inappropriate reading material. Use of the Fry Readability Graph (Fry et al., 1985), which is approximate, may have resulted in the selection of material that was too difficult. It could have been level of difficulty, rather than content, that Jered actually disliked. This unfortunate effect was countered by the positive results for comprehension and by the consistent direction of Jered's performance trend after the material was changed.

The researcher's intervention with Jeremy's peers was unlikely to have had a significant effect for this subject. His significant performance change (accuracy) was established before the classroom visit. The visit apparently resulted in more frequent independent uge of the overlay by Jeremy.

There was little indication that experimenter effect was significant for Melissa. Her decreasing independent use of overlays, as the study progressed, was troublesome. Melissa provided some insight into this with a self disclosure: that she continued to be frustrated over her inability to decode words, and the overlay could not help her learn new words. The peer environment, as discussed in Chapter IV, was also a possible deterrent. Recommendations for Future Research

A practical extension of this study would be to explore the usefulness of transparent overlays and tinted paper for older students. A method for identification of high school subjects was developed and piloted as an adjunct to this study. The trial of spectral modification techniques with older students would produce 
information useful to practitioners at that level. It is possible that adolescent subjects would present age-specific issues regarding the user's level of comfort with the techniques, and also with benefits derived.

To this researcher's knowledge, there is one study which has explored the effect of spectral modification on the employability of older students (Adler \& Atwood, 1987). Additional work in this area could analyze the barriers to employment, in the current economy, raised by the visualization difficulties which respond to spectral modification. This would provide a base for additional work on the relationship of Irlen lenses to employability or employment status.

Several issues arose directly from the study, and suggested possibilities for additional research. One involved the continued use of, and benefit from, Irlen overlays by the four subjects after the conclusion of this study. Overlays provide an approximate measure of help for individuals with Irlen Syndrome. Lenses provide more precise treatment, and have a much broader range of applications. A school-based study of longer duration in which students use overlays for several months, and are then fitted with lenses, could provide practitioners with more complete information on the limitations and potential of the technology.

According to results of this study, the subject with Irlen syndrome in the moderate range (Jered) made apparent gains in oral reading rate and possible gains on the other two indicators. Gains made by two of the high-syndrome subjects (Jeremy and Melissa) concurred with the treatment of other visual problems. The third 
high-syndrome subject (Samantha) did not demonstrate significant gains during the trial procedure. This indicated a possibility that high-range scotopic sensitivity is a manifestation of other learning and vision problems, for which other treatments are appropriate. It would be interesting to study a larger sample of moderate-syndrome overlay users to see if the improvements demonstrated by Jered were unique or typical. If the learning profiles and visual functioning of additional moderates were compared to parallel data on additional high-syndrome individuals, a possible relationship between high-range Irlen syndrome and co-existing problems could be illuminated.

Prior to commencing this study, the researcher provided the screening service for a study designed to investigate a possible relationship between IDPIS. findings and optometric findings for 39 subjects. A relationship was found between a high level of Irlen syndrome and a need for vision therapy. Conversely, those with low-level syndrome were more likely to have normal optometric findings (Lopez, Yolton, Kohl, Smith \& Saxerud, 1993). Additional interdisciplinary work with highly gcotopic individuals could further illuminate the relationship detected by Lopez et al. and demonstrated by two subjects in this study.

It would be useful to investigate the possibility that transparent colored overlays can improve the reading accuracy of individuals with insufficient convergence, as they did for Jeremy. This could establish overlays as a low-cost assistive device for individuals unable to access vision therapy services. Further work 
with individuals who demonstrate Irlen syndrome and convergence insufficiency could determine whether the conditions co-exist or are mutually exclusive.

The subject in this study (Samantha) who demonstrated high-level syndrome on the IDPIS, but minimal benefit from using overlays for reading trials, presented additional questions. Further case studies of similar subjects could illuminate poychoeducational factors which (a) partially or fully invalidate the screening process for these individuals, or (b) interfere with the effects of treatment. There have been few known efforts to validate the IDPIS as an assessment tool. Miller's 1984 study could be interpreted as an effort to validate it as a predictor of reading difficulties. It is possible that validity studies will emerge as further scientific inquiry is made into the hypothetical relationship between Irlen syndrome and magnocellular dysfunction. This is a promising focus for research which could both validate and refine spectral modification technology.

\section{Conclusions}

The sample selection and diagnostic procedures employed in this study led to the following conclusion: a significant prevalence of moderate to high Irlen Syndrome exists in the specific population from which subjects were selected. This population consists of students who qualify for special education as learning disabled in reading, and who demonstrate observable symptoms associated with Irlen Syndrome. 
The study was designed to address two research questions. The first addressed the extent and direction of change in reading performance as demonstrated by subjects who used colored transparent overlays for reading during a nine-week period. Three of the four subjects demonstrated improvement on one of three dimensions of reading performance $(\mathrm{e} . \mathrm{g}$. oral reading rate, oral reading accuracy, silent reading comprehension). Each demonstrated gains on a different dimension, indicating that the effects of spectral modification are dependent upon individualized factors.

Analysis of the subjects' reading performance also indicated that the severity of Irlen Syndrome does not predict the degree of change that may result from the use of overlays. Benefits detected for the one moderate-range subject were equivalent to (or possibly greater than) those demonstrated by the three high-range subjects. Examination of all diagnostic and performance data on high-range subjects indicated the presence of other learning issues that:

1. May contribute to a "false positive" diagnosis;

2. Iimit the usefulness of spectral modification as the sole method of treatment.

Each of the four subjects was given a comprehensive medical evaluation of their visual systems. Vision therapy was prescribed for one subject, reading glasses for another. These interventions were provided concurrently with spectral modification, and generated two conclusions:

1. Spectral modification and vision therapy may produce similar results in the area of reading accuracy. 
2. Spectral modification can complement the use of reading glasges for some individuals.

The second research question was intended to generate recommendations for the implementation and use of spectral modification techniques in the public school setting. Results of interview and observational procedures indicated that the consistent use of overlays requires structured reinforcement and social support from learning specialists, classroom teachers and peers. 
References

Adler, L., \& Atwood, M. (1987). Poor readers: What do they really see on the page? (Cooperative Agreement No. 86-06-03770-7419-01). East San Gabriel Valley Regional Occupational Program and California Department of Education.

Anderson, D. G., Stone, C. R., \& Burton, A. E. (1978). New practice reader (2nd ed.). New York: Webster Division, McGraw-Hill.

Ary, D., Jacobs, L. C., \& Razavieh, A. (1985). Introduction to research in education. New York: Holt, Rinehard and Winston.

Auch, M. J. (1989). Angel and me and the bayside bombers. Boston: Little, Brown \& Company.

Bassi, C. J., \& Lehmkuhle, S. (1990). Clinical implications of parallel visual pathways. Journal of the American Optometric Association, $\underline{61}(2), 98-110$.

Blaskey, P., Scheiman, M., Parisi, M., Ciner, E. B., Gallaway, M., \& Selznick, R. (1990). The effectiveness of Irlen filters for improving reading performance: A pilot study. Journal of Learning Disabilities, $\underline{23}(10), 604-612$.

Blakeslee, S. (1991, september 15). Research links brain abnormality to dyslexia. The sunday oregonian, p. Al4.

Breitmeyer, B. G., \& Ganz, L. (1976). Implications of sustained and transient channels for theories of visual pattern masking, saccadic suppression, and information processing. Paychological Review, $83(1), 1-36$.

Brigance, A. (1976). Inventory of basic skills. North Billerica, MA: Curriculum Associates.

Chan, L. K. S., \& Robinson, G. L. W. (1989). Effects of comprehension monitoring instruction for reading disabled students with and without tinted glasses. The Australian Journal of Special Education, I3 (1), 4-13.

Critchley, M. (1970). The dyslexic child. London: William Heinemann Medical Books Limited. 
Education for All Handicapped Children Act of 1975, Sec. 602, 20 U.S.C., Sec. 1401 (1975).

Fitzgerald, A. (1989). Tinted lenses and dyslexia: A review of the literature. Australian Orthoptic Journal, 25(1), 1-6.

Fricker, S. (1989). Do Irlen coloured qlasseg improve stereopsis and reading ability in children who have reading difficulties caused by visual perceptual distortions when they look at black print on white paper, and does their color vision differ from the normal population? Hobart, Tasmania, Australia: Education and Medical Department of the Tasmania Government.

Fry, E., Fountoukidis, D., \& Polk, J. (1985). The new Reading Teachers Book of Lists. Englewood Cliffa, NJ: Prentice-Hall.

Garzia, O. D., \& Nicholson, S. B. (1990). Visual function and reading disability: An optometric viewpoint. Journal of the American Optometric Association, 61(2), 88-97.

Gole, G. A., Dibden, S. N., Pearson, C. C., \& Pidgeon, K. J. (1989). Tinted lenses and dyslexics - A controlled study. Australia and New Zealand Journal of Ophthalmology, 17, 137-141.

Gregg, P. J. (1988, January 29). Dyslexia and tinted filters, a small research project. Optician, pp. 17-20.

Griffen, M., \& Jongsma, K. (1980, May). Adaptations of retelling: Two variations on a theme. Paper presented at 25 th Annual Meeting of the International Reading Association, St. Louis, Mo.

Hannell, G., Gole, G. H., Dibden, S. N., \& Rooney, K. F. (1989). Reading improvement with tinted lenses: A report of two cases. Clinical and Experimental Optometry, 72(5), 170-176.

Helveston, E. M. (1990). Scotopic Sensitivity Syndrome. Archives of Ophthalmology, 108, 1232-1233.

Hoyt, C. S. (1990). Irlen lenses and reading difficulties. Journal of Learning Disabilities, $\underline{23}(10), 624-626$.

Irlen, H. L. (1983, August). Successful treatment of learning disabilitieg. Paper presented to American Paychological Association.

Irlen, H. L. (1990). Reading by the colors: Overcoming dyslexia and other reading disabilities through the Irlen method. New York: Avery.

Irlen, H. I. (1991). Scotopic Sensitivity syndrome screening Manual (5th ed.). Long Beach: Perceptual Development Corporation. 
Irlen, H. L., \& Lass, M. J. (1989). Improving reading problems due to symptoms of scotopic sensitivity syndrome using Irlen lenses and overlays. Education, 109(4), 413-417.

Kazdin, A. E., \& Kopel, S. A. (1975). On resolving ambiguities of the multiple baseline design: Problems and recommendations. Behavior Therapy, 6 , 601-608.

Lea, A. R., \& Hailey, D. M. (1990). Tinted lenses in treatment of reading disabled (2nd ed.). Australian Institute of Health: Health Care Technology Series No. 2, Agos, Canberra.

Livingstone, M. S., Rosen, G. D., Drislane, F. W., \& Galaburda, A. M. (1991, September). Phygiological and anatomical evidence for a magnocellular defect in developmental dyslexia. Proceedings of the National Academy of Science, U.S.A., 88, $7,943-7,947$.

Lobel, A. (1978), Days with frog and toad. New York: Harper \& Row.

Lopez, R., Yolton, R. L., Kohl, P., Smith, D., \& Saxerud, M. (1993). Comparison of Irlen Scotopic Sensitivity syndrome test results to academic and vigual performance data. Forest Grove, OR: Pacific University College of Optometry.

Lovegrove, W., Martin, F., \& Slaghuis, W. (1984). A theoretical and experimental cage for a visual deficit in specific reading disability. Hobart, Tasmania, Australia: University of Tasmania Department of Pgychology,

Meares, 0. (1980). Figure/ground, brightness contrast, and reading disabilities. Visible Language, XIVI $(14: 1), 13-29$.

Miller, L. S. (1984). Scotopic sensitivity and reading disability. Unpublished paper.

Natteoni, L., Wilson, H. L., \& Sucher, F. (1982). Puddle iumpers. Key test basal reader. Oklahoma City: Economy Company.

O'Connor, P. D., \& Sofo, F. (1988). Dyslexia and tinted lenses: A response to Gordon Stanley. Australian Journal of Remedial Education, 20(1), 10-12.

O'Connor, P. D., Sofo, F., Kendall, L., \& Olsen, G. (1990). Reading disabilities and the effects of colored filters. Journal of Learning Disabilitieg, 23(10), 597-604.

Pitluk, S. B. (1990, March 6). A case for further investigation of the Irlen lens [letter to the editor]. California Optometry. 
Podell, S. M. (1990). An overview of the Irlen method. Journa? of Behavioral optometry, 1(7), 171-173.

Reeves, B. (1988, January 29). Reading through rose-tinted spectacles. Optician, 21-30.

Rickelman, R. J., \& Henk, W. A. (1990). Colored overlays and tinted lens filterg. The Reading Teacher, 44(2), 166-167.

Riding, R. J., \& Pugh, J. C. (1977). Iconic memory and reading performance in nine-year-old children. British Journal of Educational Psychology, 47, 132-137.

Robinson, G. L. W., \& Conway, R. N. F. (1990). The effects of Irlen colored lenses on students' specific reading skills and their perception of ability: A 23-month validity study. Journal of Learning Disabilities, 23(10), 589-596.

Robinson, G. I. W., \& Miles, J. (1987). The use of colored overlays to improve visual processing: A preliminary survey. The Exceptional Child; 34 (1), 65-70.

Rosner, J., \& Rosner, J. (1987). The Irlen treatment: A review of the literature. Optician, 194(5116), 26-33.

Sackitt, B. (1976). Iconic memory. Psychological Review, 83 (4), 257-274.

San Diego Quick Assessment. (1977). Unpublished assessment tool.

Scales, A. A. (1980). The Informal Reading Assessment Inventory. The Reading Instruction Journal, 24, 5-7.

Scheiman, M., Blaskey, P., Ciner, E. B., Gallaway, M., Parisi, M., Pollack, K., \& Selznick, R. (1990). Vision characteristics of individuals identified as Irlen filter candidates. Journal of the American Optometric Association, 61 (8), 600-605.

Scheiman, K., Blaskey, P., Gallaway, M., Ciner, E., \& Parisi, M. (1990). Vision characteristics of adult Irlen filter candidates: Case studies. Journal of Behavioral Optometry, 1(7), 174-178.

Sharmat, M. (1984). Nate the great and the case of the snowy trail. New York: Dell Publishing Company.

Simons, S. M., \& Division of Urban Education. (1979). Rally! A reading program, level " $A$ ". New York: Harcourt Brace Jovanovich.

Slosson, R. L. (1963). Oral Reading Test. New York: Slosson Educational Publications. 
Solan, H. A. (1981). A rationale for the optometric treatment and management of children with learning disabilities. Journal of Learning Disabilities, $14(10), 568-572$.

Solan, H. A. (1990). An appraisal of the Irlen technique of correcting reading disorders using tinted overlays and tinted lenses. Journal of Learning Disabilitieg, 23(10), 621-626.

Solman, R. T., Dain, S. J., \& Keech, S. L. (1991). Color-mediated contrast sensitivity in disabled readers. Optometry and Vision Science, 68 (5), 331-337.

Suchoff, I. B. (1981). Research on the relationship between reading and vision--What does it mean? Journal of Learning Disabilities, $\underline{14}(10), 573-576$.

Tawney, J. W., \& Gast, D. I. (1984). Single subject regearch in special education. Toronto: Merrill.

United States Statutes at Large (Volume 89). (1975). Public law 94-142 U.S. Congress. Washington, D.C.: U.S. Government Printing office.

Whiting, P. R. (1988). Improvements in reading and other skills using Irlen coloured lenses. Australian Journal of Remedial Education, 20(1), 13-15.

Whiting, P. R., \& Robinson, G. L. W. (1988). Using Irlen coloured lenses for reading: A clinical study. The Augtralian Educational and Developmental Psychologist, $8,7-10$.

Williams, M. C., \& Lecluyse, K. (1990). Perceptual consequences of a temporal processing deficit in reading disabled children. Journal of the American Optometric Association, 61(2), 111-121.

Williams, M. C. (1990). Reading-disabled children: A simple, new, inexpensive treatment. Research to Prevent Blindness Science Writers Seminar, 11-13.

Wilson, R. G., \& Rudolph, M. K. (1986). Merrill linguistic reading program (4th ed.). London: Charles E. Merrill. 
APPENDIX A

PRE-SCREENING MATERIALS 
ATTRIBUTES OF A GOOD SUBJECT

1. Student is in grade $4,5,10$, or 11 .

2. Student is LD in reading.

3. I.Q. is solid average (90 to 110 ).

4. Student has normal uncorrected vision.

5. Oral communication skills are adequate to good.

6. Student appears to be an auditory learner.

7. Specialized reading instruction does not seem to help significantly.

8. student does not exhibit serious behavior problems.

9. Environmental, family, or emotional problems do not interfere with school progress consistently.

10. Student's history shows limited movement among schools.

11. Student has been in Special Education for one year or longer. 
Name:

Schoo: :

Age/Grade:

WISC-R:

Hancicapping Concition:

Date Qualified for Sp. Ed.:

Vision Data:

Current Reading Level:

Specialized Instructional Program:

Special Assessment Data, Reading:

Date: Test: 8 -ile/G.E.:

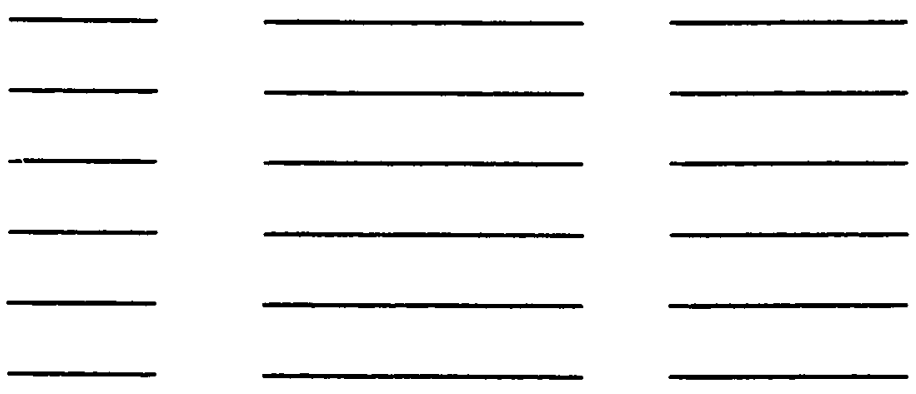

PALT Reading:

Date: Results: Date: Results:

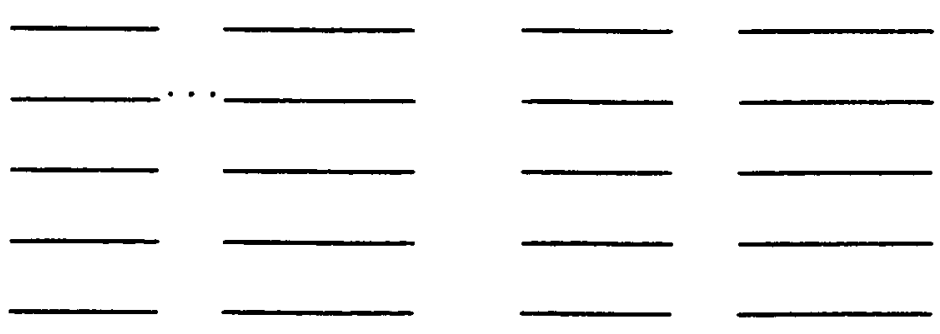


DRE-SCEEENING DATA. CONT. Learning style:

Skill Strengths:

Skill Deficits:

Prior School Enrollments:

Incl. Dates: school/Distzict:

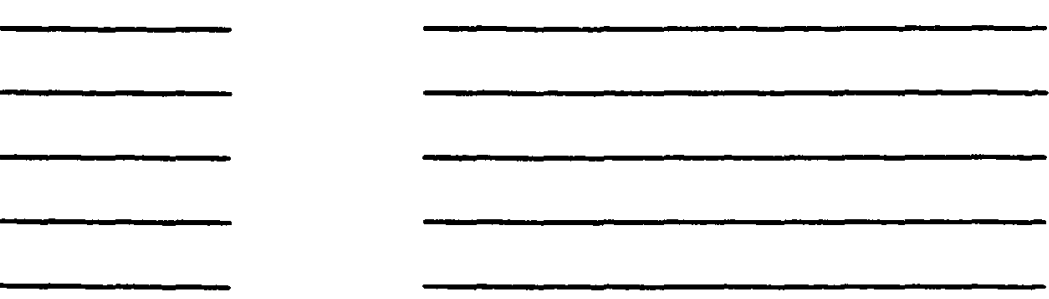

Behavioral Issues:

Environmental Issues: 
APPENDIX B

PERMISSION AND CONSENT DOCUMENTS 
PARENT PERMISSION SLIP

FOR SCOTOPIC SENSITIVITY SYNDROME SCREENING

Dear

I believe may benefit from a screening for Scotopic Sensitivity Syndrome. This syndrome is a sensitivity to light that has been found to cause some people to see distortions when they try to read black print on white paper.

If the screening shows that your child has some degree of Scotopic Sensitivity Syndrome, a colored transparent overlay will be given to It has been found that when colored overiays are placed over reading material, the symptoms of Scotopic Sensitivity Syndrome are reduced or eliminated.

Be assured that this screening will not affect your child's grades, classroom placement, or continued eligibility for Special Education.

The screening will be performed by Ms. Kathleen Farber, a Special Education teacher who has been trained and certified to perform the screening.

If you have questions, please contact your child's Special Education teacher:

If you have no objections to this screening, please sign and date the bottom of this form and see that it is returned to at

*NOTE: This screening is strictly voluntary. You may withdraw permission at any time.

I grant Ms. Farber permission to screen for Scotopic Sensitivity Syndrome. I understand that this screening will not affect my child's continued eligibility for Special Education. 


\section{STUDENT CONSENT FOR SCREENING}

Ms. Farber has explained Scotopic Sensitivity Syndrome to me. I understand what screening for Scotopic Sensitivity Syndrome involves, and I consent to being screened.

Student: Date: 


\title{
ELEMENTARY SUBJECT CONSENT FORY
}

\author{
You, have been chosen to \\ be a subject in an experiment this year. A "subject" \\ is a person who takes part, often by trying something \\ new to see if it will work. These two pages will \\ explain the experiment, and what you will be doing \\ as a subject. If you agree to be a subject, you will \\ sign the second page. \\ 1. Why is this experiment taking place?
}

The purpose is to see if some colored plastic sheets, called "overlays", will help some students read easier and faster.

\section{How did you get chosen?}

You were given a test for which you looked at some designs, answered questions about them, and tried out overlays in different colors. The test showed that you have a sensitivity to light, which could be one of the things that causes you trouble with reading. You were chosen as a subject because the overlays were designed for people who have this light sensitivity.

\section{Who will be in charge?}

A Special Education teacher (me/Ms. Farber) is in charge; the term for the person in charge is "investigator". Her job as investigator will not involve any teaching, and she will not be giving you grades or rewards. Try not to think of her as testing or evaluating you; you and she are working together to see if the overlays can work for you. and maybe for others.

\section{What does the subject's job involve?}

It has several parts, listed here as "A" to "g":

A. First you will give Ms. Farber a good idea of how you read without overlays. You will read to her twice each week, for a short reading trial. This will go on for at least two weeks, but not more than four weeks. 
B. You will then read to Ms. Farber once each week, using an overlay. This will be the experimental part, and it will take nine weeks. We want to see if overlays work over time, and if they are convenient to use.

C. You will use overlays when you do silent reading in your grade classroom. Sometimes Ms. Farber will observe in the classroom.

D. You will use overlays if and when you read at home. You will keep a list of anything you read at home.

E. You will talk to Ms. Farber once a week about the things on your reading 1 ist, and about how you are getting along with the overlays.

F. If the overlay works for you, you will use one when you take the Spring PALT Reading Test.

\section{What happens if the overlays don't help?}

If you try them for several weeks and they don't help your reading at all, you can stop using them before the end of the experiment.

\section{How might other kids react?}

The teacher in your regular classroom will not remind you openly to use the overlay, so you can use it without being noticed by most of the students. Your teacher will help out if anyone else makes you feel conspicuous. You, Ms. Farber, and your Resource Teacher will work out a plan to help the other kids in your Resource group cooperate with this experiment.

\section{What else should you know?}

The first thing is that you have the right to stop being a subject in this experiment, if you decide you want to stop for any reason. stopping will not affect anything at school: your grades, or how teachers feel about you.

Secondly, your parents will come to a meeting if you agree to be a subject. They will go over and sign a form that has the same information as this one. Your Resource Teacher and the school principal will be invited to the meeting.

8. Do you have any questions of your own? 


\section{ELEMENTARY SUBJECT'S INFORMED CONSENT}

I, agree to be a subject in

Ms. Farber's experimental study.

student :

Date: 
APPENDIX C

SCREENING REPORT FORMAT 
IRLEN DIFFEREATIAL PERCEPTOAL IKTERVIEN SORVET SCREENING SUMMARY

Student :

Date Screened: $12 / 03 \& 12 / 16 / 92$

School: Screener: Rathleen Farber

Grade and Age: 4,9

This screening indicated that scotopic sensitivity syndrome may be a factor in reading.

Scotopic sensitivity syndrome is a visual-perceptual condition which makes an individual appear to be light sensitive, and to have difficulty reading black print on white paper under normal lighting conditions. It can cause the reader to perceive the print or background as moving or changing, to see print as blurring out, and/or to experience eyestrain and mental fatigue from the effort of reading.

Screening indicated that this student experiences the following difficulties in visualiring black print on white paper:

1) Interview portion of screening-said that he usually prefers to read in dim light, with or without his glasses. He wears glasses to correct astigmatism. The glasses relieve the mental fatigue and eyestrain he experiences when attempting to read without them. However, he sometimes has the following difficulties when reading with the glasses: skipping words, misreading words, rereading lines, inserting words from the line above or below, and perceiving print as blurry. 
2) Screening tasks--These involved counting spaces in a cube figure, counting a row of symbols in a field of like symbols, and answering questions about his perception of straight lines and symbols that surrounded a point of focus. Although wore his glasses for the tasks, he percieved significant distortions of the print and background. These included jiggling and moving of lines and symbols, blurriness, print appearing to rise up, and background brightening. Straight lines near his point of focus appeared to be crooked, and to merge, flicker, and disappear. When he focused on a point, he said he was unable to see surrounding symbols clearly.

3) Trial of colored overlays--on the first screening date, wore his glasses as the seven colored transparent overlays were tried singly and in combination. He selected a goldenrod overlay as the one that made the print look clearest. When he read a passage orally with and without the overlay, there was no observable difference. Chris was uncertain whether he preferred reading with or without the overlay. was given a second overlay trial on $12 / 16$, to see if layering overlays and using a magnifying bar could help. Chris did not have his glasses at school on that day. He again selected the goldenrod after repeated trial of all colors. Without the glasses, he expressed a definite preference for reading with the overlay. This confirmed an observation made on the first screening day: Chris was able to name letters in a line of small princ with the overlay and without his glasses. He was unable to recognize them on the white page without the glasses.

CONCLUSIONS AND RECOMMENDATIONS:

1 . should wear his glasses for reading, writing, and all activities that require perception of fine detail.

2 . should use the goldenrod overlay, in combination with his glasses, for reading at home and at school. 
3. demonstrated basic light sensitivity to

the screener by complaining of glare and shading the page. The Irlen Institute's list of strategies and modifications for light sensitive students is attached.

4. Additional overlays can be ordered from the Irlen Institute for $\$ 2.00$ each. The address is at the bottom of the strategies list.

5. Tinted eyeglass lenses can be considered for if the overlay proves beneficial over time. The Irlen Institute has a traveling clinic which can prescribe the optimal tint. However, it is not recommended that glasses be tinted the same color as the overlay. A much more exacting process is used for determining the lens tint. 
APPENDIX D

OBSERVATION AND INTERVIEW FORMS 
HEEKLY SUBJECT QUESTIONNAIRE

1. How much do you use your overlay(s):

$$
\begin{aligned}
& \text { Regular classroom--usually__ sometimes__don't__ } \\
& \text { Resource Center--usually__ sometimes__don't___ } \\
& \text { At home--usually__ sometimes__don't__ }
\end{aligned}
$$

2. If you don't always use it, or never use, what is your reason?

3. Have teachers reminded you to use overlay(s) and colored paper? If so, which teachers and how?

4. Do your parents say anything about using the overlay(s) at home?

5. How do other students react:

In R.C.

In regular class

6. How is your reading affected by the overlay(s)?

less blurry
feel more confident
read faster
read for longer
r make fewer mistakes
mundergtand better

feel less tired head feels better other eyes feel better

7. What do you like best about the overlays?

8. What do you like least about the overlays? 
FEERLY QUESTIONNAIRE, continued

9. Do you like the colored paper? Which color?

Why do you prefer colored paper to white?

easier to stay on lines

can make neater letters

don't need to erase as much

easier to look at

other:

10. What are some ways you work on reading in your regular classroom?

What is most helpeul?

11. What are some of the ways you work on reading in R.C.?

What is most helpful? 
SUBJECT INTARE DATA

Subject :

School:

Information supplied by (parent):

1. Is the student currently taking medication? yes no If yes, what is the medication?

For what purpose is the medication taken?

What effects, if any, does the medication have on the student's school performance?

2. Please describe any of the following therapy's that the student is currently undergoing, or has undergone during his/her school career.

Drug therapy:

Controlled diet:

Vision therapy:

Sensory-motor integration therapy:

Tutoring outside of school:

Counseling: 
Subject Intake Dara (continued)

3. Does anyone in the family have reading or learning problems? yes no who?

Is anyone light sengitive and bothered by sunlight or glare? yes no who?

Has anyone else sought assistance through an Irlen clinic? yes no who? If "yes", what treatment was provided and what were the effects?

(Use reverse side if more space is needed.)

4. When was the most recent optometric or ophthalmic examination?

By whom?

What specific visual problems, if any, does the student have?

Does the student have a prescription for eyeglasses? If so, what are the glasses to be used for?

Are glasses effective? 


\section{Subject Intake Data (continued)}

5. Would you object to the student having a complete eye examination prior to participation in this study?

This would be provided by the Pacific University downtown clinic, at no cost to the student or family.

If you consent to the eye examination, please sign below.

$$
\text { Date }
$$

(student's consent to eye

examination) 
TEACHER PROGRESS CHECK

Scotopic sensitivity study

Student :

พeek of:

1. For silent reading in the classroom, student uses overlay always sometimes never

2. During silent reading, student appears to be on task 758 to 1008 ___ 508 to 758 ____ 508 or less__

3. For oral reading in the classroom, student uses overlay always___ sometimes___ never

4. When student uses overlay for oral reading, rate and accuracy is observed as (compared to last week) improved about the same

5. Written assignments:

How many reading-based written assignments were given to the class during the last five days?

How many of these assignments did the student complete on colored paper on white paper

Does the use of colored paper appear to be affecting the quality of written work (compared to last week)? yes same as last week

6. Comments : 


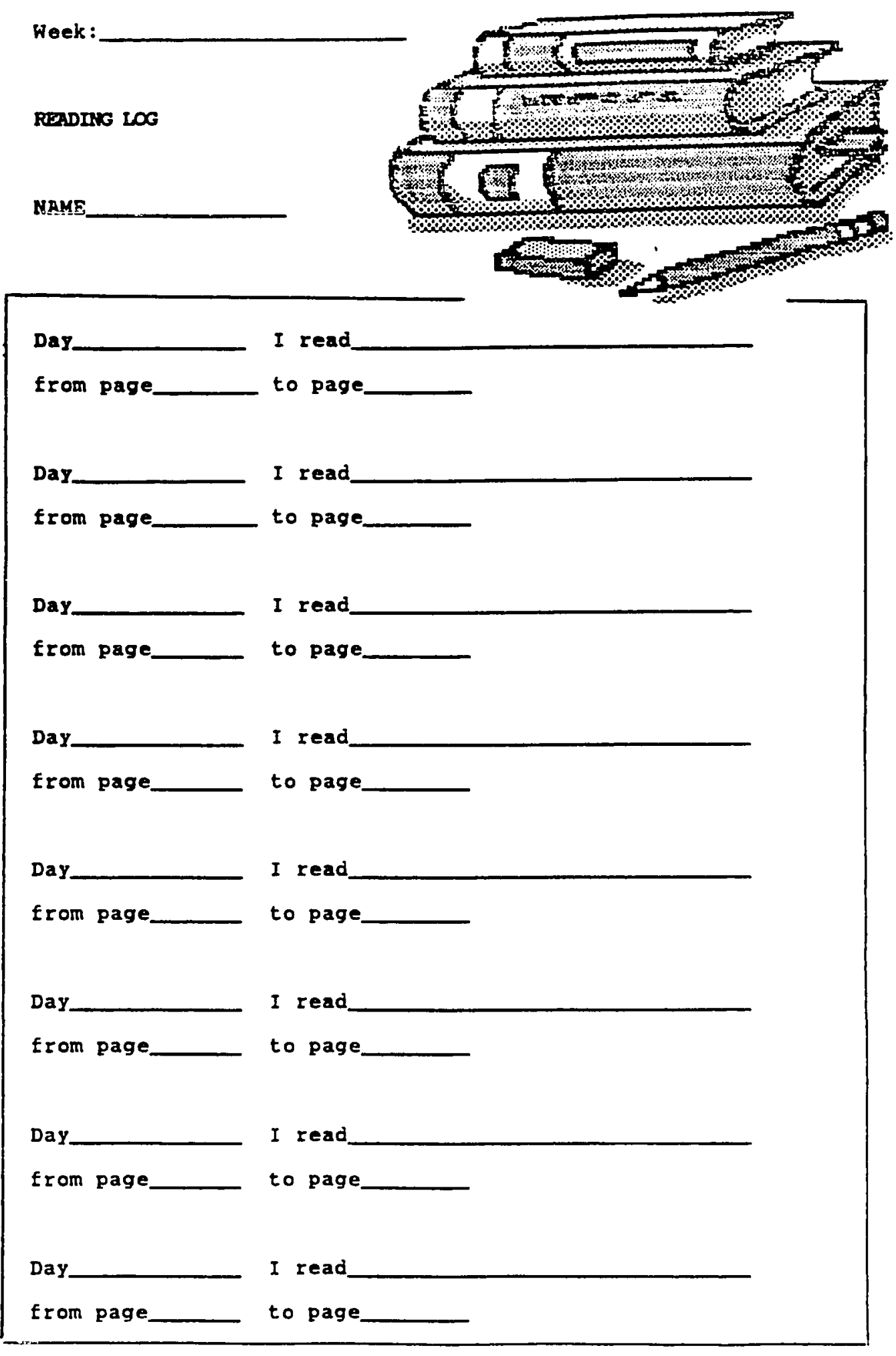




\begin{abstract}
APPENDIX E
ADDITIONAL INFORMATION FROM OBSERVATIONS

AND INTERVIEWS
\end{abstract}


Jeremy

JEREMY

\section{Intrasubject Characteristics}

Attention deficit was noted as a secondary handicapping condition on Jeremy's special education eligibility documents. This accounted for a high level of distractability and poor organizational skills. These attributes were recognized by the subject's resource and mainstream teachers as prime factors in his school performance. Procedures not in the usual routine were observed as anxiety-producing for Jeremy. Before several trials he mentioned a school activity that would occur later in the day, and expressed concern that the reading trial not interfere with it. The scattered and nervous affect he presented on these occasions would subside once his attention was focused in the trial tasks. He would, however, often break focus to question or comment on the reading material. When directed to refocus he complied promptly. Jeremy's resource teacher assessed his distractability as a barrier to learning that equaled his perceptual difficulties. In her classroom he would voluntarily isolate himself in order to complete seat work. This reflected a desire to meet the expectations of others, a trait which Jeremy demonstrated in several ways throughout the study. The researcher felt that Jeremy's voluntary compliance, plus his ability to redirect his own attention without taking medication, made him a viable subject despite the attentional characteristics. 
This attention deficit factor may have accounted for the fluctuations in this subject's rate and comprehension. The alternating high and low scores made it difficult to determine a directional trend for the subject's performance in these areas. The mainstream teacher noted gimilar inconsistency in the quality of Jeremy's performance in the classroom. Her summation was that performance at any given time reflected his state of mind.

When questioned on what he liked least about the overlays, one of Jeremy's responses was that he had difficulty keeping track of them. One effect of the attention deficit was poor organization of his personal environment and belongings. Teachers observed this as negatively affecting the consistency of his independent practice with the overlay. Even though Jeremy had an overlay envelope taped to his desk, he explained that he sometimes did not use one because he was in a hurry or forgot.

A second important attribute was the subject's binocular dysfunction, best defined as his inability ot converge visual focus at a nearpoint of less than 18 inches. This indicated a need for vision therapy, which was evaluated as an additional intervention. The subject's adaptation to vision therapy was documented through a parent interview, and by a written statement from the optometrist who superviged the therapy program.

Jeremy attended therapy once weekly, from the fourth week of intervention until the conclusion of the study. Both the subject and his stepmother reported daily practice, for approximately 15 minutes, 
of the prescribed exercises. When interviewed at the end of the intervention phase, the parent commented that Jeremy had improved the rate and accuracy of letter reading exercises. She also observed a developing ability to make eye contact, which had previously been lacking. It was reported that the subject could, at that time, read for 15 minutes without his overlay. When he had tired and lost focus, he would use the overlay for visual assistance.

The clinic report stated that Jeremy demonstrated a high rate of compliance with therapy homework and had made excellent progress. After six weeks of therapy the subject demonstrated ability to converge focus at the nearpoint of his nose. He also reported that the double vision in reading had been eliminated. Observed Use of Overlays

The indication from teacher observation and subject self-report was that Jeremy used his overlay inconsistently in the classroom, which could be attributed to his distractability. The subject's stepmother reported that he used the overlay consistently during his homework time, which was a regularly scheduled half hour on each week day. As the vision therapy progressed, he continued to use his overlay to sustain focus after reading for a period of time without it.

During the warm-up portion of the firgt intervention trial (trial 6), the subject used three overlay variations: single turquoise, 
double turquoise, and turquoise with yellow. The researcher observed a slight deterioration in fluency when yellow was added. Jeremy said that the yellow seemed to reduce blurriness, but it added brightness which made him less comfortable. He also said that no variation eliminated blurriness entirely.

The subject's subjective preference, for this first trial situation, was for double turquoise. This was used for trial 6 . When interviewed before trial 7, Jeremy said he preferred using a single density overlay at home and in his classroom. Since Jeremy wavered on density preference, the researcher alternated single and double densities for trials 6 through 9 . Performance for rate and comprehension fluctuated downward on the single density trails $(7$ and 9). Double density was therefore used for trials 10 through 12 , although rate was at its lowest point on two of these trials.

A single overlay was again used for trial 13, when both rate and accuracy were at higher levels. Double density was used for the last intervention trial, when all three measurements decreased. The researcher's conclusion was that overlay density did not have a reliable effect on this subject's performance.

When asked to state his reasons for not using an overlay in the classroom, Jeremy responded that he forgot, was too hurried, or was reading something short. He said that both teachers would remind him to use them once each week or more, and that teachers prompted more frequently than did his parents. He did not complain of teasing or 
derision from peers. His report was that other students were "just curious" and enjoyed trying them out.

During the subject-researcher interview, students were asked to state how the overlay assisted their reading, and also to confirm or deny some possible improvements that were suggested. The two suggestions that Jeremy confirmed consistently were that words looked less blurry, and that he made fewer mistakes. The statement offered, in his own words and on several occasions, was that the overlay helped him to read better.

This subject offered two responses when asked what he liked least about the overlay: that they would dent and scratch easily, and that he had a hard time keeping track of them. Near the end of the intervention phase, he said the "keeping track was getting easier." The classroom teacher concurred that he improved on this aspect. 
JERED

\section{Intrasubject Characteristic}

This subject's demonstrated short attention span and high level of distractability were referral concerns when he was first assessed for special education as a second grader. Although he continues to exhibit these characteristics in the classroom, they were a less gignificant factor in Jered's profile than in Jeremy's. In the trial situation, Jered often became fidgety as he was being interviewed. Once the reading trial itself was begun, Jered remained focused on the task.

This subject's distractability did affect his classroom performance, according to teacher observations. The mainstream teacher commented that Jered needed monitoring in order to remain focused and on task. He (the teacher) reported that Jered was often reminded to use his overlay, and that he had difficulty keeping track of them. One of his overlay half-sheets had been found in a classroom dictionary. This suggested poor organizational skills, but also that he did use his overlays for a variety of purposes.

Both the mainstream and resource teachers described this student as often off-task for seat work activities such as surt.ained silent reading. Jered stated, during three interviews, that silent reading was his favorite reading activity and also the most helpful. Comprehension was an area of strength for this student, as demonstrated by his reading trial performance. This was also corroborated by the results of Jered's recent re-evaluation with the 
Jered

Woodcock Johnson Psychoeducational Battery. Jered scored at the twenty-second percentile in reading comprehension, as opposed to the seventh percentile in word recognition. This comprehension subtest involved a cloze procedure, and the assessment report concluded that Jered doeg best when material is presented in a meaningful context. Despite this demonstrated strength, and the subject's stated preference for silent reading, both teachers reported that he needed close supervigion to remain focused and be productive for independent reading tasks.

This researcher was asked to do a classroom observation by Jered's mainstream teacher, for the purpose of gaining a first-hand perspective on the teacher's input. Since the observation occurred between the last two trials, it was not expected to produce significant effect on the subject's performance trends.

The class was involved in a teacher-directed spelling game. Jered appeared focused on the game throughout the 30 minute session. He participated cooperatively and reacted appropriately when his team scored a point. He also volunteered to answer a question at the conclusion of the game, and did so correctly. His answer revealed knowledge of expectations that had not been communicated directly before or during this game session. In other words, he had been attentive when it was played on other occasions. Although this observation revealed nothing of Jered's reading or seat work behavior, it did indicate that this student could be focused and attentive in classroom situations. 


\section{Observed Use of Overlay}

This subject used a single density turquoise overlay for all reading trials, and for practice in the other settings. When interviewed following the first week of intervention, he said he usually used it in the mainstream classroom. This may have reflected the subject's desire to satisfy the researcher, since the classroom teacher stated that he did not know Jered had the overlay at this time and had not seen him using it. Jered was informed that part of the researcher's task was to collect information from different sources, and that his teacher would by answering some of the same questions that he answered. On subsequent interviews Jered stated that he sometimes used the overlay in the classroom; the teacher concurred. Jered reported that the resource teacher occasionally directed him to use the overlay, and that he was not reminded by the mainstream teacher. Although the latter stated that Jered needed reminding, he did not say that he actually did so. The extent to which Jered was prompted to use the overlay in the 5 th grade classroom was not determined.

The subject's self-report on use of an overlay in the resource room was that he usually did not. This was because the group was doing math, or an activity that did not require individual reading. The resource teacher's statement was that he sometimes used it for oral reading in the small group.

Jered's mother explained that his use of an overlay at home depended on the lighting conditions, the difficulty of the material, 
Jered

and on how much he had to read. She read with him regularly, and had observed that he did best when the text was printed on gray paper and the light was not more than 60 watts. Jered used his overlay consistently when doing homework at the dining room table, where the light was brighter.

Reasons given for not using the overlay were that he forgot, could not $f$ ind it, or that the light was not bright enough to need it. A variety of responses were given to the question, "What do you like best about the overlay?" He liked the color and its effect (on reading), friends liked to borrow them, and they "don't shine." A creative solution was also offered: math problems could be worked on an overlay, and the answers wiped off. An attraction to the novelty effect was also revealed by the disclosure that he enjoyed reading comic books with the overlay because the faces looked blue and the blood looked green.

Jered was unable to state, in his own words, how the overlay actually helped his reading. The researcher suggested improvements and asked him to state whether they applied, did not apply, or that he was uncertain. This subject's most consistent confirmations were that it enabled him to read for longer, he could understand the material better, it made his head feel better, and he became less tired from reading. Jered's statements of what he liked least about the overlay were similar to Jeremy's. He disliked having to carry it around and keep track of it. They also had a "static cling" to paper, and scratched and bent easily. 


\section{SAMANTHA}

\section{Intrasubject Characteristics}

Samantha demonstrated evidence of learning disabilities that compounded her manifestation of Irlen Syndrome. These should be considered in interpreting her reading trial results; which indicated little change in her rate and accuracy. Despite a modest positive change in silent reading comprehension, performance was still 608 or less on six of the nine intervention trials.

The 5th grade teacher commented that Samantha exhibited a short attention span before and during the study. She was seated in front of the classroom for minimization of distraction. It was nonetheless described as an ongoing struggle to keep her focused. This subject did not display fidgety or distractable behavior to the researcher. During the comprehension exercises, Samantha had difficulty retrieving factual information from what she had read. She would often give an incorrect response based on information given in the question. Her mother stated that she seemed unable to assimilate information or instructions by listening, and was easily confused. This apparent difficulty with assimilation and retrieval could have affected the speed at which she remembered and applied phonetic patterns and other reading strategies.

It was also possible that Samantha had unexplained decoding difficulties in addition to Irlen Syndrome. Most of her errors involved word substitutions which were based on the meaning context. 
She seldom attempted to sound words out based on the actual

configuration. In other words, she did not seem to be using visual cues even when she was using the overlays.

During the concluding interview, the mainstream teacher expressed concern over Samantha's self image. She not only appeared depressed at this point, but verbalized fear that she was retarded and would never catch up. The teacher communicated this to the parent, had made similar observations and who was equally concerned.

Samantha's reaction to peer responses to her use of the overlays appeared consistent with low self-esteem. When asked how peers responded during the first interview, she complained of one student's verbal derision. The teacher stated that Samantha herself would frequently denegrate others. On two occasions, Samantha reported that friends liked using her overlays. The teacher observed that, for a period of two weeks, she was loaning overlays out to the point of not having them available for her own use. The disclosure that the teacher usually reminded Samantha to use her overlays, and that the student seemed comfortable with the reminding, was also shared. Samantha's self-esteem issues gave rise to the possibility that her response to screening was, to some extent, motivated by a desire for recognition and positive attention. It is also possible that her co-existing learning disabilities contributed to her oral reading performance, and to her processing of the screener's questions. At 
minimum, her use of overlays in the classroom appeared to be guided by a desire for attention. Observed Use of Overlay

Samantha had stated, during her overlay re-trial, that adding yellow to the originally selected green and turquoise enabled her to "gee better." The three-color combination was used until trial 11. The researcher had observed the subject reading with and without the yellow during the warm-up exercise. The effectiveness of yellow had not been denionintrated. When asked about her independent use of yellow before trial 11, Samantha said she had stopped adding it on her own. The addition of yellow was discontinued for trials 12 to 14 .

Samantha's self-report of overlay use in the mainstream classroom was that she sometimes used them until the week of trial 11, when she lost her classroom supply. For the balance of the study she claimed that she usually used them. The teacher's reports did not concur that there were periods of frequent independent use. The subject would usually not get the overlays out until she had been reminded by the teacher. It is possible that Samantha interpreted this as teacher support, for which she felt a need.

When asked to state her own reasons for not using overlays, Samantha said on three consecutive interviews that she forgot until getting a headache. The onset of a headache would remind her to use the overlays. Samantha said twice that her mother had reminded her to use the overlays at home. At other times she explained that it was 
unnecessary for her Mother to say anything, because she used both overlays and colored paper regularly. During the concluding interview, the parent stated that Samantha's use of overlays at home was steady. This subject was not required to attend the resource room regularly, so she was not observed reading with overlays in that setting.

Samantha stated that she liked the overlays because they relieved headaches, prevented words from getting blurry, and helped her to read better. When asked what she liked least about them she responded that they scratched easily, peers teased her, it was necessary to keep track of them, and she would sometimes forget to use them until getting a headache.

When asked to state how overlays assisted her reading, Samantha stated in her own terms that "words don't pop out" and that they "make my headaches go away." She consistently confirmed the researcher's suggestions that using overlays made her feel more confident about reading, allowed her to read for longer and to understand the material better, and made both her head and eyes feel better when reading. 
MELISSA

\section{Intrasubject Characteristics}

Melisga demonstrated signs of learning disabilities that co-existed with her Irlen syndrome. As in Samantha's case, it was suspected that her performance on reading trials was significantly affected by these factors. This subject frequently reversed the letterg "b" and " $d$ " when reading. For example, she read the word "doll" as "ball" whenever the word appeared in a Brigance passage. This indicated decoding difficulties that would need to be treated separately from Irlen syndrome.

Melissa explained to the researcher, during several interviews, that her chief problem in reading new material was not knowing words. She also expressed awareness that the overlay could not help her learn new words. When asked about her favorite reading activity, she named a word recognition program that she worked on in the resource room. Although Melissa was getting specialized assistance with decoding, word recognition continued to be a barrier to her. Memory and retrieval problems may have interfered with her decoding, as did difficulties with visual perception.

Melissa also demonstrated auditory processing delay. This was noted by the researcher as she attempted to answer the comprehension questions. She sometimes verbalized attempts to understand the question itself, and required time to produce an answer. Both resource and mainstream teachers confirmed this characteristic when questioned. During an early interview, Melissa said she preferred to 
read aloud in the classroom because she was unable to remember

anything she attempted to read gilently.

The need for reading glasses was also a significant

characteristic. Glasses were prescribed to relieve Melissa's slight

farsightedness and below normal focusing ability. These interacted

with the overlay to produce the measurable and observable results.

Melissa got her glasses during the spring break, which fell between

her 9 th and loth trials.

Melissa's subject interviews included questions about her

adjustment to the glasses, their effectiveness, and the regularity

with which she wore them. She demonstrated a generally positive

attitude toward the glasses and looked forward to getting them. When

asked what she liked best about the glasses, after she had begun using

them, she gave several responses: the color of the frames,

complements received from some of her peers, and that they helped her

to read better.

Before getting the glasses, Melissa assessed the overlay as

making the words look clearer, relieving her headaches, and causing

the words not to jump or wiggle. However, her eyes still itched from

reading. The glasses relieved this element of eyestrain, and further

reduced word blurriness. Melissa also felt that the glasses enabled

her to read for longer and make fewer mistakes. These effects were

mentioned during three subject interviews that followed the

introduction of glasses. 
Melissa had her glasses at school on every trial day except one. This trial (16) was conducted without glasses and entered as a post-intervention trial. Both teachers observed that she used the glasses regularly and independently during the first two weeks of having them. During the final three weeks of intervention the mainstream teacher commented that she needed reminding to wear the glasses, and would occasionally misplace them. This teacher also commented on an observable improvement in accuracy when Melissa first used the glasses with the overlay.

The resource teacher reported that Melissa's enthusiasm about her glasses lagged during the final two weeks. She was fined tokens for forgetting to bring or wear her glasses in that setting. Melissa's self report was that she usually used her glasses at school and at home. The parent reported that she used both overlay and glasses regularly at home. Observed Use of Overlay

Melissa used a single green overlay for all reading trials and independent practice. She reported using it regularly during the first three weeks of intervention in the mainstream classroom, the resource room, and at home. This was consistent with teacher observations and her mother's report. The mainstream teacher commented that she did not appear to be self-conscious about using her overlay at this point.

Melissa herself reported a decline in overlay use by the 11 th week, which was also documented by teacher observation. It was used 
sometimes during the 11th week, and not at all during the 12 th week. Melissa explained that she had lost the overlay for several days, but had found it again. She continued to not use her overlay during the 13th week. The reason given, during the subject interview, was that the one she had in the classroom had gotten too scratched. She was given a new supply of overlays. Melissa reported regular use during the final week; however, the teacher reported that it was necegsary to remind her consistently.

subject interviews provided some clues which illuminated Melissa's reluctance to use her overlay as the study progressed. One was her hesitancy to explain how it helped her reading, combined with the assertion that not knowing words was her main obstacle. Neither the overlay (nor the glasses) could help her learn new words. Before the final results were shared with her, Melissa probably felt that these interventions were not providing the help she needed. Another clue was in a comment Melissa made during the final interview: that she was still embarrassed to read orally, even when using glasses and overlay. She may have felt a heightened expectation to read orally and to do better at it, since she was getting special treatment. The reading trials did emphasize oral reading. Therefore, Melissa probably associated the overlay with something she was basically embarrassed to do for an audience.

Reports provided by Melissa and her mother indicated that she used overlay and glasses consistently at home, where she probably felt relieved of embarrassment. Reports of this subject's reading engagement at home were decidedly positive. 
Melissa

When probed by the researcher for ways in which the overlay could assist reading, Melissa did confirm the following points consistently: the overlay made words look less blurry, enabled her to read for longer, and made her "head feel better." This last reference was to headaches, which had apparently been a frequent occurrence for Melissa when reading black on white. Melissa complained of a headache during trial 16, when she used her glasses without the overlay. When asked what she liked least about the overlay, Melissa stated that it "shines under the light" on four occasions. Other responses were that it slid off the paper and became scratched. 
APPENDIX F

COMPARATIVE OVERVIEW OF READING INSTRUCTION 
Comparative Overview of Reading Instruction Provided to the Four Subjects

\begin{tabular}{|c|c|c|c|c|}
\hline & Jeremy & Jered & Samantha & Melissa \\
\hline $\begin{array}{l}\text { IEP } \\
\text { Goals }\end{array}$ & $\begin{array}{l}\text { 1. Decoding: specific } \\
\text { sound-symbol association. } \\
\text { 2. Strategies: use syntax, } \\
\text { word meaning, features of } \\
\text { print. } \\
\text { 3. Comprehension: predict, } \\
\text { draw inference. }\end{array}$ & $\begin{array}{l}\text { 1. Activities: peer tutor, } \\
\text { practice reading. } \\
\text { 2. Strategies: semantic } \\
\text { substitutions, meaning from } \\
\text { punctuation. } \\
\text { 3. Comprehension: preview } \\
\text { key words, chapter questions. }\end{array}$ & $\begin{array}{l}\text { 1. Decoding: word patterns, } \\
\text { base, prefix, suffix. } \\
\text { 2. Strategies: pictures, } \\
\text { context, punctuation, semantic } \\
\text { cues for meaning. } \\
\text { 3. Comprehension: predict, } \\
\text { recognize story elements. }\end{array}$ & $\begin{array}{l}\text { 1. Decoding: use phonetic } \\
\text { cuing systems. } \\
\text { 2. Strategies: semantic and } \\
\text { syntactic cues. } \\
\text { 3. Activities: practice through } \\
\text { oral reading and writing; } \\
\text { phonics workbook. }\end{array}$ \\
\hline $\begin{array}{l}\mathrm{RC} \\
\text { Activity }\end{array}$ & $\begin{array}{l}5 \times 30 \text { min. pullout. } \\
\text { Multisensory direct inst. } \\
\text { Group reading \& } \\
\text { discussion, questioning, } \\
\text { story maps. }\end{array}$ & $\begin{array}{l}3 \times 30 \text { min. pulled or within } \\
\text { classroom. Help on class } \\
\text { work, study skills } \\
\text { incorporation. }\end{array}$ & No regular pull-out. & $\begin{array}{l}3 \times 35 \text { min. pull-out. Timed drill } \\
\& \text { practice, oral reading, } \\
\text { joumal writing and proofing. }\end{array}$ \\
\hline $\begin{array}{l}\text { Mainstream } \\
\text { Objectives }\end{array}$ & $\begin{array}{l}\text { 1. Improve fluency. } \\
\text { 2. Practice: independent } \\
\text { reading and conference. } \\
\text { 3. Comprehension: question } \\
\text { before and after, main idea } \\
\text { and supporting details. }\end{array}$ & $\begin{array}{l}\text { 1. Practice: read novels as } \\
\text { group, various types; book } \\
\text { reports. } \\
\text { 2. Comprehension: story } \\
\text { elements, compare/contrast, } \\
\text { summarize. }\end{array}$ & $\begin{array}{l}\text { 1. Improve fluency and sight } \\
\text { word recognition. } \\
\text { 2. Gain confidence. } \\
\text { 3. Comprehension: grade } 5 \\
\text { curriculum goals. }\end{array}$ & $\begin{array}{l}\text { 1. Impiove decoding, fluency, } \\
\text { expression. } \\
\text { 2. Comprehension: story } \\
\text { elements, grade } 4 \text { curriculum } \\
\text { goals. }\end{array}$ \\
\hline $\begin{array}{l}\text { Mainstream } \\
\text { Activities }\end{array}$ & $\begin{array}{l}\text { Oral reading } 1-1 \mathrm{w} / \mathrm{t} \text {; } \\
\text { Report Form (project Read) } \\
\text { outlining; } \\
\text { T. conference on outside } \\
\text { reading. }\end{array}$ & $\begin{array}{l}\text { Oral and silent reading; } \\
\text { Teacher conference; } \\
\text { Write about reading -book } \\
\text { reports, research reports; } \\
\text { Book talks. }\end{array}$ & $\begin{array}{l}\text { Called on for discussion; } \\
\text { Word list, Reading for } \\
\text { Concept class novel; } \\
\text { Silent reading of library } \\
\text { material. }\end{array}$ & $\begin{array}{l}\text { Oral reading with partner; } \\
\text { Sight word list; } \\
\text { Class novels with discussion; } \\
\text { Read w/parent, retell or } \\
\text { predict. }\end{array}$ \\
\hline $\begin{array}{l}\text { Extra } \\
\text { Help }\end{array}$ & $\begin{array}{l}\text { Extra time in RC for } \\
\text { assignment completion. }\end{array}$ & None. & Optional time in RC. & $\begin{array}{l}\text { Peer tutors in class; } \\
\text { R.C. study hall, } 30 \mathrm{~min} \text {. } \\
2 \times \text { per week. }\end{array}$ \\
\hline
\end{tabular}

